Volume 12, Issue 2 (Summer 2020)

\title{
Decision Trees for Watermark Identification in Rembrandt's Etchings
}

C. Richard Johnson Jr.

crj2@cornell.edu

Recommended Citation:

C. Richard Johnson Jr., "Decision Trees for Watermark Identification in Rembrandt's Etchings," Journal of Historians of Netherlandish Art 12:2 (Summer 2020) DOI: 10.5092/jhna.12.2.5 Available at https://jhna.org/articles/decision-trees-for-watermark-identification-in-rembrandts-etchings

Published by Historians of Netherlandish Art: https://hnanews.org/

Republication Guidelines: https://jhna.org/republication-guidelines/

Notes: This PDF is provided for reference purposes only and may not contain all the functionality or features of the original, online publication. This PDF provides paragraph numbers as well as page numbers for citation purposes.

ISSN: $1949-9833$ 


\title{
Decision Trees for Watermark Identification in Rembrandt's Etchings
}

\author{
C. Richard Johnson Jr.
}

Erik Hinterding's classification and chronological arrangement of hundreds of distinct watermarks in Rembrandt's prints has resulted in a deeper understanding of the artist's production methods and his artistic development as a prolific etcher. This article explains the decision-tree-based approach to rapid identification of watermarks in Rembrandt's etchings that is under development at Cornell University and uses it to identify the watermarks and watermark fragments in seven Rembrandt prints in The Frick Collection in New York.

\section{Introduction}

Incorporating watermark classification in studies of prints has been common practice for several centuries. As imaging technology continues to improve, higher-quality images reveal finer details of watermarks and offer more possibilities for their computational exploitation in print support analysis. In this article, suitably high-resolution scans of radiographs of prints by Rembrandt van Rijn (1606-1669) are processed to identify papers made on the same mold, which assists in dating the creation of the impressions. We exploit the decision-tree concept to build a tool for identifying watermarks in the paper supports of Rembrandt's prints. This user-friendly tool can be used to find sheets of paper with the same watermark, and therefore made on the same mold. Our motivation can be explained by our agreement with Neil Harris's claim that "If we can work backwards from the object made on the mould to establish the physical characteristics of the mould itself, and thus to relate it to other objects formed on the same mould, the outcome is an important tool for bibliographical research" ${ }^{1}$ and Louisa Wood Ruby's observation that "identifying watermarks has always been a laborious process." The decision-tree tool described here, with examples of its use and fabrication, is intended to make that process much less laborious.

2 The wire watermark sits atop a screen of parallel wire lines laid close together (5 to 20 wires $/ \mathrm{cm}$ ). 
The watermark is tied down to this laid-line screen. The laid-line screen is supported by a perpendicular set of wire chain lines (spaced approximately 1 inch apart). This screen is anchored to a rectangular wooden frame, with parallel rods in the frame below the screen typically spanning the shorter dimension of the rectangular frame. The mold, i.e. the screen and frame combination, is dipped by the vatman into a vat of aqueous pulp. The vatman pulls the screen from the vat in a horizontal position and shakes it slightly to encourage the water to drain through the screen, leaving a sheet of paper of near-uniform thickness on the screen. The vatman hands the mold with the new sheet to the coucher, who presses and rotates the face of the mold against a piece of felt to clear the sheet from the screen. While the coucher removes the new sheet of paper from one screen, the vatman scoops pulp for the next sheet, using the second "twin" mold in a pair that were made together and equipped with nearly identical watermarks. ${ }^{4}$

A seventeenth-century European rectangular paper-making mold composed of a wooden rim surrounding a screen of (horizontal) closely-spaced laid lines and (vertical) further-apart chain lines can have a watermark centered in one half and a countermark centered in the other half. Countermarks are typically not as intricate as watermarks. In the two "twin" molds used to produce a batch of paper at a single vat, the two watermarks were made to be nearly identical. The countermarks were also made to match each other, but typically not as carefully. Sheets in a batch of paper made with a pair of molds illustrated in figure 1 might be cut in half or quarters or eighths before being sold. The resulting batchmates could have watermark 1, watermark 2, countermark 1, or countermark 2; or a fragment (for quartos and octavos) of any of these; or both watermark 1 and countermark 1 or both watermark 2 and countermark 2 , in a single sheet. Due to the common practice, following Rembrandt's death, of trimming prints to the edge of the plate mark, there is also the possibility that sheets may have no watermarks or fragments, which is common in quartos and octavos.

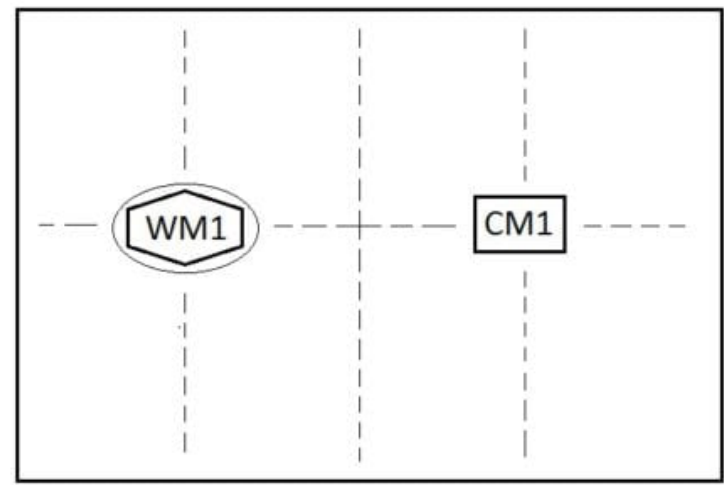

Mold 1

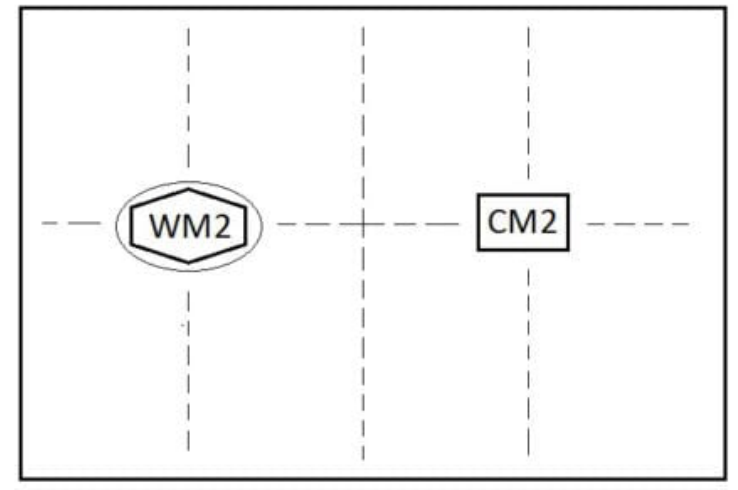

Mold 2

Fig. 1 Twin molds with dashed lines indicating the cutting up of full broadsheets into separate sheets of paper, all of which are batchmates (illustration by author)

4 All three manufactured patterns-watermarks/countermarks, chain line spacings, and (less clearly) laid line density - are visible in a transmitted-light photo of a blank sheet of sixteenth-century French laid paper in figure 2. Here the reader will find all three pattern types (legible due to thinner, more transparent segments of the paper) with labels. Given the opaque ink in the printed surface image, a key portion of the watermark could be hidden in a transmitted light image. 
To address this problem, a commonly used imaging technology for the study of watermarks in antique laid paper is beta-radiography, which is unaffected by the thin ink layer but attenuated relative to the paper thickness. ${ }^{5}$ Figure 3 provides an example where, in the transmitted-light image, the surface art obscures the area just below the "IHS," making a decision about possible features in that location impossible. A beta-radiograph reveals the full watermark and nearby chain lines and laid lines but does not include the artwork on the surface of the paper.
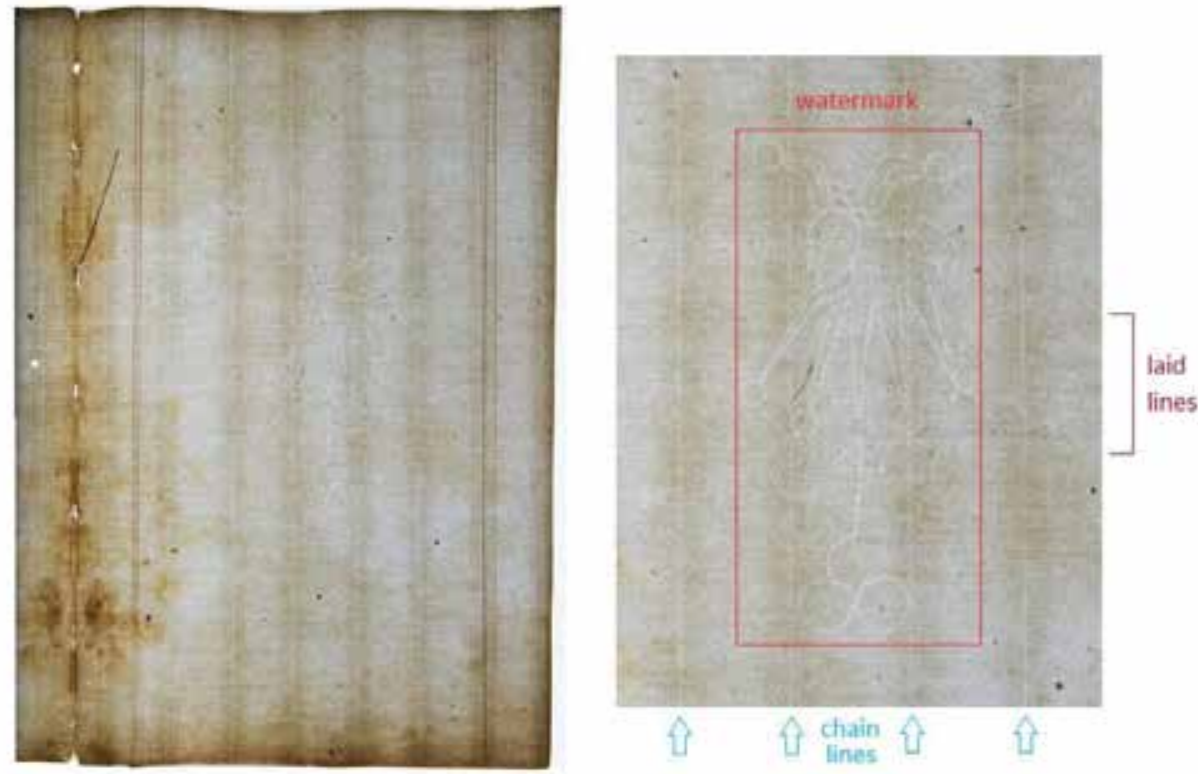

Fig. 2 Transmitted-light photograph of a blank sheet of laid paper from a 1536 French book. Left: Right half of a full-mold sheet containing Foolscap with Five-pointed Collar watermark. Right: Enlargement of region around watermark with chain lines and laid lines (sheet from study collection of Conservation Center in the Institute of Fine Arts provided by Margaret Hoben Ellis (New York University); photographs provided by S. Schlick and P. Messier (Yale))

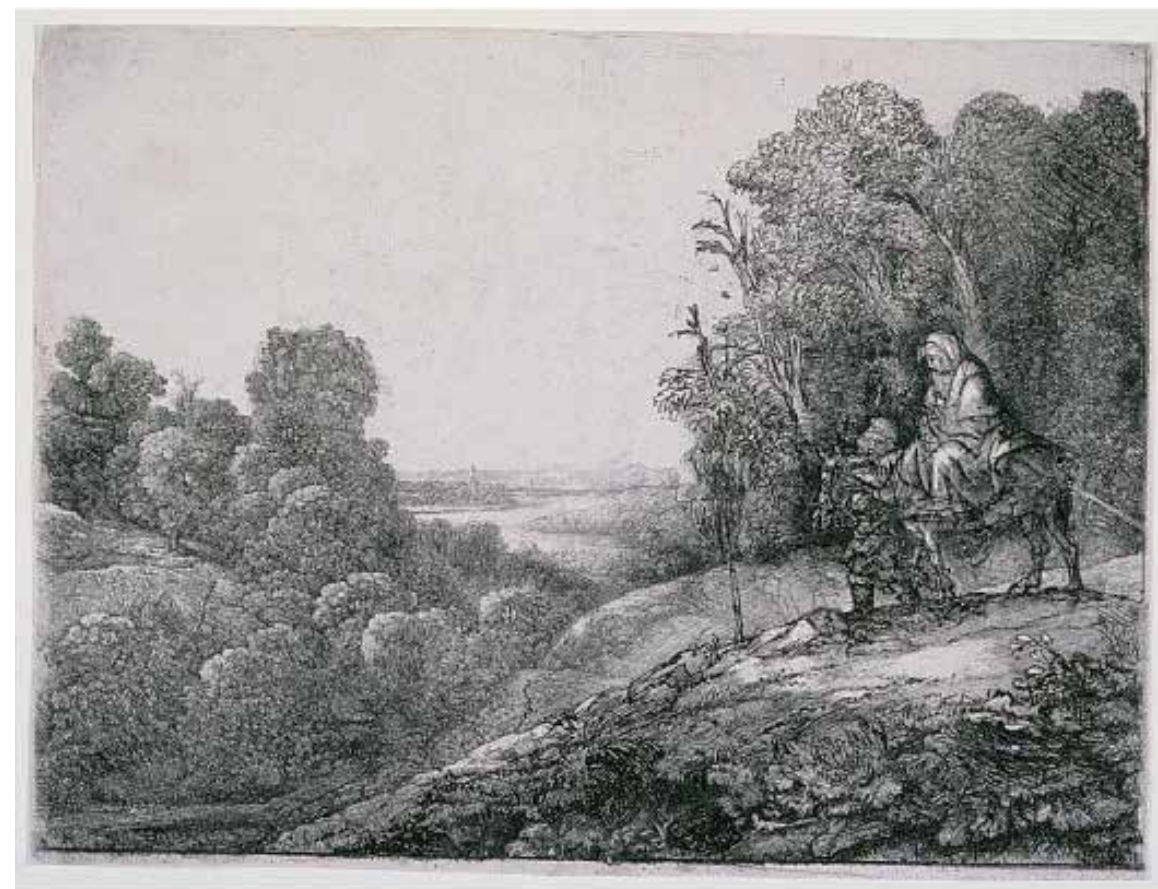

Fig. 3 Rembrandt Harmenszoon van Rijn, The Flight into Egypt, after Hercules Seghers, Herbert F. Johnson Museum, Cornell University, Ithaca, NY, etching, drypoint and engraving on paper, $21.6 \mathrm{x}$ $28.6 \mathrm{~cm}$ (sheet), B56vi(?), 84.010, c. 1652 


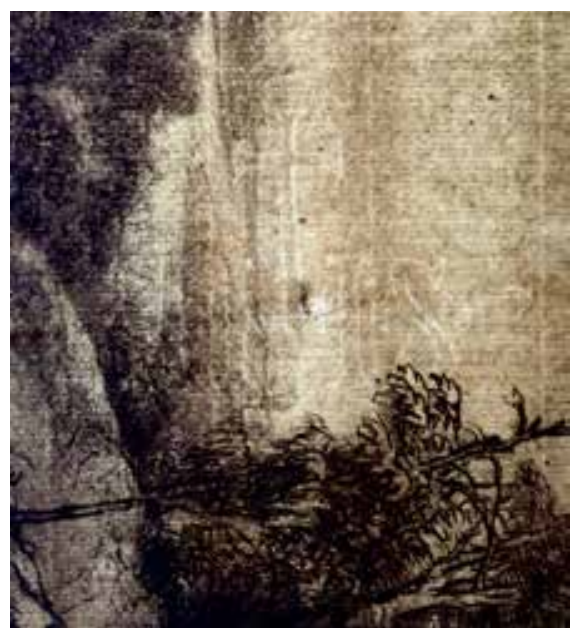

Fig. 3-1 Rembrandt Harmenszoon van Rijn, The Flight into Egypt, after Hercules Seghers, Transmitted-light image showing watermark

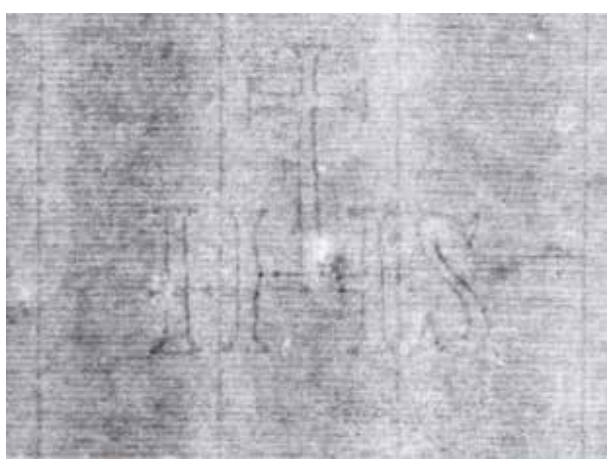

Fig. 3-2 Rembrandt Harmenszoon van Rijn, The Flight into Egypt, after Hercules Seghers, Excerpt from beta-radiograph

Shortly before the end of the twentieth century, Nancy Ash and Shelley Fletcher provided a foundation for a hierarchical classification of the various watermarks in the European laid-paper supports of Rembrandt's prints. ${ }^{7}$ This focus on the paper supports of work by a single artist is one reason that precise classification can be done visually. Watermark identification of a denser group, such as all artists in Amsterdam in the seventeenth century, would probably result in such a large database of watermarks that totally visual distinctions between separate batches would be practicably unfeasible. Another benefit of classifying the watermarks in Rembrandt's prints is that these prints have been well studied. There are a variety of facts and opinions about various aspects, including dating, with which the watermark information can meld.

Ash and Fletcher's test of an exact match relied on the ability to collect contact (exact-size) photographic images from beta-radiograph negatives for overlay comparison. A strong impetus for identifying a group of impressions from different plates on papers displaying the exact same watermark is the assistance such identification can provide in the dating of impression creations. For example, for impressions made on the same paper, the latest dated plate provides a date at or after which the paper must have been used. This is due to Rembrandt's practice of reprinting plates at dates later than the date inscribed in the plate, along with more recently completed plates. For their study, Ash and Fletcher examined 2,765 impressions, of which only 936 (or approximately one-third) contained watermarks.

Erik Hinterding's classification of the watermarks in Rembrandt's prints used the hierarchical labeling foundation established by Ash and Fletcher. ${ }^{8}$ Hinterding examined more than 7,000 Rembrandt etchings, among which approximately one-third $(2,369)$ had complete or fragmentary watermarks. He identified 1,998 of these marks and found 680 different ones, classified in fifty-four general types (Ash and Fletcher listed only thirty-nine), 294 variants across all of the types, and 512 subvariants (including twins). Hinterding estimates that Rembrandt used approximately 258 batches of paper. All papers with the watermark of a particular subvariant are batchmates, and their associated prints' creation dates are all assumed to be from the same period. 
Since 2012, we have been evaluating the uniqueness of chain line patterns in Rembrandt's etchings. ${ }^{9}$ This was motivated by a desire to extend moldmate identification beyond the one-third of prints that possess legible watermarks. Our original image data came from the Morgan Library \& Museum and the Metropolitan Museum of Art, both in New York. To increase the likelihood of moldmates, we needed access to a database of radiographs of Rembrandt's prints from many collections. We were fortunate to be granted access to such an image dataset developed by the Dutch University Institute for Art History in Florence. This provided us with more than 700 fullprint radiograph images of full watermarks. We had written software for marking and matching chain line patterns, but a problem remained: how would we confirm that prints with matching chainspace patterns were indeed moldmates? The obvious answer was to have previously identified all of the watermarks in our dataset. Then confirmation could be done quickly. But separately identifying the hundreds of watermarks in our dataset with confidence was considered far too time-consuming, given the close similarity of many of the watermarks, unless we could at the same time develop a procedure that could be used by future researchers to shorten significantly the time needed for watermark identification in Rembrandt's etchings.

The WIRE (Watermark Identification in Rembrandt's Etchings) Project was launched in 2015 to address this issue. ${ }^{10}$ The intent from the start was to involve students in the development of decision trees for all fifty-four watermark types in Hinterding's catalogue. We began by imagining a computer-based interrogatory that at each step poses a yes/no question (or another "binary" question having two answers) to address the two possibilities for a particular feature. Each question is accompanied by two figures, one providing a sample for which the answer is "no," and another for which the answer is "yes." ${ }^{11}$ The selection of "yes" or "no" will determine the next question. Questions will continue until the user reaches an endpoint of the decision tree. At that point, there will be no other watermark in Hinterding's classification library that has the same sequence of yes/no answers to the questions the user has answered, and thus the given support will be identified. By 2018, we had developed many branches of the decision tree.

10 In 2018, just over one hundred years after Henry Clay Frick purchased eight prints by Rembrandt van Rijn on European laid paper, beta-radiographs revealed that seven of these prints had watermarks or watermark fragments. These seven prints, each accompanied by its beta-radiograph displaying the watermark (or a fragment), appear in figures 4-10.
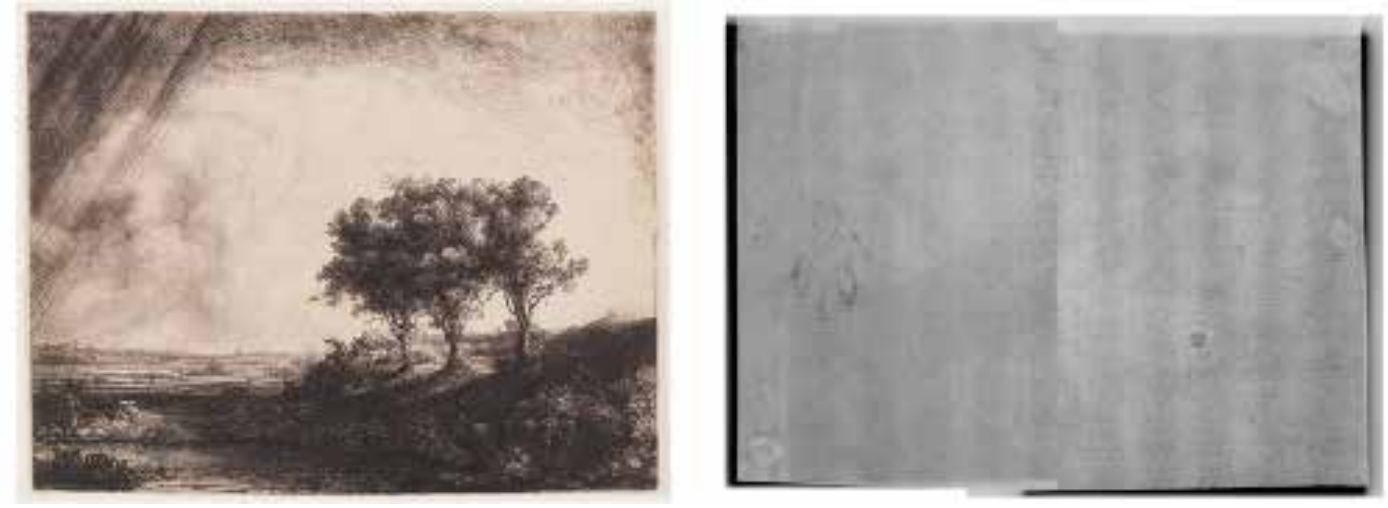

Fig. 4 Left: Rembrandt Harmenszoon van Rijn, Landscape with Three Trees, The Frick Collection, 1915.3.28. Right: Beta-radiograph of portion around watermark (provided by Margaret Hoben Ellis (NYU) and Reba Fishman Snyder (Morgan)) 

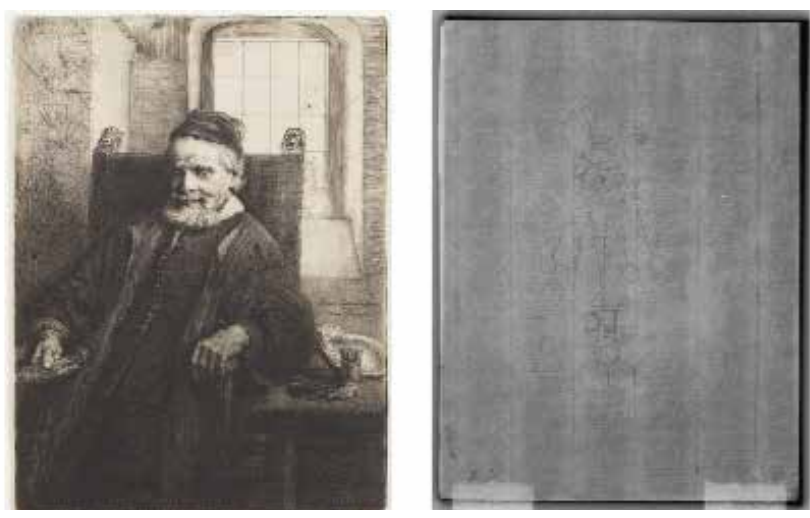

Fig. 5 Left: Rembrandt Harmenszoon van Rijn, Jan (Johannes) Lutma the Elder, The Frick Collection, 1916.3.37; Right: Beta-radiograph of portion around watermark (Provided by Margaret Hoben Ellis (NYU) and Reba Fishman Snyder (Morgan))
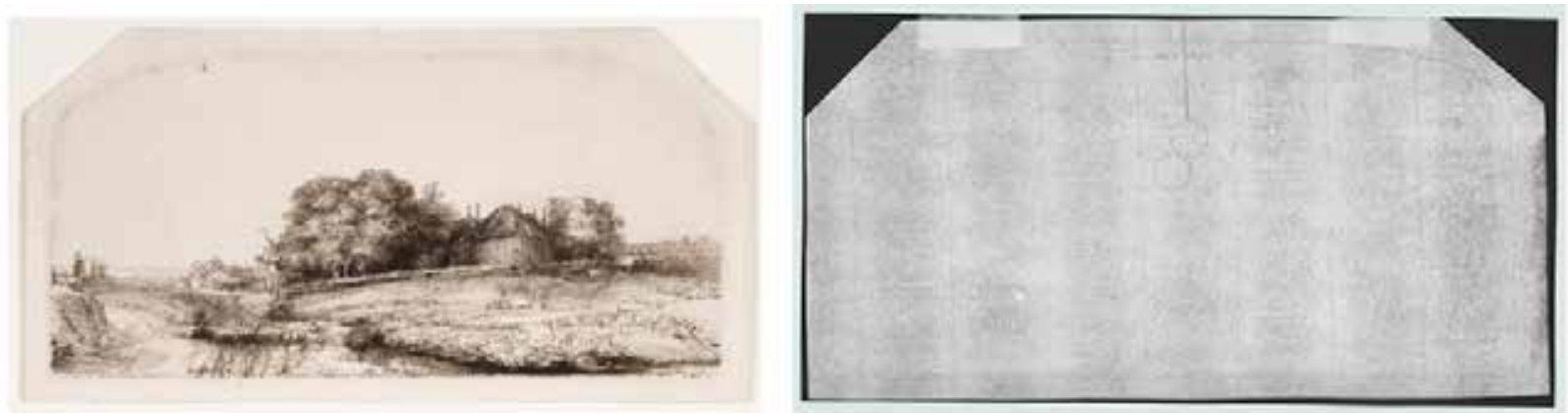

Fig. 6 Left: Rembrandt Harmenszoon van Rijn, Landscape with Haybarn and Flock of Sheep, The Frick Collection, 1916.3.29. Right: Beta-radiograph of portion around watermark (provided by Margaret Hoben Ellis (NYU) and Reba Fishman Snyder (Morgan))
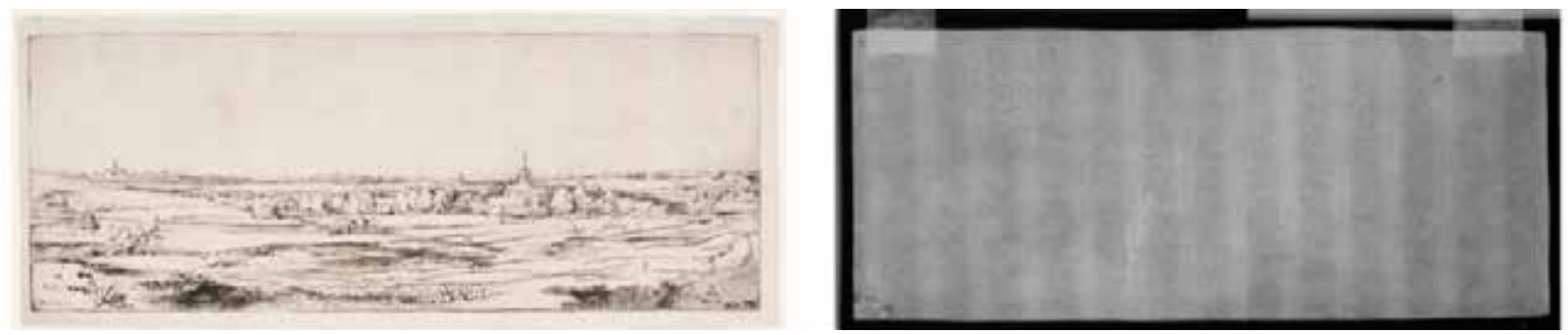

Fig. 7 Left: Rembrandt Harmenszoon van Rijn, The Goldweigher's Field, The Frick Collection, 1915.3.31. Right: Beta-radiograph of portion around watermark (provided by Margaret Hoben Ellis (NYU) and Reba Fishman Snyder (Morgan))
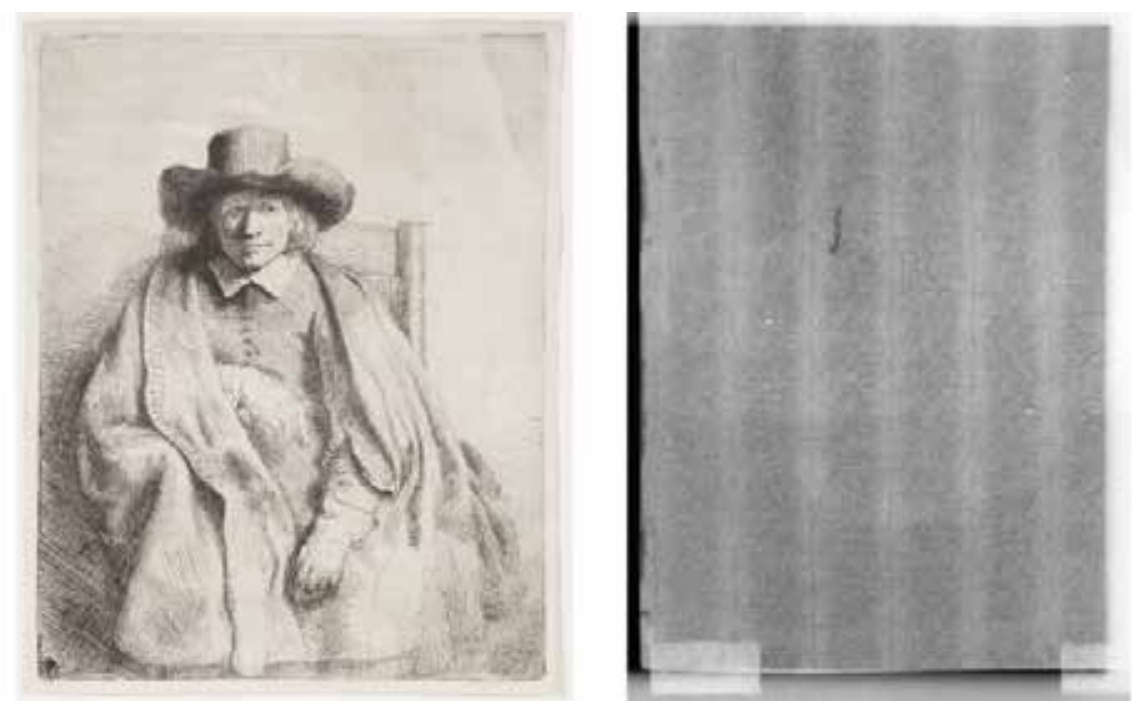

Fig. 8 Left: Rembrandt Harmenszoon van Rijn, Clement de Jonghe, The Frick Collection, 1916.3.36. Right: Beta-radiograph of portion around watermark (provided by Margaret Hoben Ellis (NYU) and Reba Fishman Snyder (Morgan)) 

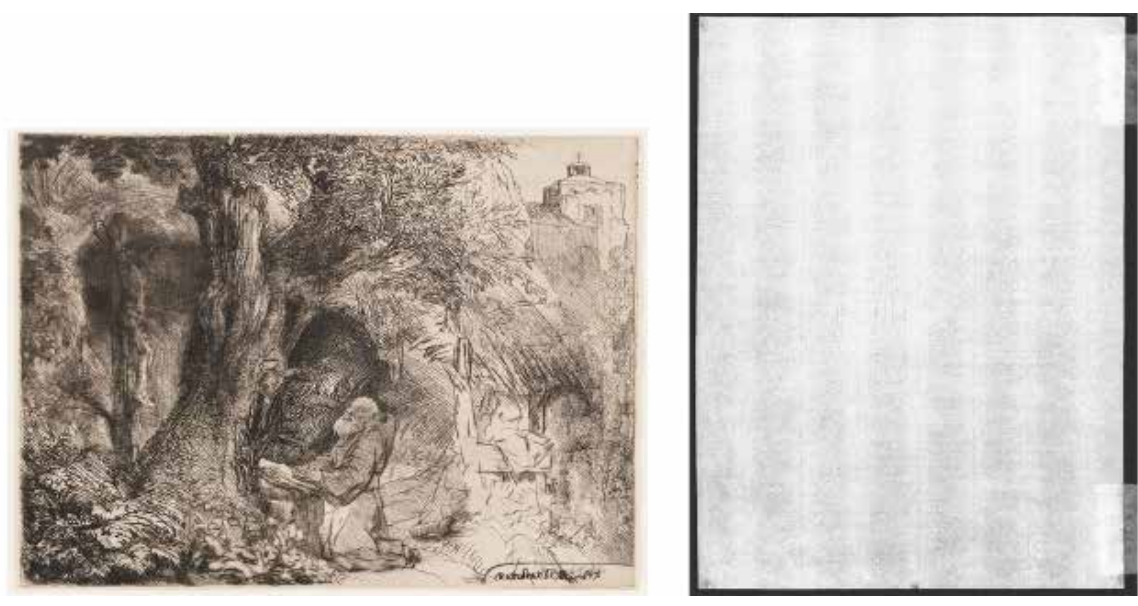

Fig. 9 Left: Rembrandt Harmenszoon van Rijn, St. Francis Praying Beneath a Tree, The Frick Collection, 1916.3.35. Right: Beta-radiograph of portion around watermark (provided by Margaret Hoben Ellis (NYU) and Reba Fishman Snyder (Morgan))
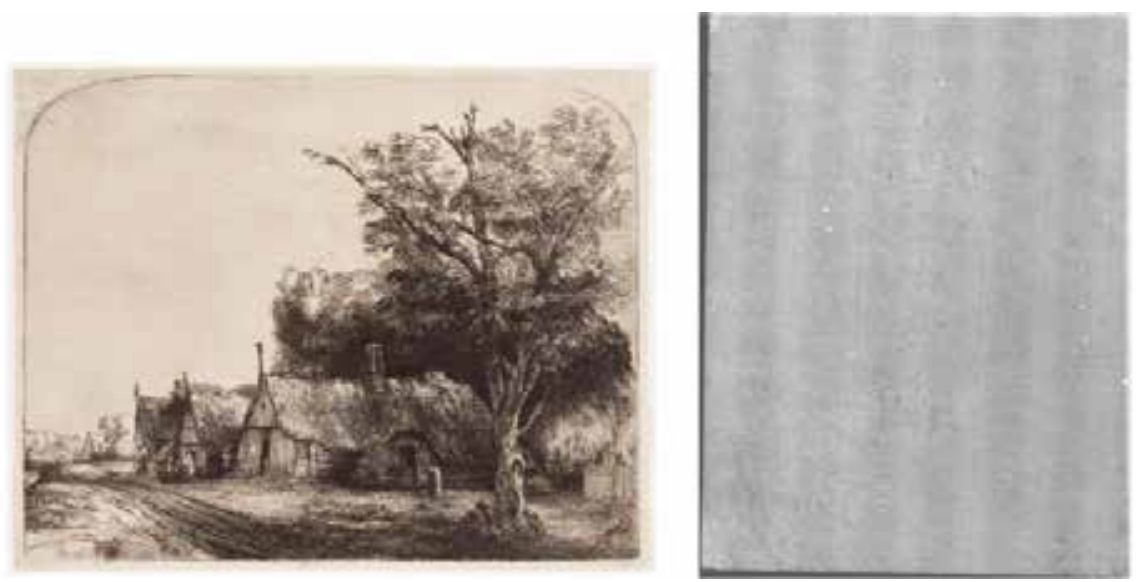

Fig. 10 Left: Rembrandt Harmenszoon van Rijn, Landscape with Three Gabled Cottages, The Frick Collection, 1916.3.30. Right: Beta-radiograph of portion around watermark (provided by Margaret Hoben Ellis (NYU) and Reba Fishman Snyder (Morgan))

11 The discovery of the watermarks prompted The Frick Collection to share the beta-radiographs with the WIRE Project, with the goal of using the decision trees being developed to identify the watermarks (and possibly even the fragments) in this latter group of objects. This research resulted in the following discoveries.

One print in The Frick Collection can be dated to a particular year in the seventeenth century by its watermark. The same print offers the first case in which an impression of this plate has been found bearing this watermark.

The watermark in another print suggests a different date than that adopted by The Frick Collection. The same print has a watermark appearing in impressions from nineteen different plates.

Two of the prints are on paper from the same batch.

One print is a portrait that was printed after the plate had been transferred to the sitter, yet it is on paper with the same watermark as that of the first state, which was printed by Rembrandt. This possibly indicates a closer interaction between Rembrandt and the patron than previously imagined. 
The insights listed above were based on watermark identification performed in mere minutes, using a binary decision tree, once the branch for each corresponding watermark type had been constructed.

13 With further applications of the WIRE Project's methods in mind, this article describes the decision tree branches used to identify the watermarks in the seven Frick Collection prints by Rembrandt. It aims to help guide the development of decision trees for rapid and confident identification of watermarks in works by other artists, and for rapid identification of a variety of other maker marks. Once we have described the mechanism supporting our watermark identifications, we can connect specific prints to the discoveries above. ${ }^{12}$

\section{Watermark Identification using the Decision-Tree Format}

14 The WIRE Project at Cornell uses a decision-tree format to accelerate the process of identifying watermarks in Rembrandt's etchings according to Hinterding's taxonomy. Such watermark identification can support the development of a chronology of Rembrandt's print production, which is useful in analyzing Rembrandt's artistic development and commercial activities. ${ }^{1.3}$

15 A difficulty with utilizing Hinterding's hierarchical labeling to identify a specific watermark is the tediousness of searching through more than 500 possible matches, many of which are highly similar to one another. This is best demonstrated by an example: the Foolscap with Five-pointed Collar. Four of the eighteen variants of this type are illustrated in figure 11, and each variant has distinct subvariants, for a total of thirty. ${ }^{14}$ Four of these, all subvariants of variant K, are illustrated in figure 12. The four subvariants in figure $\mathbf{1 2}$ are more similar to one another than are the four variants in figure 11. Furthermore, within a subvariant category there can be highly similar twins, such as in figure 13. As can be inferred from the watermark labels in figures 11-13, the labeling convention is an uppercase letter for a particular variant, a first lowercase letter for a specific subvariant, and a second lowercase letter designating the specific twin. A watermark with a chain line down its middle is identified with an uppercase letter including an apostrophe as the variant label, e.g. A. ${ }^{15}$ Highly similar twins arise due to the rotation of a pair of papermaking molds in a production process that is intended to produce a batch of paper with the "same" watermark. ${ }^{16}$ As one progresses deeper into the type/variant/subvariant/twin taxonomy, the differences become
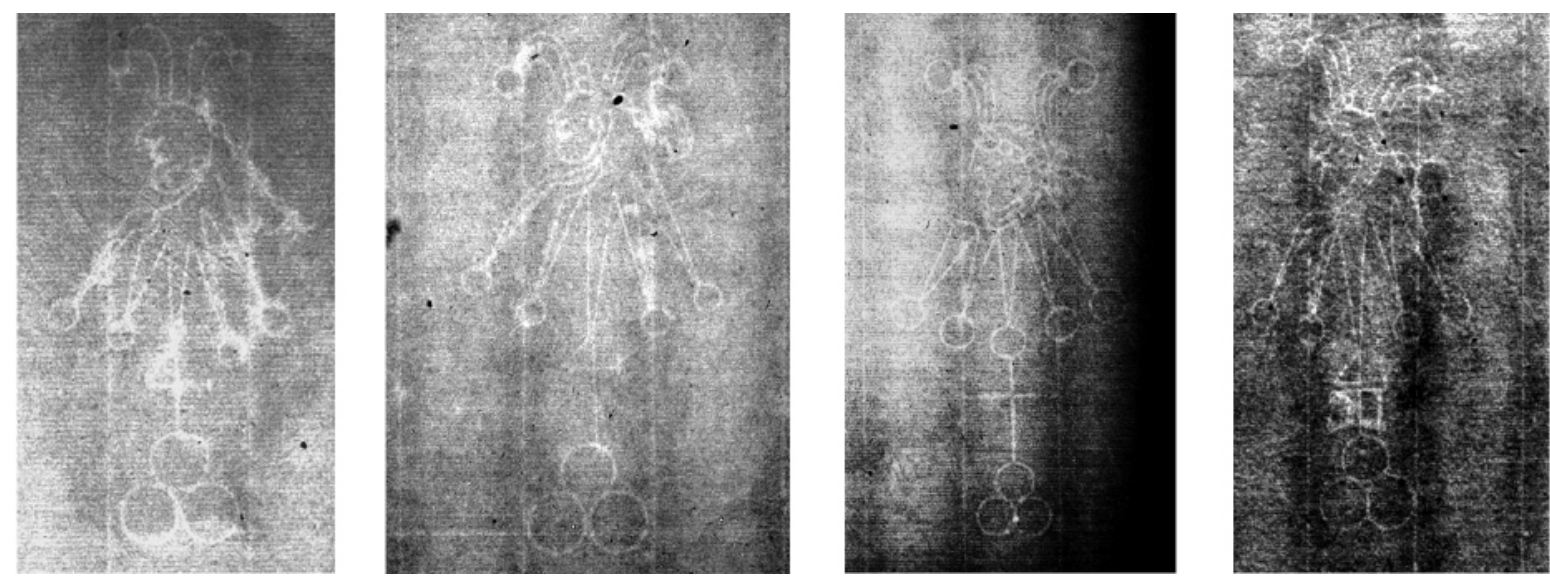

Fig. 11 Four variants of Foolscap with Five-pointed Collar. Left to right: A.a.a., H.b.a., K.a.a., N.a.b (images courtesy of Sound and Vision Publishers BV) 

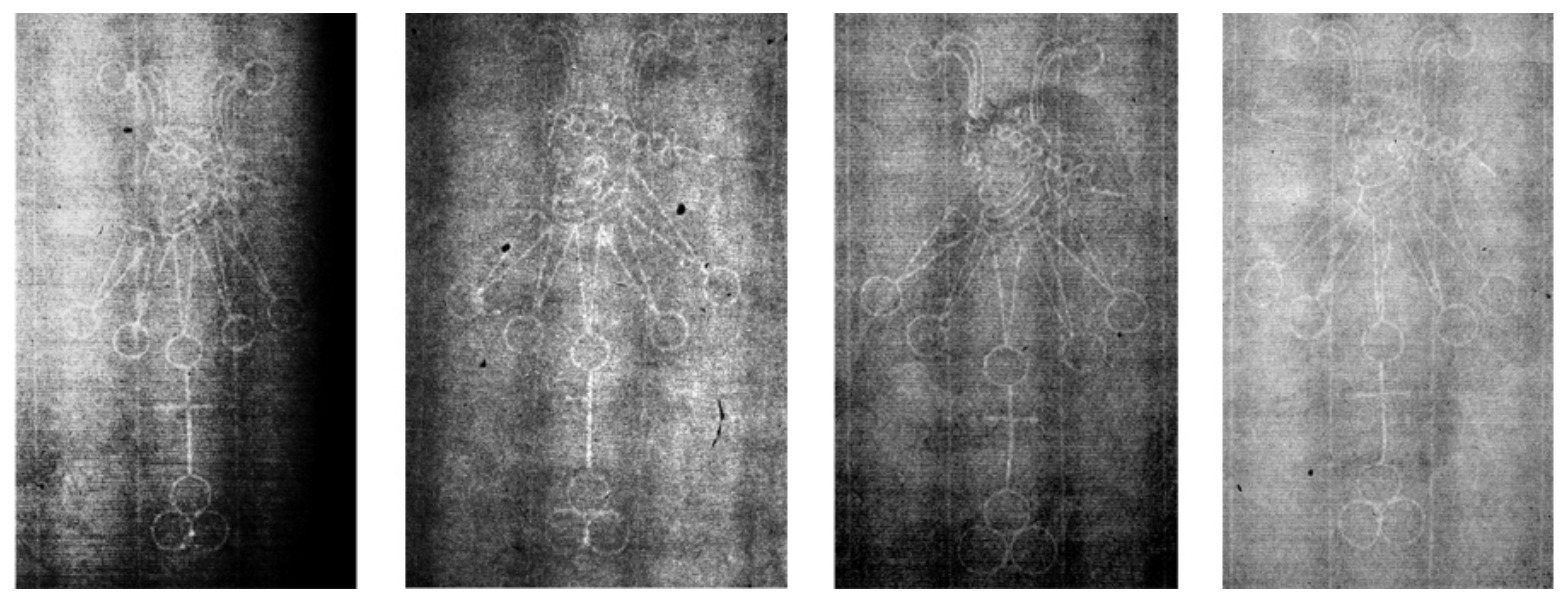

Fig. 12 Four subvariants of Foolscap with Five-pointed Collar, variant K. Left to right: K.a.a., K.c.a., K.e.a., K.f.a (images courtesy of Sound and Vision Publishers BV)
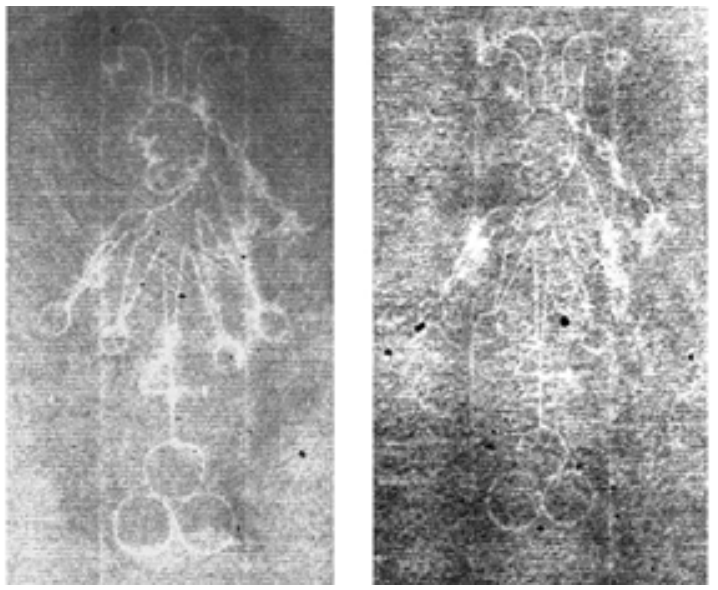

Fig. 13 Two twins of Foolscap with Five-pointed Collar, subvariant A.a. Left to right: A.a.a., A.a.b (images courtesy of Sound and Vision Publishers BV)

harder to recognize unless one knows which specific points to compare in the watermark images.

The decision-tree concept used here is similar to the parlor game of "Twenty Questions." The category of "animals" provides a good example. Reasonable questions might include: "Can it fly?" "Does it have four legs?" "Does the mature version typically weigh less than one pound?" "Can it be found in North America?" If the answers pertained to a particular type of dog, the responses to these questions would be "no," "yes," "no," and "yes." The answer to each question shrinks the group of possible solutions. For example, the answer "no" to the first question eliminates most birds as a possibility. But, because many animals would satisfy all four answers, such as a cat, many more questions would be needed to arrive at the specific type and breed of the animal. Along the way, as one gets closer to the final answer the questions asked could depend on the answer to the preceding question(s). For example, if the answer to the first question were "yes" instead of "no," the next question might not be about the number of legs but rather whether or not it has feathers.

Returning to the variants in figure 11, we can refine our identification by asking the following questions: 
1. Are there letters above the roundels?

2. Are both bells on the peaks of the cap within the chain lines on either side of the face?

3. Does the center collar point have a ball at its apex?

The first problem in answering these questions is one of terminology. For example, what are "roundels," "bells," "peaks," "collar points," "balls," and "chain lines"? Refer to figure 14, which distinguishes the circles at the top as "bells," those in the middle as "balls," and those at the bottom as "roundels."

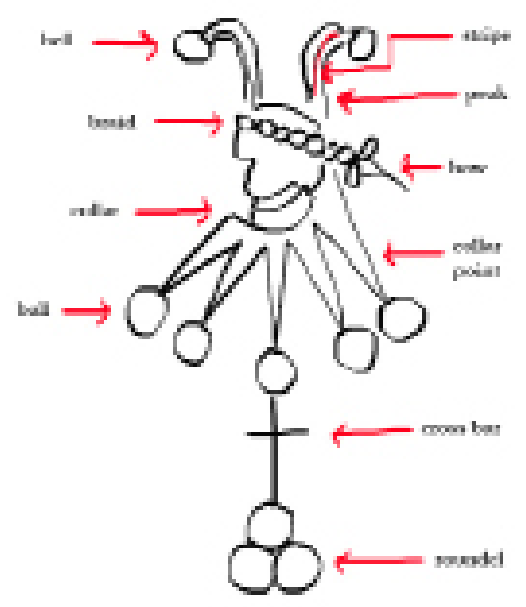

Fig. 14 Feature labels for Foolscap with Five-pointed Collar (illustration by Margaret N. Canfield (Cornell))

Once we resolve our terms, the answers to question 1 for the four watermarks in figure 11 are: far left, no; middle left, no; middle right, no; and far right, yes. Thus, question 1 separates the lower-right image for N.a.b from the others. If the watermark of interest was known to be one of these four choices, an affirmative answer to question 1 would end the search, with N.a.b as the answer. A negative answer leaves the three remaining choices. Asking question 2 of these three yields the following answers: top left, yes; top right, no; and bottom left, no. This separates A.a.a from the other two. Assuming that the answer for the watermark being identified is "no," we proceed to ask question 3 . The answers for the remaining two choices are: top right, no, bottom left, yes. If the answer for the watermark being identified is "yes," this identifies the watermark of interest as K.a.a. This sequence of questions results in the decision tree in figure $\mathbf{1 5 .}$

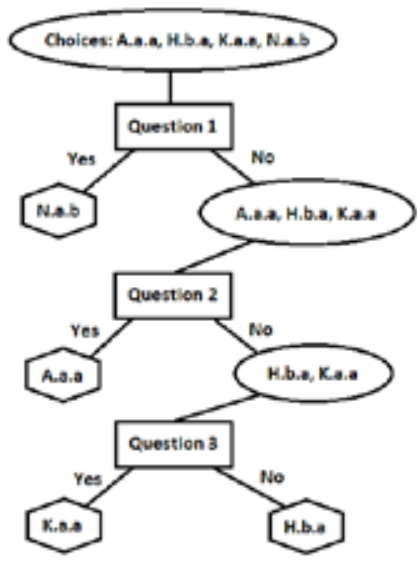

Fig. 15 Decision tree for four variants of Foolscap with Five-pointed Collar in figure 11 (illustration by author) 
Another way to organize the information gained by answering the three questions in our example is as a decision table including binary yes/no answers to all questions for all possible classifications, as in Table 1 where yes $=1$ and no $=0$. The sequence of binary digits represents an identifying code for each watermark, with A.a.a identified by 010, H.b.a by 000, K.a.a by 001, and N.a.b by 100 . Note that the four codes are different. Furthermore, each code has only one nonzero digit. This suggests that any ordering of the questions will result in a successful decision tree.

\begin{tabular}{|c|c|c|c|}
\hline & Question 1 & Question 2 & Question 3 \\
\hline A.a.a & 0 & 1 & 0 \\
H.b.a & 0 & 0 & 0 \\
K.a.a & 0 & 0 & 1 \\
N.a.b & 1 & 0 & 0 \\
\hline
\end{tabular}

Table 1: Decision Table for Watermarks in figure 11

21 Selecting features around which to compose yes/no questions is the time-consuming portion of decision-tree construction. One key requirement of these questions is that they should be phrased in such a way that users can answer them with total confidence. This is best tested by vetting the candidate questions with a team rather than a single individual. The questions should not solicit an opinion but should query an obvious fact. Also important is the ability of the questions to accommodate images without regard to their scale. Re-scaling images to a common resolution requires accurate recordkeeping about their creation, including the particulars of their digitization. However, such records often are unavailable (or unreliable). Thus, only scale-invariant questions are used. For example, a question asking if a dimension of some element in the image is longer than, for example, 2 centimeters is unacceptable; the specified resolution in dots per inch may be imprecise or unavailable. Questions should focus on the relative size (e.g., is the distance between two specified points in the watermark greater than the distance between another pair of specified points), relative location (e.g., is one particular element of the watermark to the left or above another element of the watermark, which will require adherence to a specific orientation for evaluation of that watermark), relative orientation (e.g., is some element of the watermark tilted relative to a nearby chain line), or relative number (e.g., does a foolscap collar have four points). Following these guidelines, the WIRE Project team has produced the decision tree in figure 16 for all full-watermark occurrences of the Foolscap with Five-pointed Collar watermark in Rembrandt's etchings in Hinterding's catalogue. ${ }^{17}$

Sometimes the decision tree cannot be completed successfully because the watermark being identified is only a fragment of the full watermark, because the user erred when answering the decision-tree questions, or because the watermark being identified may not be in Hinterding's catalogue. Thus, verification mechanisms are needed. To this end, we compare the watermark of interest to the image of the watermark in Hinterding's catalogue that was identified as a match by the decision tree. We also check the match of the chainspace pattern in the print of interest to the 


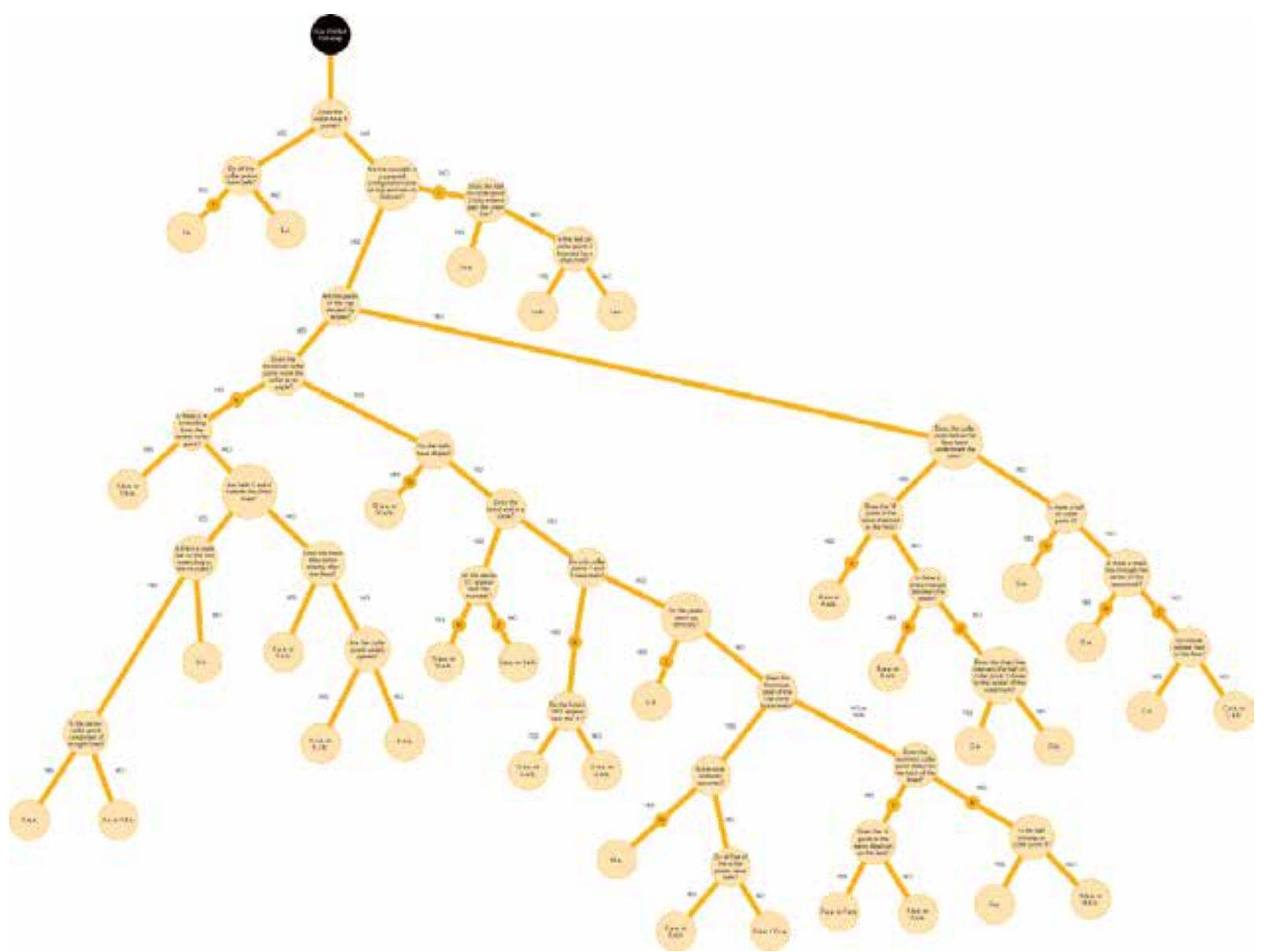

Fig. 16 Decision tree by the WIRE Project from type to subvariant for Foolscap with Five-pointed Collar in Rembrandt's etchings (illustration by Margaret N. Canfield (Cornell))

reference print from Hinterding's catalogue. In both instances the match should be exact.

The first mechanism requires close looking. ${ }^{18}$ The second mechanism will probably require some adjustment in one of the two images, as they will often be digitized at different resolutions. Furthermore, prints that have been subject to different degrees and types of conservation may exhibit different amounts of shrinkage. While these shrinkage effects are typically modest, a small difference could lead to the failure of a visual overlay comparison..$^{19}$ Fortunately, shrinkage appears to be largely uniform in the direction perpendicular to the chain lines. Thus, the chainspace comparison can be done by first re-scaling one image so the same pair of chain lines near the center of the watermark is matched in the two images, and then checking to see if the other chain lines in the two images are aligned. (The verification is more reliable for images including more chain lines. ${ }^{20}$ ) Consequently, the flowchart for watermark identification in figure $\mathbf{1 7}$ has a feedback loop in case of a confirmation failure, through a refine/expand mode that leads the user back to the start of the identification procedure. Construction and use of the decision-tree-based watermark identification procedure is illustrated in the next section using the seven Rembrandt prints with watermarks in The Frick Collection. ${ }^{21}$ This study of the watermarks in The Frick Collection's Rembrandt prints is the centerpiece of this paper. 


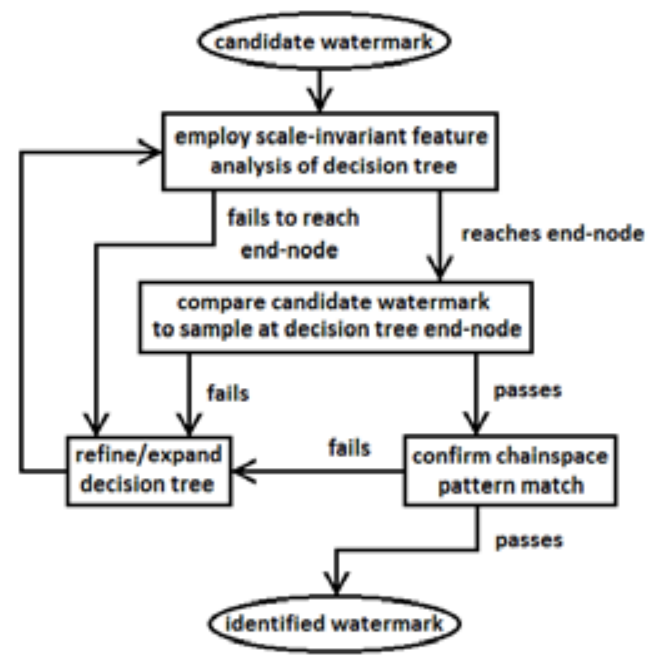

Fig. 17 Flowchart for watermark identification (illustration by author)

\section{The WIRE Project Examines the Frick Collection's Rembrandt Prints}

In July 2018, Margaret Holben Ellis (New York University) and Reba Fishman Snyder (The Morgan Library \& Museum) took beta-radiographs of prints by Rembrandt in The Frick Collection. Lydia Aikenhead (New York University) stitched together the resulting images. Watermarks or watermark fragments appeared in radiographs of seven of the prints. These images were sent to the WIRE Project for analysis, using the decision trees under development. Watermark identification was successful for all seven prints.

\section{Landscape with Three Trees}
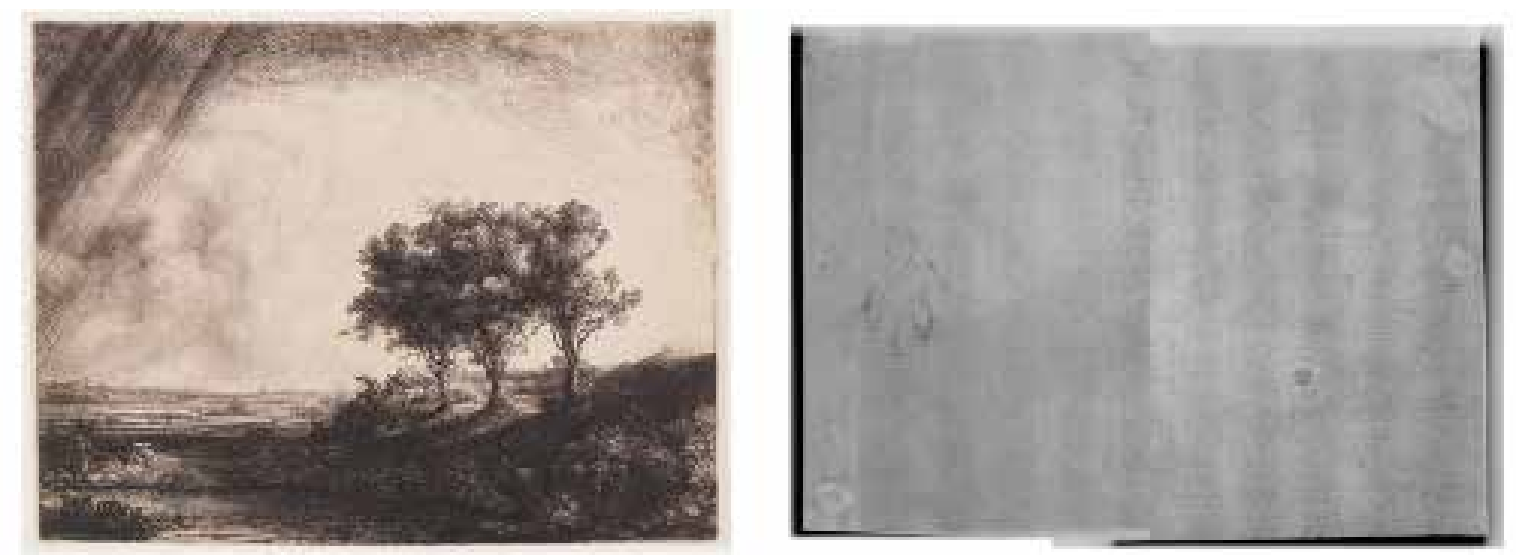

Fig. 4 Left: Rembrandt Harmenszoon van Rijn, Landscape with Three Trees, The Frick Collection, 1915.3.28. Right: Beta-radiograph of portion around watermark (provided by Margaret Hoben Ellis \{NYU\} and Reba Fishman Snyder \{Morgan\})

The Frick Collection's impression of Rembrandt's Landscape with Three Trees and its beta-radiograph appear in figure 4 . The watermark appears near the left edge of the beta-radiograph. A close-up of the watermark appears in the left image in figure 18.

Five questions and answers form the path highlighted in figure 19, through the Foolscap with Five-pointed Collar decision tree in figure $\mathbf{1 6}$ to identification of the watermark in the left image in figure 18. 

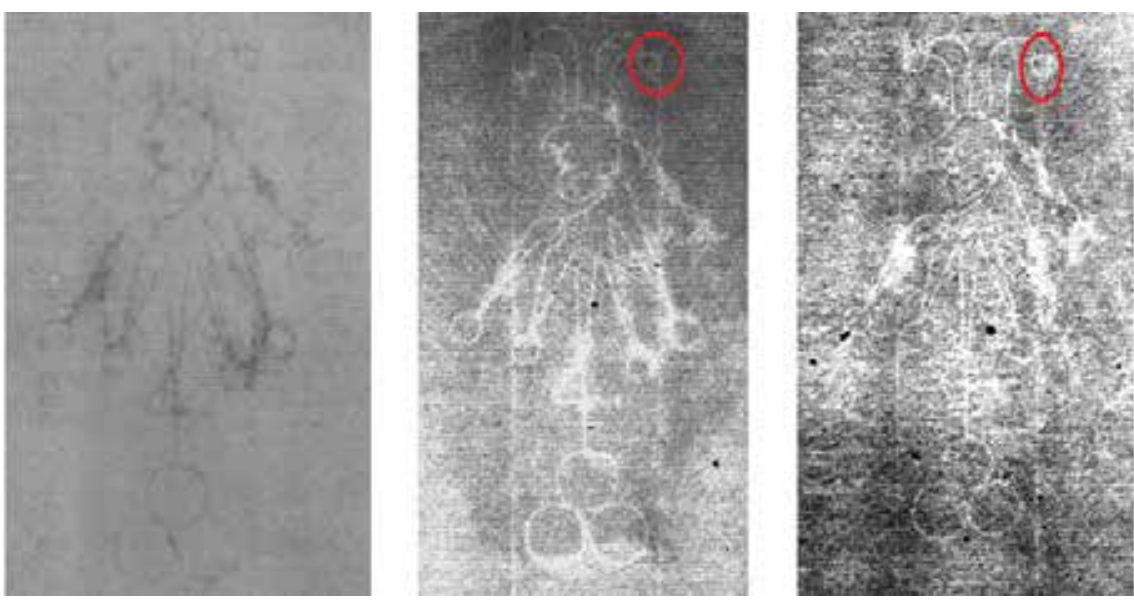

Fig. 18 Left to right: Watermark under investigation, A.a.a., A.a.b (middle and right images courtesy of Sound and Vision Publishers BV; red markings by author)

\begin{tabular}{|l|l|}
\hline \multicolumn{2}{|l|}{ Questions and Answers Leading to Foolscap with Five-pointed Collar A.a } \\
\hline Does the collar have four points? & NO \\
\hline Are the roundels in a pyramid configuration (one on top and two on bottom)? & YES \\
\hline Are the peaks of the cap divided by stripes? & NO \\
\hline Does the collar point below the face bend underneath the chin? & YES \\
\hline Does the "4" point in the same direction as the face? & YES \\
\hline
\end{tabular}

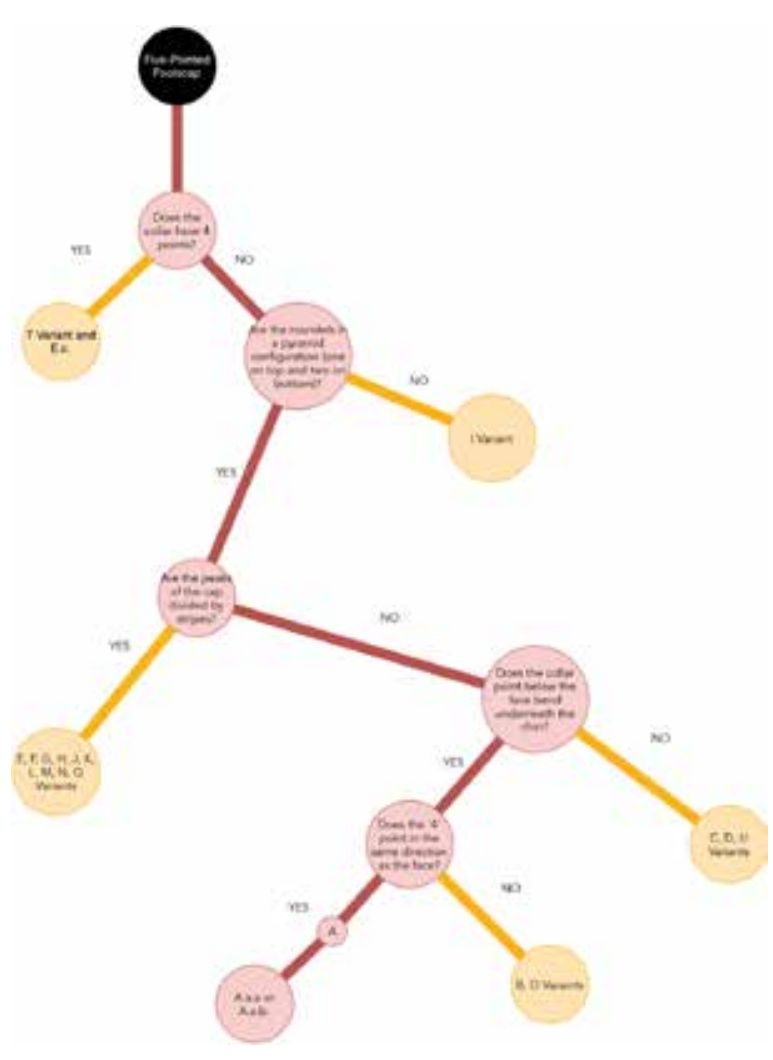

Fig. 19 Type to subvariant path through decision tree to Foolscap with Five-pointed Collar A.a in Rembrandt's etchings (illustration by Margaret $\mathrm{N}$. Canfield (Cornell)) 
27 To help interpret the features cited in these questions, refer to the feature labels in figure 14. In the envisioned computer-based interrogatory, examples of "yes" and "no" answers to each of the questions would be provided, as in figures 20-24, to assist the user. This decision-tree path terminates with a designation of the subvariant as A.a

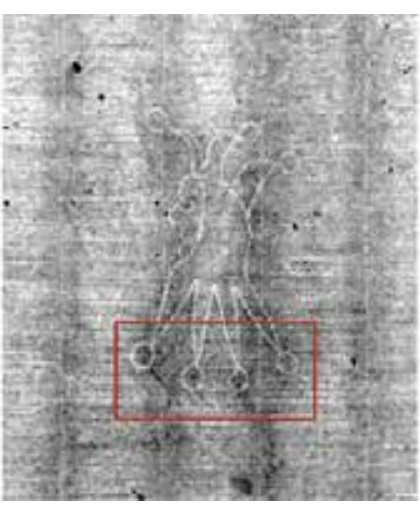

Fig. 20 Does the collar have 4 points? Left:YES. Right: NO (images courtesy of Sound and Vision Publishers BV; red markings by Margaret N. Canfield (Cornell))
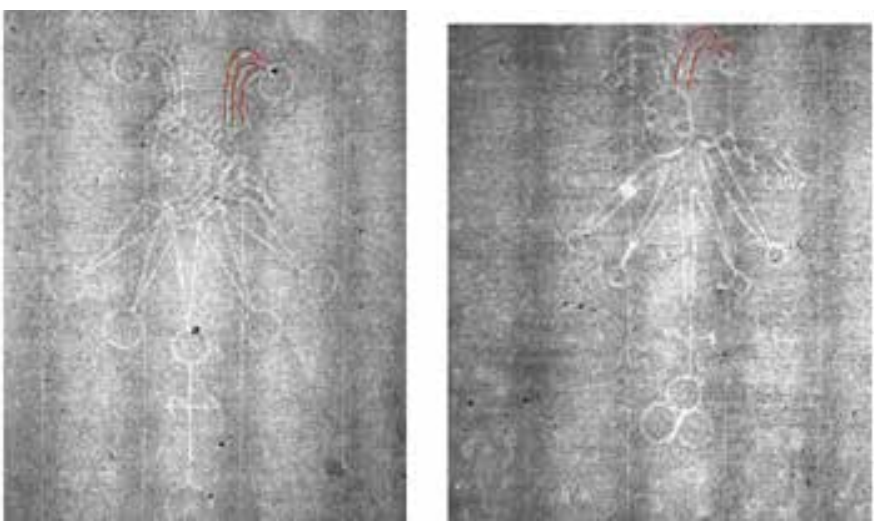

Fig. 22 Are the peaks of the caps divided by stripes? Left:YES. Right: NO (images courtesy of Sound and Vision Publishers BV; red markings by Margaret N. Canfield (Cornell))
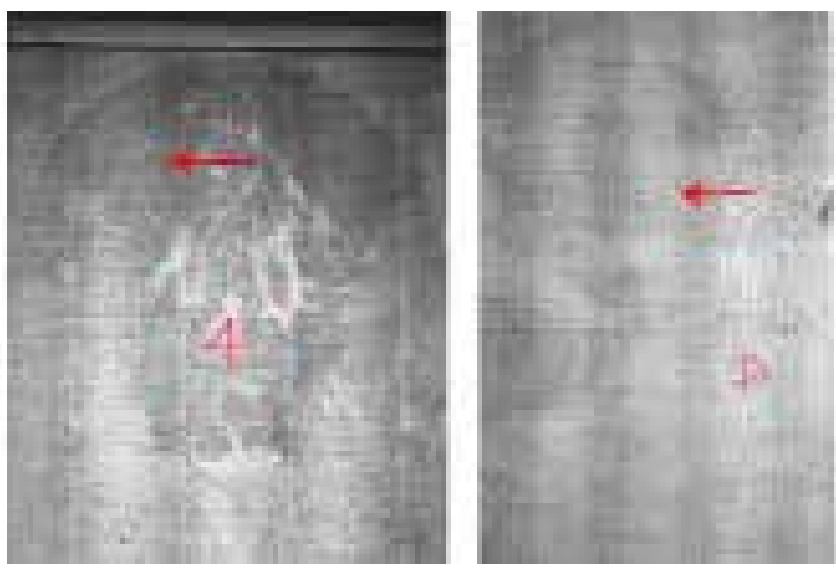

Fig. 24 Does the " 4 " point in the same direction as the face? Left: YES. Right: NO (images courtesy of Sound and Vision Publishers BV; red markings by Margaret N. Canfield (Cornell)) 
The Foolscap with Five-pointed Collar subvariant A.a has twins A.a.a and A.a.b illustrated in the middle and right images in figure 18. The twins A.a.a and A.a.b are very similar, but not identical. One distinction is that the bell on the right peak of A.a.b is bisected by a chain line, while the bell on the right peak of A.a.a is not. These bells are circled in red in figure 18. The corresponding bell in the watermark under investigation is not bisected by a chain line. Thus, the watermark comparison indicates that The Frick Collection's Landscape with Three Trees has watermark A.a.a. This identification is supported by the chainspace pattern match in figure 25 .

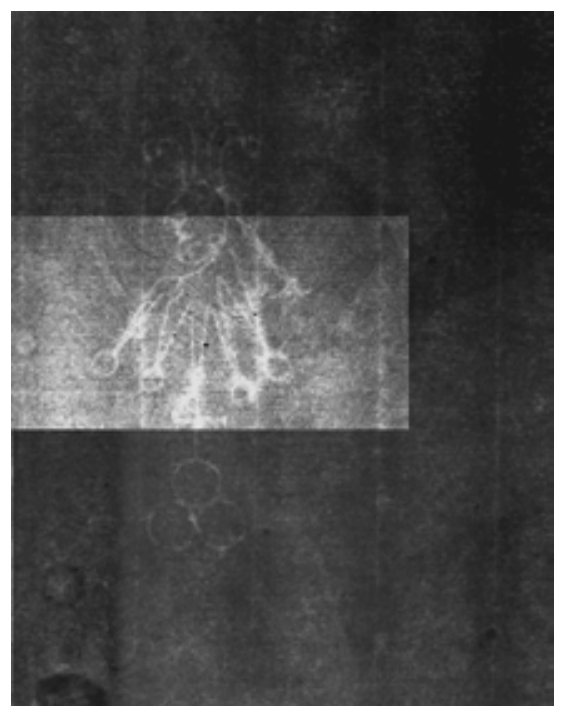

Fig. 25 Chainspace alignment test (watermark of interest over Foolscap with Five-pointed Collar A.a.a) and match (images courtesy of Sound and Vision Publishers BV; overlay composed by Margaret N. Canfield (Cornell))

Hinterding cites six impressions of Landscape with Three Trees with this watermark (A.a.a), nine impressions of the same print with the twinmark (A.a.b), three impressions of the same print with an "unidentified twinmark," and one as an "unverified reference." ${ }^{22}$ Hinterding dates the prints in this batch (and thus The Frick Collection's impression) to 1643 and cites ten prints with thirty-one impressions. ${ }^{23}$ The Frick Collection's impression expands the size of this batch to thirty-two impressions.

\section{Jan (Johannes) Lutma the Elder}
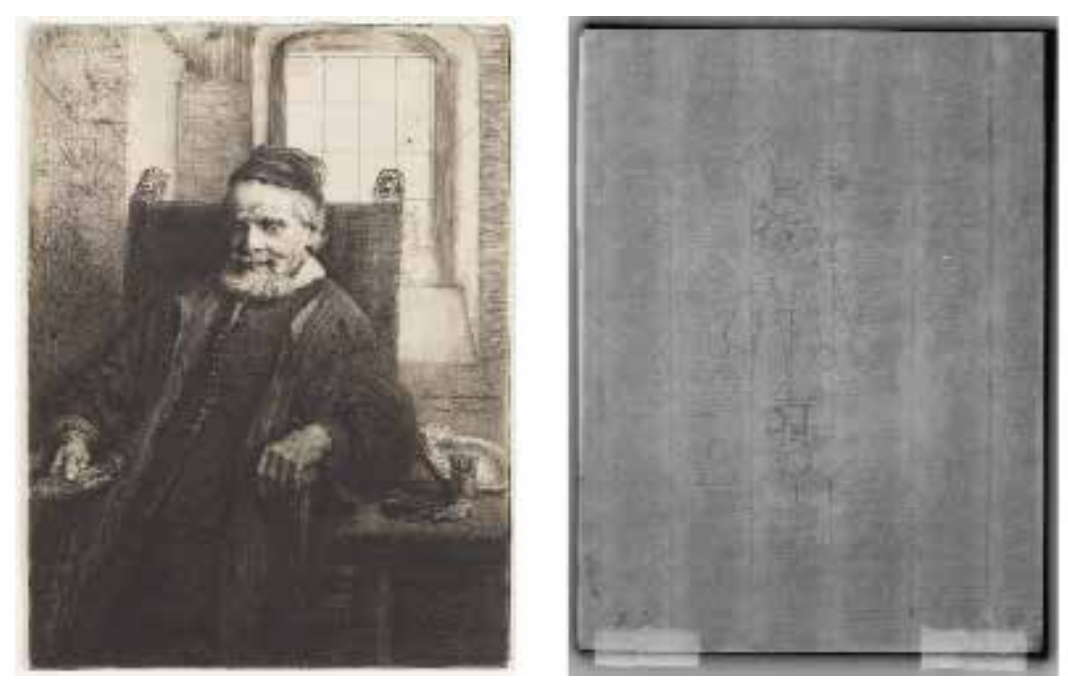

Fig. 5 Left: Rembrandt Harmenszoon van Rijn, Jan (Johannes) Lutma the Elder, The Frick Collection, 1916.3.37; Right: Beta-radiograph of portion around watermark (Provided by Margaret Hoben Ellis (NYU) and Reba Fishman Snyder (Morgan)) 
The Frick Collection's impression of Rembrandt's Jan (Johannes) Lutma the Elder and its beta-radiograph appear in figure 5. The watermark appears in the center of the beta-radiograph. A close-up of the Foolscap with Five-pointed Collar watermark appears on the left in figure 26.
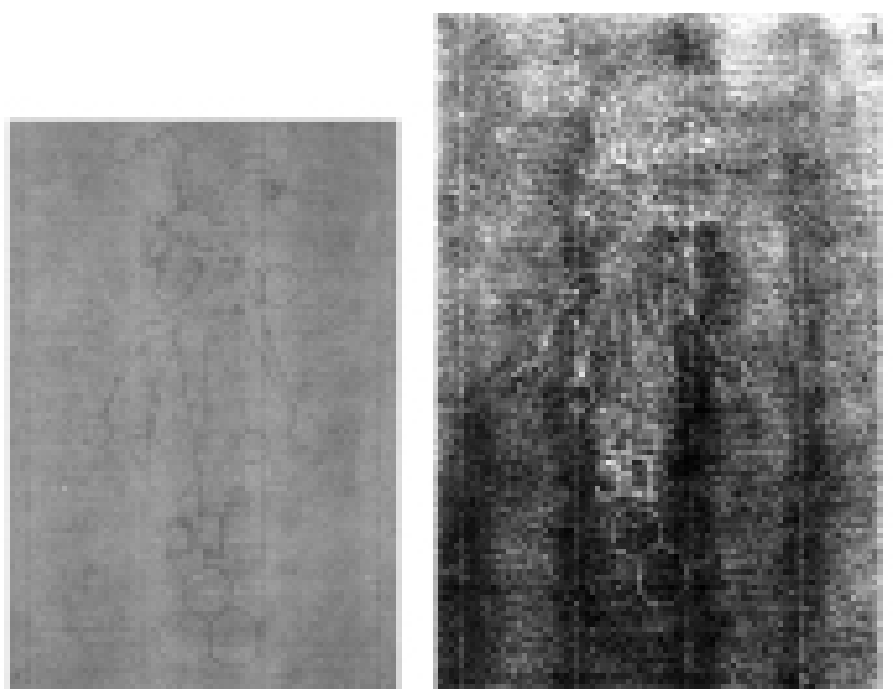

Fig. 26 Left: Watermark under investigation. Right: Foolscap with Five-pointed Collar N.a.b (image courtesy of Sound and Vision Publishers BV)

31 Seven questions and answers in the Foolscap with Five-pointed Collar decision tree in figure $\mathbf{1 6}$ identify the watermark under investigation in figure 26.

\begin{tabular}{|l|l|}
\hline \multicolumn{2}{|l|}{ Questions and Answers Leading to Foolscap with Five-pointed Collar N.a } \\
\hline Does the collar have four points? & NO \\
\hline Are the reundels in a pyramid evnfiguration (one on top and two on bottom)? & YES \\
\hline Are the peaks of the cap divided by stripes? & YES \\
\hline Does the frontmost collar point meet the collar at an angle? & NO \\
\hline Do the bells have stripes? & NO \\
\hline Does the braid end in a circle? & YES \\
\hline Do the letters "IC" appear near the roundels? & YES \\
\hline
\end{tabular}

32 To help interpret the features cited in these questions, refer to figure 14. The decision-tree path highlighted in figure 27 terminates with a designation of the subvariant as N.a. The watermark comparison in figure 26 indicates that The Frick Collection's Jan (Johannes) Lutma the Elder has watermark N.a.b. This identification is consistent with the chainspace pattern match in figure 28.

33 Hinterding cites only one impression of Jan (Johannes) Lutma the Elder with this watermark (N.a.b) and one impression of the same print with the twinmark (N.a.a). The impression with the N.a.b watermark is state i. The impression with the N.a.a watermark is state ii. Both states are dated 1656. ${ }^{24}$ The Frick Collection's impression is the third in this batch. ${ }^{25}$

34 The Frick Collection's impression is state iii, as it contains an added inscription of François Lutma, 


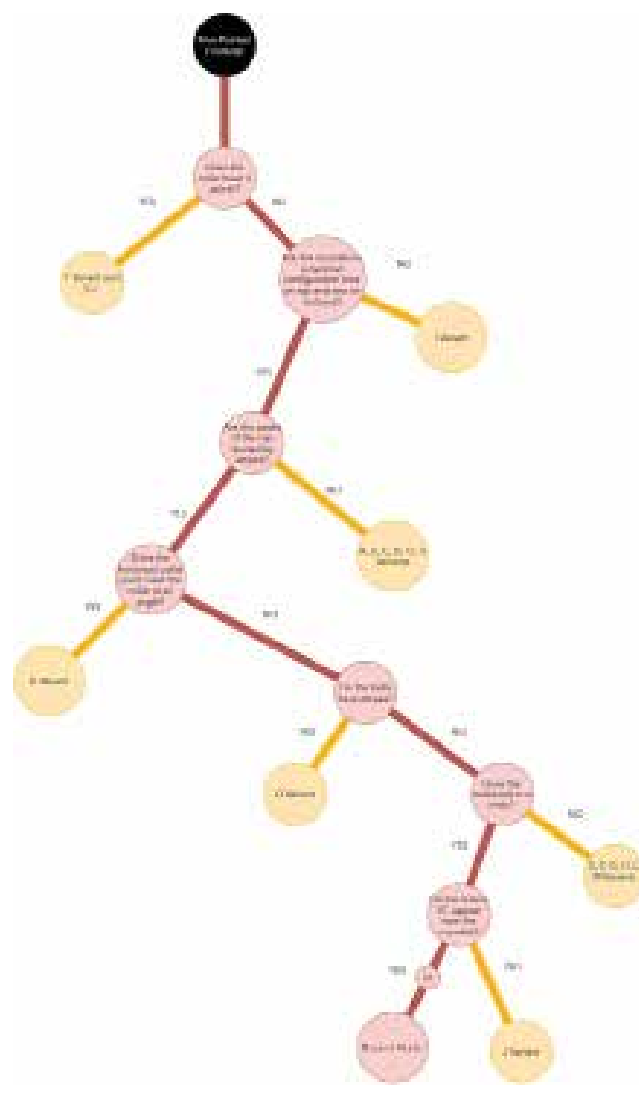

Fig. 27 Path from type to subvariant of Foolscap with Five-pointed Collar N.a (illustration by Margaret N. Canfield (Cornell))

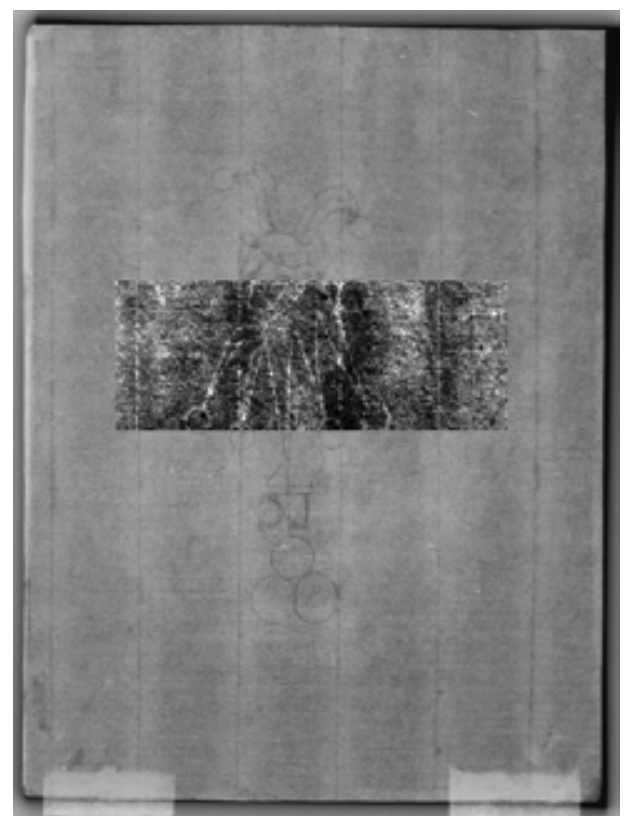

Fig. 28 Chainspace alignment test (Foolscap with Five-pointed Collar N.a.b over watermark of interest) and match (images courtesy of Sound and Vision Publishers BV; overlay composed by Margaret N. Canfield (Cornell))

and, therefore, was printed while the plate was no longer in Rembrandt's possession. ${ }^{26}$ State i was made by Rembrandt. This suggests that either Lutma and Rembrandt somehow bought the same paper or Rembrandt could have still been working closely with Lutma when the print was made. However, the fact that the papers for all three states are batchmates favors a continued connection between François Lutma and Rembrandt. ${ }^{27}$

\section{Landscape with Haybarn and Flock of Sheep}
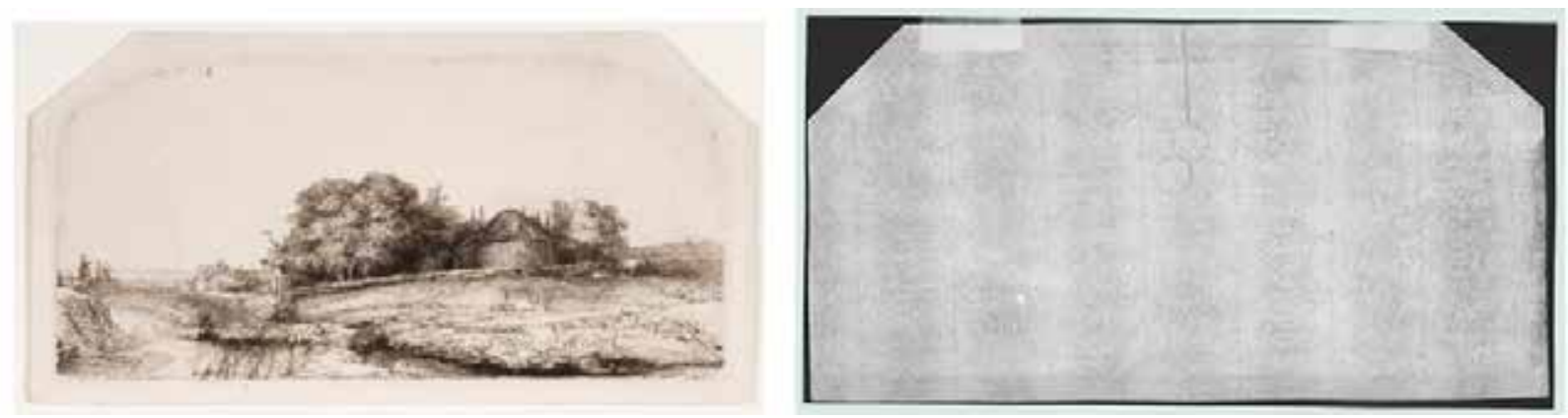

Fig. 6 Left: Rembrandt Harmenszoon van Rijn, Landscape with Haybarn and Flock of Sheep, The Frick Collection, 1916.3.29. Right: Beta-radiograph of portion around watermark (provided by Margaret Hoben Ellis (NYU) and Reba Fishman Snyder (Morgan)) [side-by-side viewer]

The Frick Collection's impression of Rembrandt's Landscape with Haybarn and Flock of Sheep and its beta-radiograph appear in figure 6. The watermark appears at the edge of the beta-radiograph and is just a fragment of a foolscap. 
There are only two types of watermarks in Hinterding's catalogue that have the cross atop a pyramid of three roundels: Foolscap with Five-pointed Collar and Foolscap with Seven-pointed Collar. All of the Foolscaps with Seven-pointed Collar watermarks have either a bent crosspost (i.e., the vertical component of the cross) or a " 4 " that incorporates the horizontal crossbar. The watermarks in figure 26 have this " 4 " that the fragment in figure 6 does not. The watermark fragment in figure 6 also has a straight crosspost. Therefore, the fragment in figure 6 must be from a Foolscap with a Five-pointed Collar.

With respect to a fragment lacking so much of the upper portion, the first question in the Foolscap with Five-pointed Collar decision tree in figure 16, about the number of collar points, cannot be answered. To proceed we need a modified strategy, as indicated by the flowchart in figure 17. Our approach taken here, which is a prototype for applying decision-tree-style questions to a fragment, is to begin by answering all of the questions from the decision tree in figure $\mathbf{1 6}$ that can be answered for the fragment of interest, which is shown in a close-up in the left half of figure 30.

\begin{tabular}{|l|l|}
\hline $\begin{array}{l}\text { All Questions in Foolscap with Five-pointed Collar Decision Tree Answerable for Fragment in Figure } \\
\mathbf{3 0}\end{array}$ & NO \\
\hline Is there a "4" extending from the central collar point (that incorporates the horizontal crossbar)? & NO \\
\hline Is there a chain line through the center of the watermark? & NO \\
\hline Do the letters "IC" appear near the roundels? & NO \\
\hline Do the letters "MG" appear near the "4" (just below the horizontal crossbar)? & YES \\
\hline Are the roundels in a pyramid configuration (one on top and two on bottom)? & \\
\hline
\end{tabular}

Any subvariants with answers opposite to those for any of the five questions posed above can be removed from the list of possibilities. Consider, for instance, the first question. With the answer for the watermark of interest being "no," none of the watermarks with a "4" will match the mark in question. The watermarks with a "4" include variants A, B, C, D', E, F, G, H, I, J, L, M, N, O, and $\mathrm{U}$, and twins K.b.a and K.b.b. The second question, about the presence of a chain line down the middle of the watermark, with an answer of "no" for the watermark of interest, removes variants D' and Q' from further consideration. As the first question already removed variant D' from consideration, the second question just removes Q. The presence of the letters "IC" or "MG" (from answering the third or fourth questions with "yes") only removes, respectively, variant J and subvariant G.a from consideration. But they were already removed by the first question. Similarly, answering "no" to the roundels-in-a-pyramid question only removes variant I, which was also removed by the first question. Thus, as illustrated in figure 29, only the first two of the five questions need be asked. These two questions alone remove all possibilities that do not produce answers to all five questions that match the answers for the watermark of interest. ${ }^{28}$ 


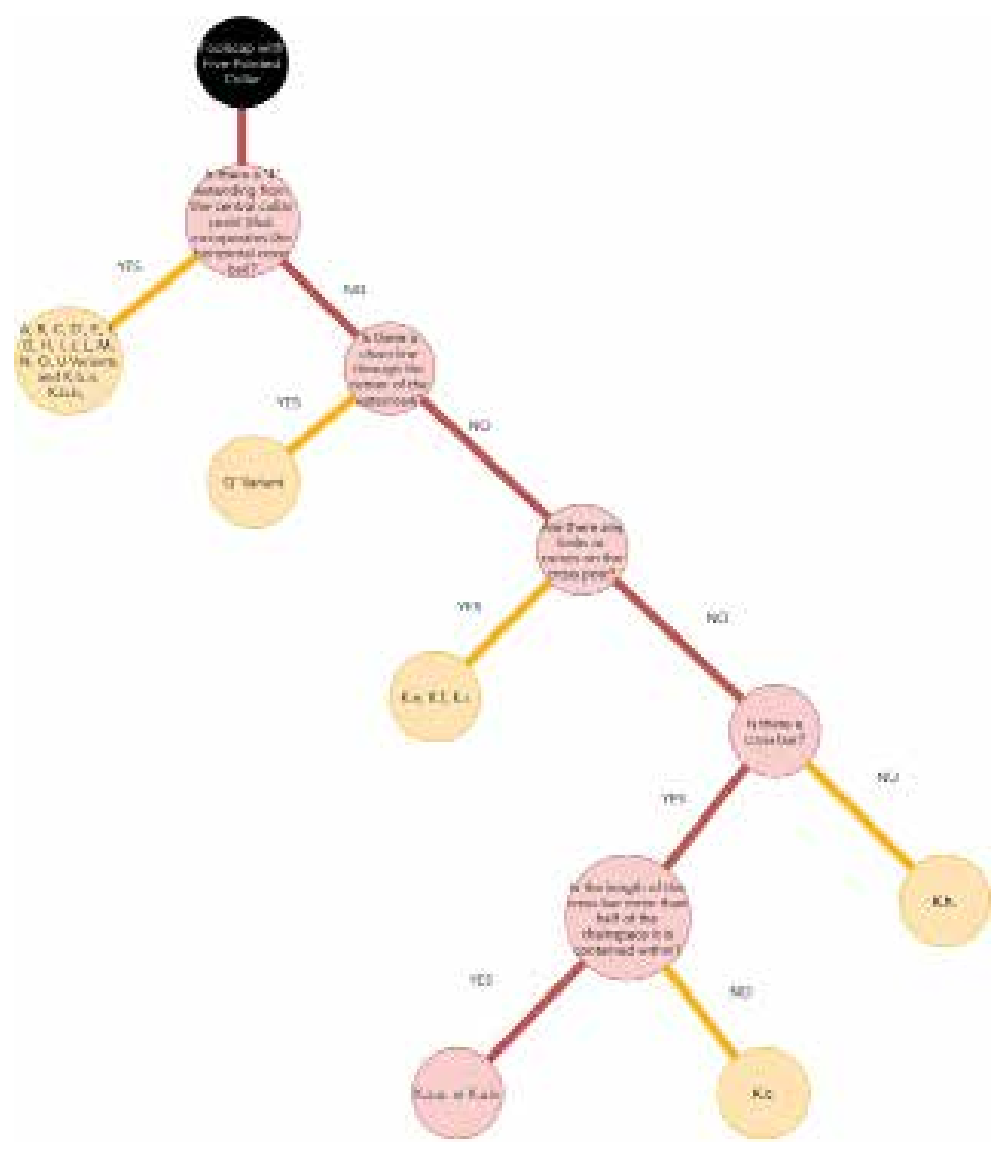

Fig. 29 Path from type to subvariant of fragment of Foolscap with Five-pointed Collar K.a (illustration by Margaret N. Canfield (Cornell)

K.a, K.c, K.e, K.f, K.h, K.i. For this reduced set of possibilities we will create a sequence of new location-appropriate questions that distinguish the fragment of interest from the remaining subvariants.

\begin{tabular}{|l|l|}
\hline \multicolumn{2}{|l|}{ New Questions for Fragment in Figure 30 Leading to Foolscap with Five-pointed Collar K.a } \\
\hline Are there any kinks or curves in the crosspost? & NO \\
\hline .... Subvariants remaining: K.a, K.c, K.h & YES \\
\hline Is there a crossbar? & YES \\
\hline .... Subvariants remaining: K.a, K.c & \\
\hline Is the length of the crossbar more than half of the chainspace it is contained within & \\
\hline .... Subvariant remaining: K.a &
\end{tabular}

The full path is illustrated in figure 29. This procedure indicates a subvariant designation of K.a. The watermark comparison in figure $\mathbf{3 0}$ supports the identification of the fragment as K.a.a. The chainspace pattern match in figure 31 supports this designation of K.a.a. 


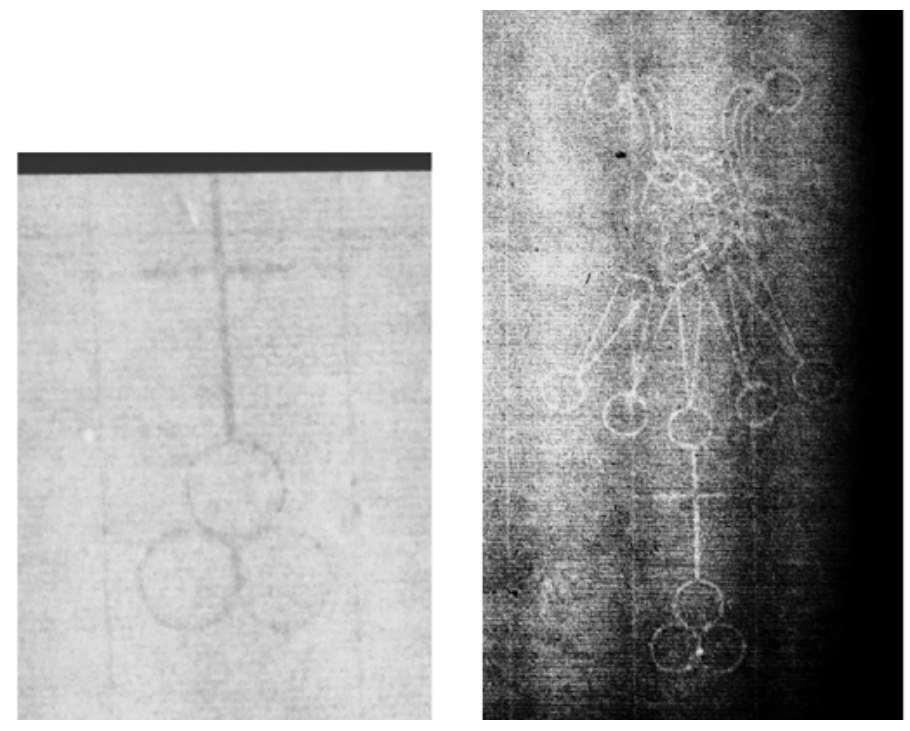

Fig. 30 Left: Watermark fragment under investigation; Right: Foolscap with Five-pointed Collar K.a.a (image courtesy of Sound and Vision Publishers BV)

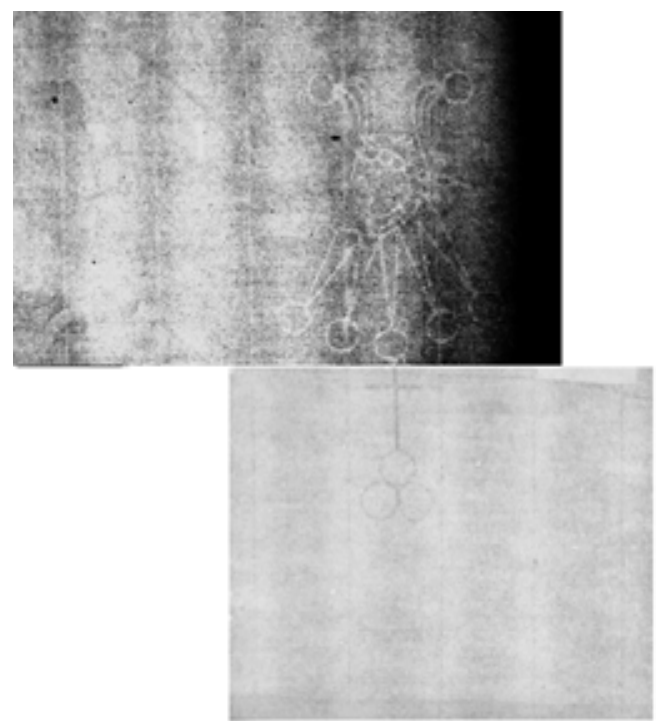

Fig. 31 Chainspace alignment of Foolscap with Five-pointed collar K.a.a (top) and watermark of interest and match (top image courtesy of Sound and Vision Publishers BV; composition by author)

41 No other impressions are cited in Hinterding's catalogue of the same print with this watermark or its twinmark. ${ }^{29}$ However, there are eighty-seven impressions of twenty-six prints with subvariant K.a and/or the associated countermark LB.a. This batch is dated to around $1650 .{ }^{30}$ Interestingly, the plate date in The Frick Collection's Landscape with Haybarn and Flock of Sheep matches this batch date.

\section{The Goldweigher's Field}
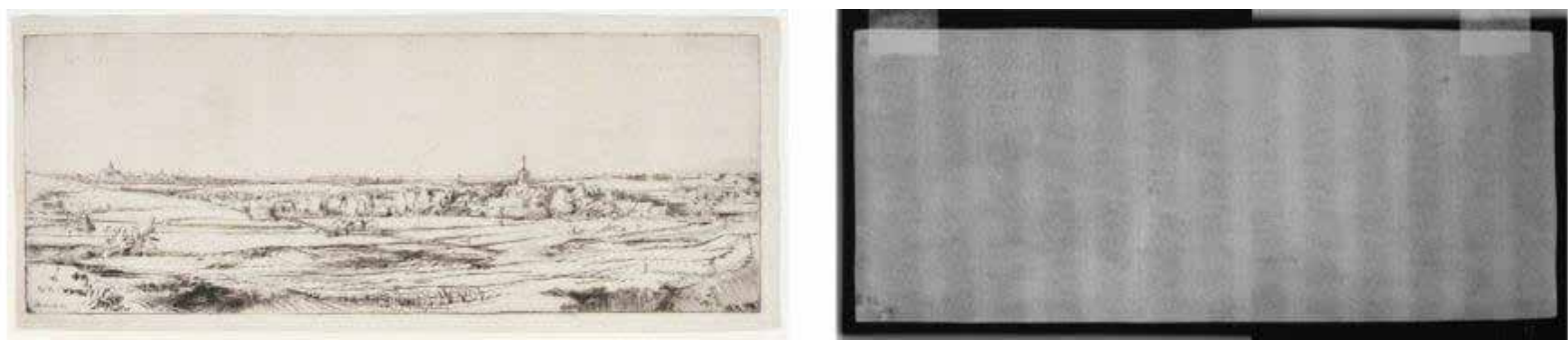

Fig. 7 Left: Rembrandt Harmenszoon van Rijn, The Goldweigher's Field, The Frick Collection, 1915.3.31. Right: Beta-radiograph of portion around watermark (provided by Margaret Hoben Ellis (NYU) and Reba Fishman Snyder (Morgan)) [side-by-side viewer]

42 The watermark in The Frick Collection's impression of The Goldweigher's Field is another fragment. It appears to the left on the upper edge of the radiograph in the figure 7. Like the Foolscap with Five-pointed Collar watermark fragment in Landscape with Haybarn and Flock of Sheep, the Paschal Lamb fragment in The Goldweigher's Field is of the bottom portion of the watermark, as is apparent in figure 7. The difference with The Frick Collection's Landscape with Haybarn and Flock of Sheep is that the fragment in The Goldweigher's Field has a larger portion of the full Paschal Lamb watermark, and the first few questions in the Paschal Lamb decision tree in figure 32 can therefore be answered. Labels for some Paschal Lamb features are illustrated in figure 33. A close- 
up of the watermark appears on the left in figure 35.

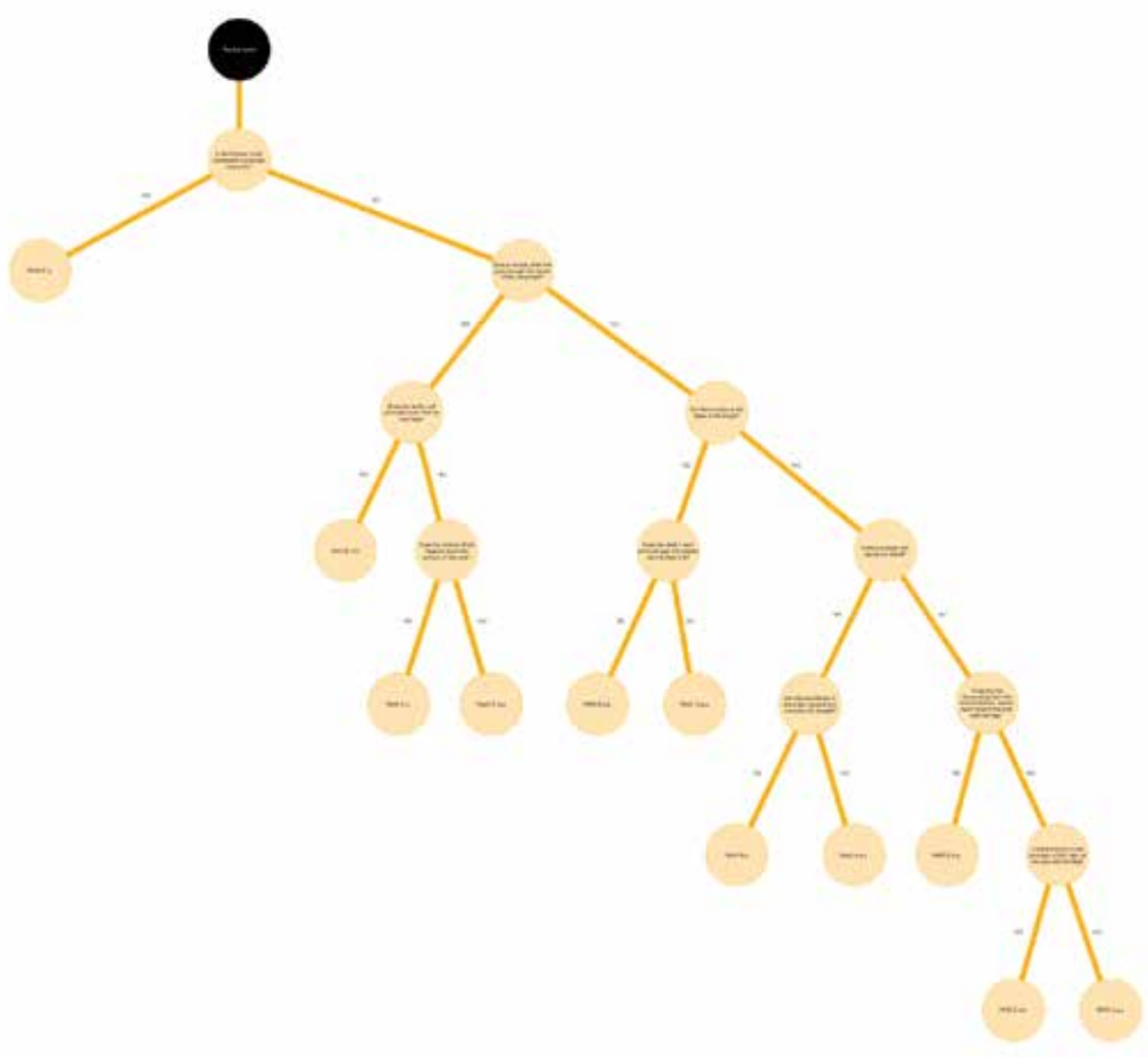

Fig. 32 Decision tree by the WIRE Project from type to subvariant for Paschal Lamb in Rembrandt's etchings (illustration by Margaret N. Canfield (Cornell))

43 A string of three questions at the top of the Paschal Lamb decision tree in figure 32 can be answered for the fragment in figure 35.

\begin{tabular}{|l|l|}
\hline \begin{tabular}{l}
$|l|$ \\
Initial Sequence of Questions in the Paschal Lamb Decision Tree Answerable for Fragment in Figure \\
\hline Is the Paschal Lamb contained in a circular cartouche?
\end{tabular} & NO \\
\hline Does a vertical chain line pass through the center of the watermark? & NO \\
\hline Are there initials at the base of the shield? & NO \\
\hline
\end{tabular}

44 At this point in the tree the only remaining destinations are A.a.a, A.b, E.a.a, E.a.b, E.b.a. Our strategy is to create a continuing sequence of new location-appropriate questions (with watermark orientation set by figure 33, thereby allowing the use of "bottom" and "right" in the questions selected) that distinguish the fragment of interest from as many of these remaining subvariants as 
possible.

\begin{tabular}{|l|l|}
\hline \multicolumn{2}{|l|}{ New Questions for Fragment in Figure 35 Leading to Paschal Lamb A.b } \\
\hline Does the bottom of the flagpole cross the chain line bisecting the lamb's head? & YES \\
\hline … Subvariants/twins remaining: A.a.a, A.b & YES \\
\hline Does a chain line touch the right edge of the lamb's eye? & \\
\hline .... Subvariant remaining: A.b & \\
\hline
\end{tabular}

45 The full path for this fragment is illustrated in figure 34. This procedure indicates a subvariant designation of A.b. Comparing the watermark of interest to the Paschal Lamb A.b in figure 35 supports the answer from the decision tree. The chainspace pattern matching in figure 36 also supports a designation of A.b.
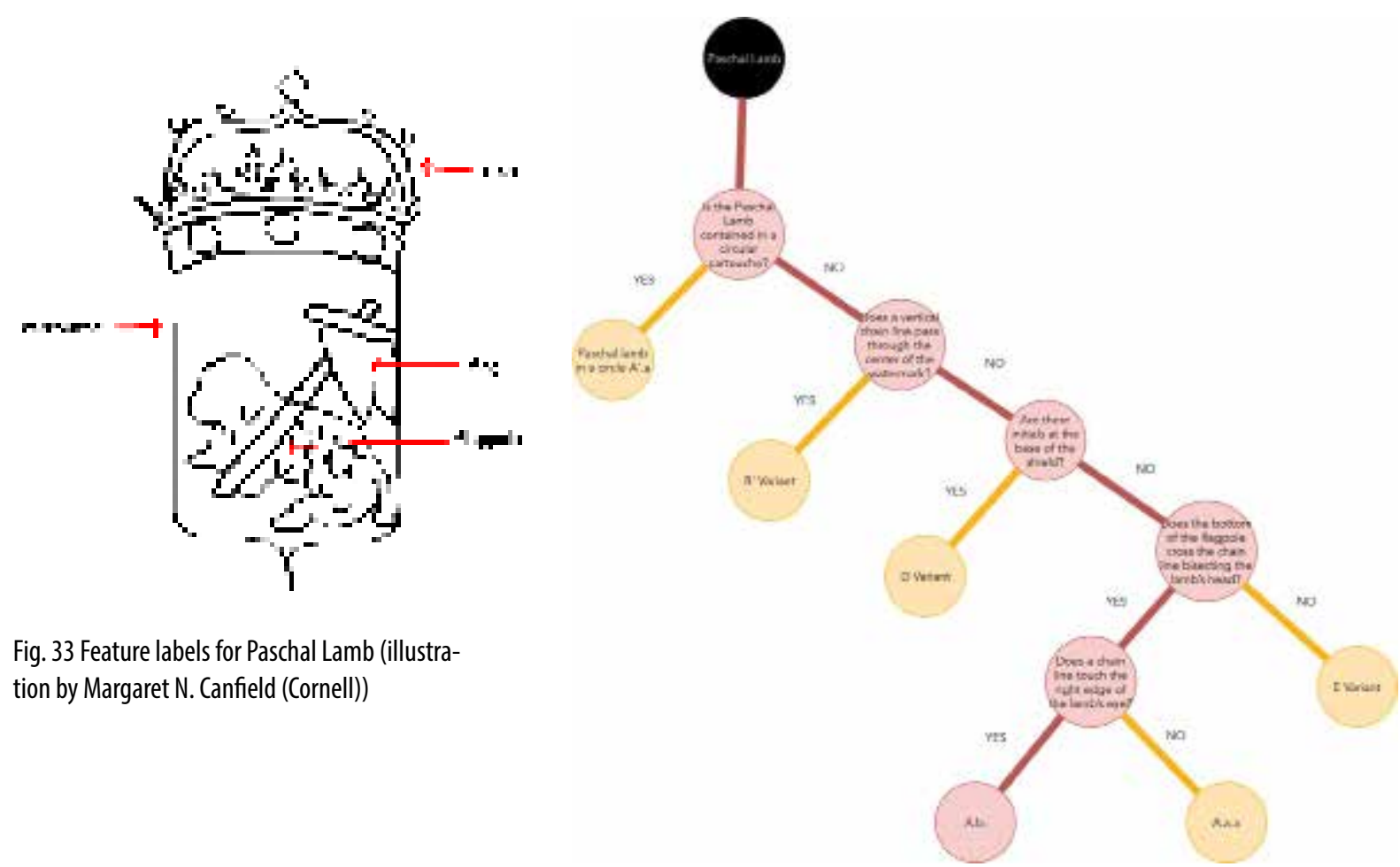

Fig. 33 Feature labels for Paschal Lamb (illustration by Margaret N. Canfield (Cornell))

Fig. 34 Type to subvariant path for Paschal Lamb fragment subvariant A.b (illustration by Margaret N. Canfield (Cornell))

All Paschal Lamb A variants are probably various twinmarks in stages of deformation and therefore all batchmates. ${ }^{31}$ The Goldweigher's Field appears five times on Paschal Lamb A.a.a, two times on A.a.b, three times on A.a, four times on A.b, and once on A.c. ${ }^{32}$ Thus, The Frick Collection's impression of The Goldweigher's Field is the fifth impression of the same print with the Paschal lamb A.b watermark. Hinterding cites sixty-two impressions of fourteen prints using Paschal 
Lamb A.a, A.b, or A.c and/or its countermark RC.a and dates the batch to $1651 .^{33}$

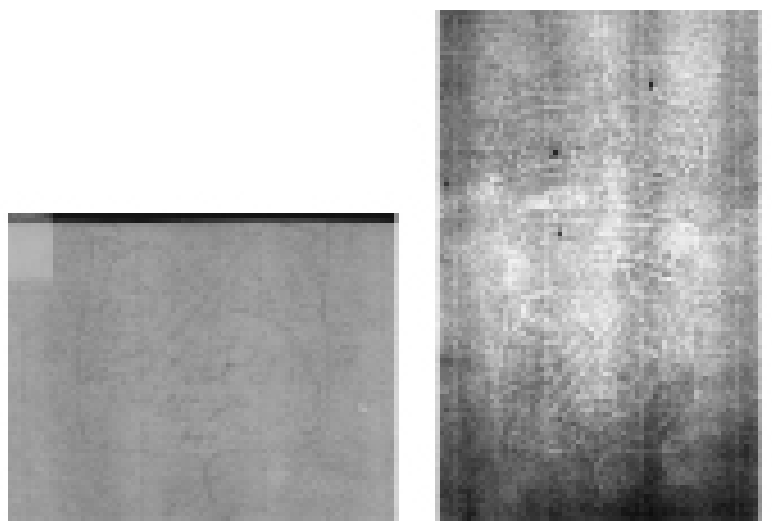

Fig. 35 Left: Watermark under investigation. Right: Paschal Lamb A.b (image courtesy of Sound and Vision Publishers BV)

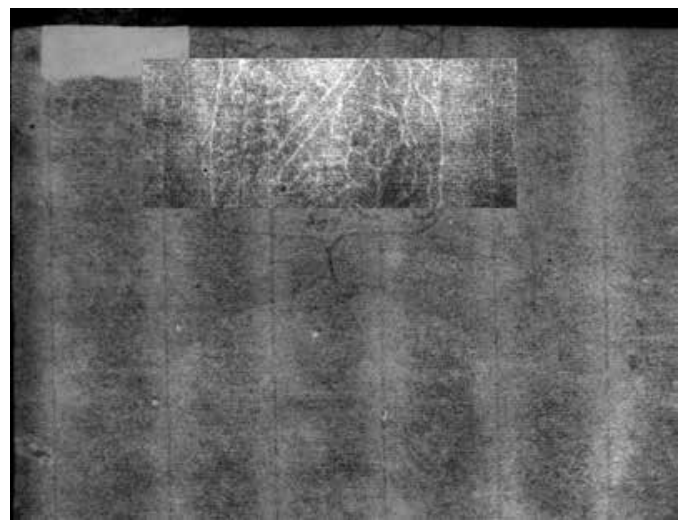

Fig. 36 Chainspace alignment of Paschal Lamb A.b over watermark of interest and match (top image courtesy of Sound and Vision Publishers BV; overlay composed by Margaret N. Canfield (Cornell))

\section{Clement de Jonghe}
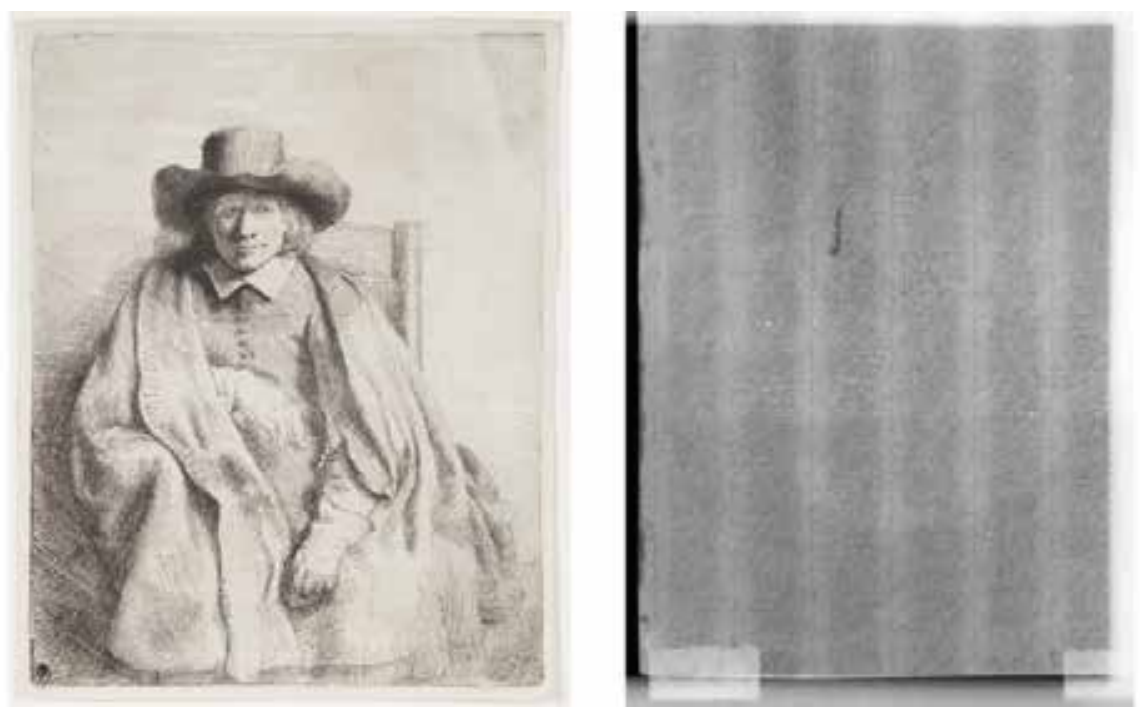

Fig. 8 Left: Rembrandt Harmenszoon van Rijn, Clement de Jonghe, The Frick Collection, 1916.3.36. Right: Beta-radiograph of portion around watermark (provided by Margaret Hoben Ellis (NYU) and Reba Fishman Snyder (Morgan))

The Frick Collection's Clement de Johnge has an RC countermark, as illustrated in figure 8. A close-up of the countermark appears on the top in figure 37. Hinterding cites only one variant (RC) for the RC countermark, which has only one subvariant (RC.a), and three twinmarks (RC.a.a, RC.a.b, and RC.a.c). ${ }^{34}$ Thus, a decision-tree branch is unnecessary in claiming that the subvariant is RC.a. The watermark comparison in figure 37 and the chainspace pattern comparison in figure 38 support a designation of RC.a.a.

Hinterding lists seven impressions of Clement de Jonghe with countermark variant RC.a, not including The Frick Collection's impression, and states that it is the countermark to Paschal Lamb variant A. ${ }^{35}$ As noted in the preceding discussion of The Goldweigher's Field, all subvariants of Paschal Lamb A are considered to be batchmates and, thus, have the same date of creation: 1651. Because The Goldweighers Field has a Paschal Lamb A watermark and Clement de Jonghe has an 

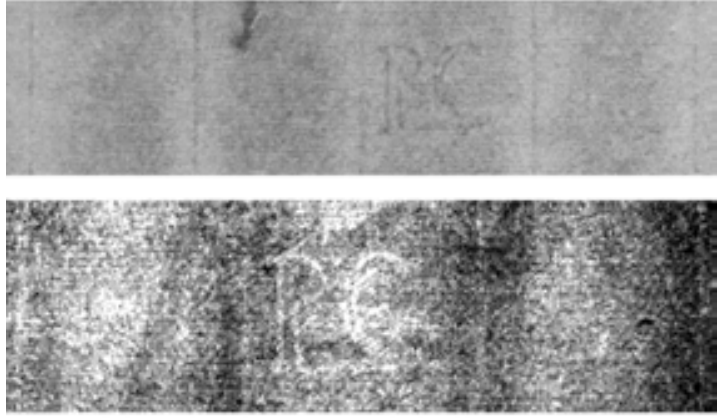

Fig. 37 Top: Watermark under investigation Bottom: RC (Countermark) RC.a.a (image courtesy of Sound and Vision Publishers BV)

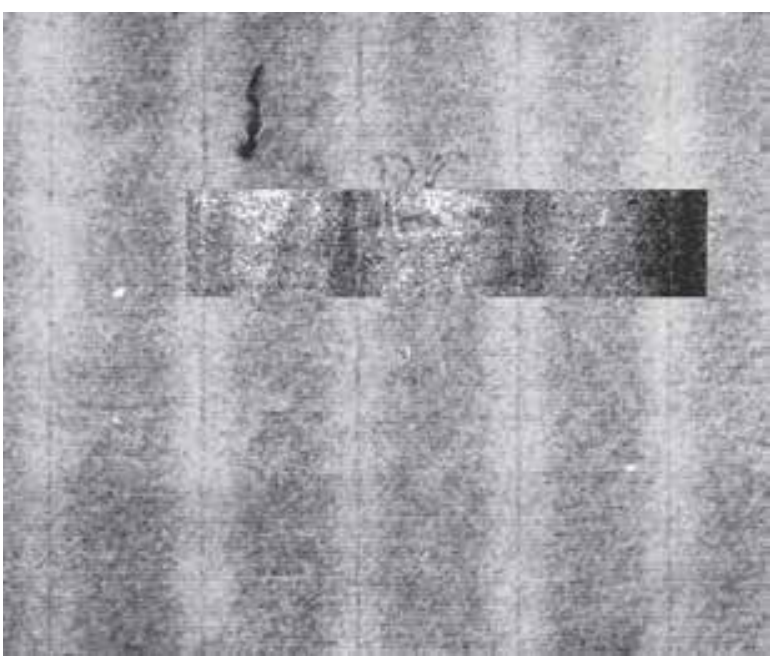

Fig. 38 Chainspace alignment of RC.a.a excerpt over watermark of interest and match (image courtesy of Sound and Vision Publishers BV; overlay composed by Margaret N. Canfield (Cornell))

RC.a.a countermark, these impressions are batchmates.

\section{St. Francis Praying Beneath a Tree}
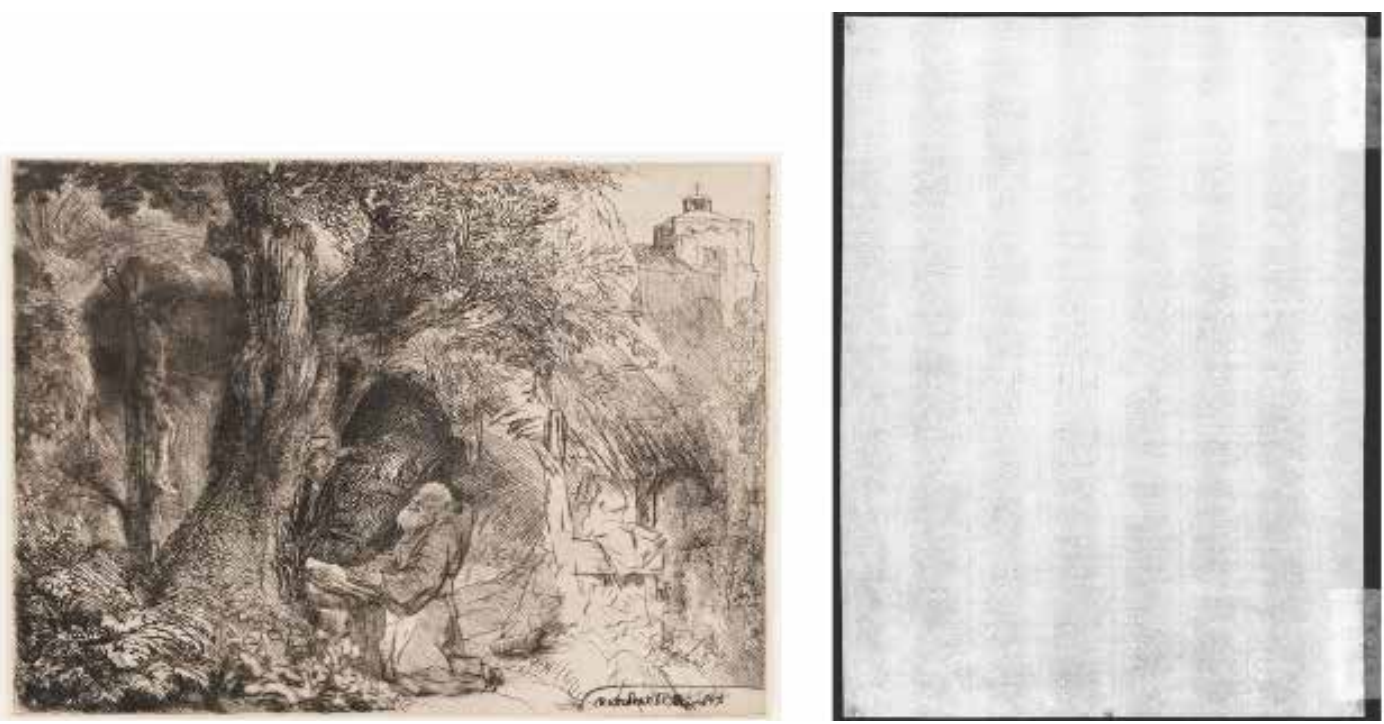

Fig. 9 Left: Rembrandt Harmenszoon van Rijn, St. Francis Praying Beneath a Tree, The Frick Collection, 1916.3.35. Right: Beta-radiograph of portion around watermark (provided by Margaret Hoben Ellis (NYU) and Reba Fishman Snyder (Morgan))

The Frick Collection's impression of Rembrandt's St. Francis Praying Beneath a Tree and its beta-radiograph appear in figure 9 with a close-up of the watermark on the left in figure 49 . The IHS countermark appears in the center of the beta-radiograph. IHS is always a countermark and has five variants and twenty-two subvariants. ${ }^{36}$ The IHS countermark will be used here as an illustration of decision-tree construction using a decision table like the one in Table $1 .{ }^{37}$ 


\section{IHS Decision Table as Construction Aid for Decision Tree}

taxonomy.

1. Using a group of images containing one representative sample from each variant, develop questions about scale-invariant features that first separate the entire set of IHS watermarks into the variant categories.

2. Confirm that these questions work for all members (subvariants and twins) of each variant by sorting them into their correct variant.

3. For each variant, develop questions that next separate the watermarks by subvariant.

4. Confirm that these questions work for all members (twins) of each subvariant by sorting them into their correct subvariant. (There is no need to distinguish twins if the watermark identification is to be used for dating, as twins will occur together in the same batch of paper and will be used in the same time period.)

To help select features used to transition from type to variant, one sample of each IHS variant is included in figure 39. Given that Hinterding's taxonomy is based on human decisions, the features distinguishing the variants should be readily observable, such as the following list of distinctions:
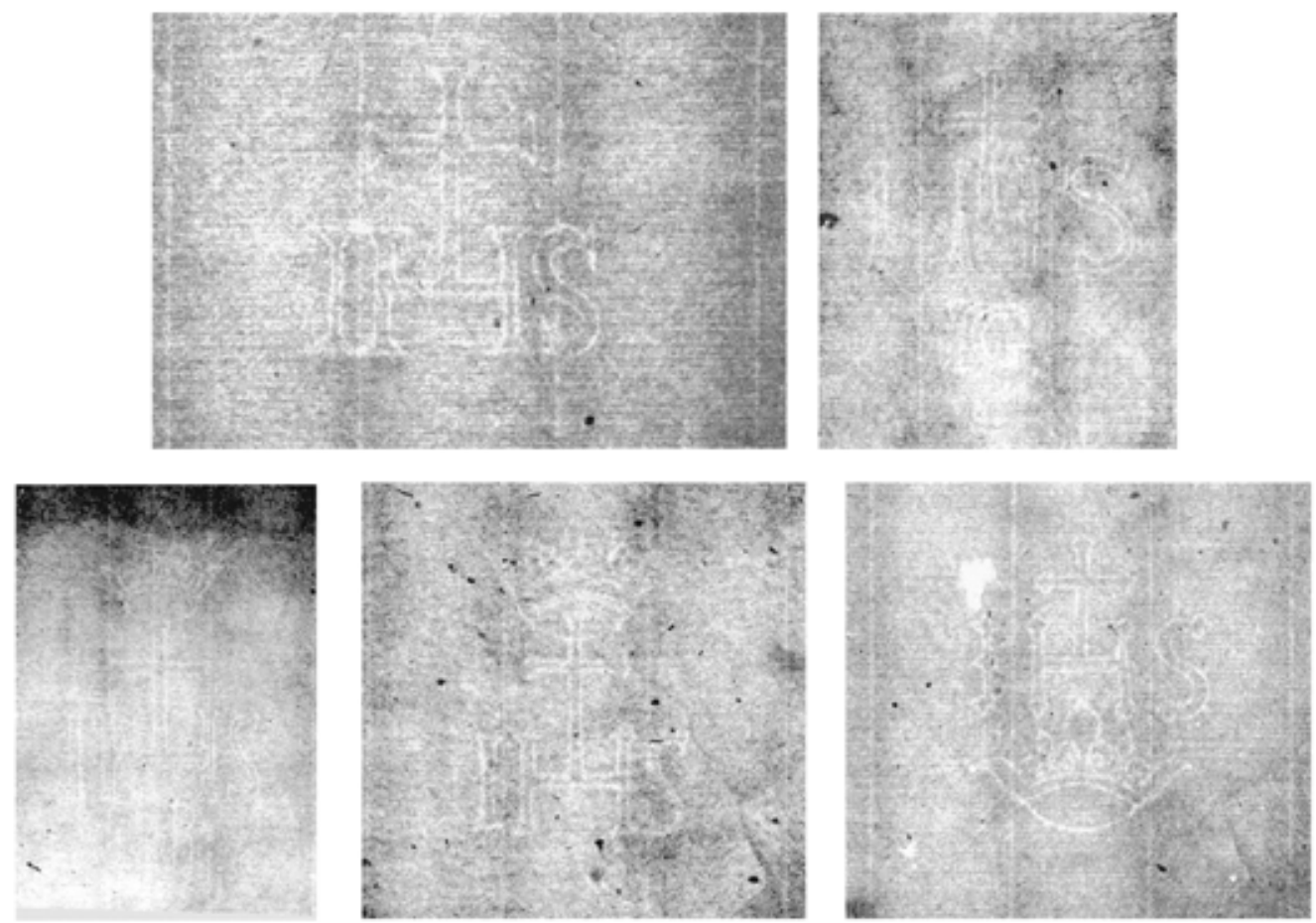

Fig. 39 0ne sample from each IHS variant. Top row (left to right): A.a, B.a.a. Bottom row (left to right): C.a.a, D.a.a., E.b (images courtesy of Sound and Vision Publishers BV) 
- IHS with cross mounted on cross bar of $\mathrm{H}$; no crown above or below $\mathrm{H}$ and no letters below $\mathrm{H}$

- letters below $\mathrm{H}$ and no crown above or below $\mathrm{H}$

- crown above and letters below H

- crown above $\mathrm{H}$ and no letters below $\mathrm{H}$

- crown below $\mathrm{H}$ and no letters

Hinterding provides a list of features possessed by each IHS variant: ${ }^{38}$
A. The initials IHS, double-wired, a Latin cross above the $\mathrm{H}$
B. Initials below the IHS
C. A crown above the Latin cross, initials below
D. As above (with the crown), but with no initials below
E. A crown below the initials

53 In this case these features correspond closely to our observations. ${ }^{39}$

54 The observed distinctions for variant separation can be captured by the following basic questions:

Q01: Are there letters below the H?

Q02: Is there a crown above the H?

Q03: Is there a crown below the H?

Table 2 lists binary answers for these three questions with "yes"=1 and "no" $=0$. Each answer listed for a particular variant is the answer to that question for every subvariant as well. The resulting binary code for each variant in the rows of Table 2 is unique.

\begin{tabular}{|c|c|c|c|}
\hline & Q01 & Q02 & Q03 \\
\hline A & 0 & 0 & 0 \\
\hline B & 1 & 0 & 0 \\
\hline C & 1 & 1 & 0 \\
\hline D & 0 & 1 & 0 \\
\hline E & 0 & 0 & 1 \\
\hline
\end{tabular}
Table 2: Decision Table Classifying IHS-Variants

56 Various orderings of the three questions distinguishing the variants of IHS can offer satisfactory decision-tree options. Two possibilities are illustrated in figure 40. Given that the variant A has more than half of the subvariants, the decision tree in the right diagram in figure $\mathbf{4 0}$ might provide a way to reduce the average number of questions needed to reach an end point in the decision tree.

57 The decision tree on the right in figure 40 includes a combination of all three questions in a logical "OR" configuration as its first inquiry. In this case, if the answer to any of the three questions is "yes," then the answer to their combination is "yes." Conversely, if the answer to all of the three 

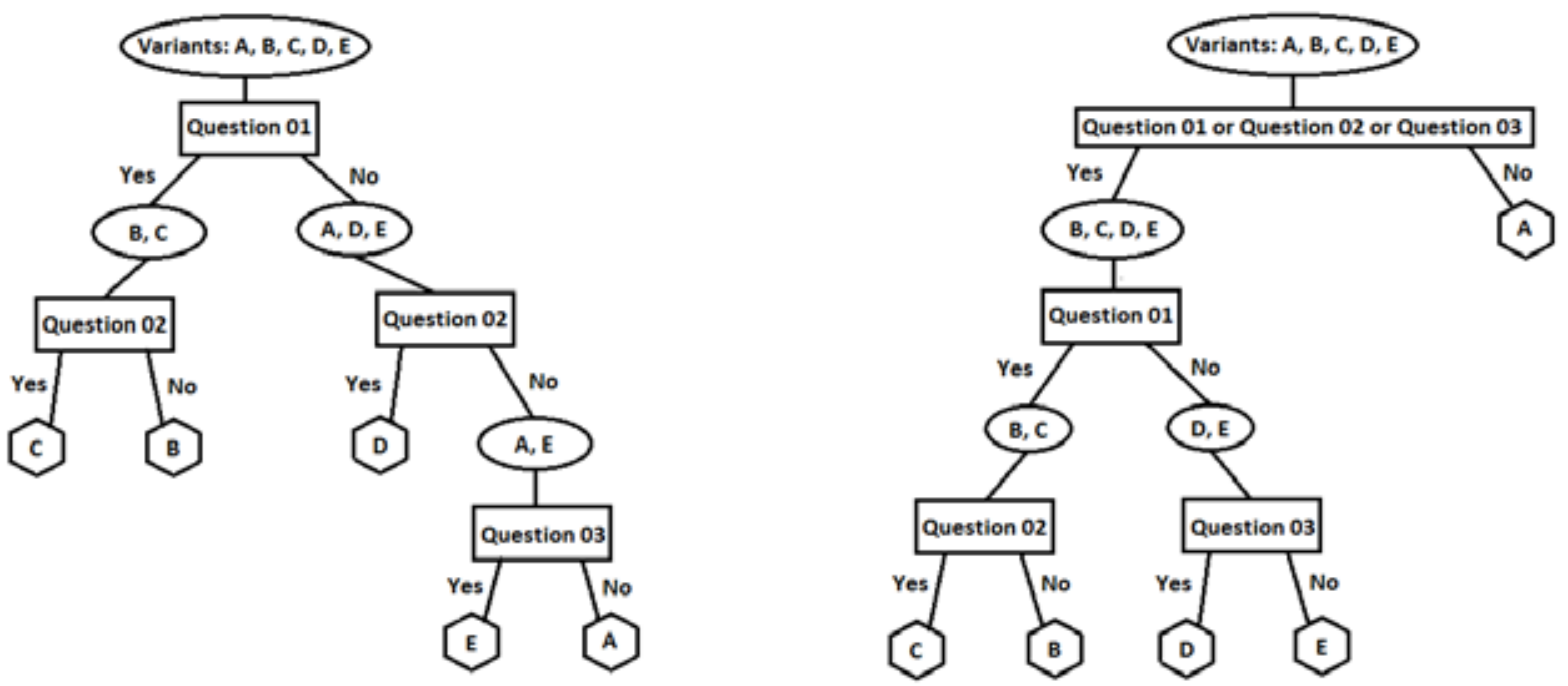

Fig. 40 Two possible decision-tree realizations for classifying variants of IHS (illustrations by author)

questions is "no," then the answer to "Question 01 OR Question 02 OR Question 03" is "no." The use of a logical AND function is also possible, though not utilized in figure 40. For example, only if the answer to both Question A and Question B is "yes" will the answer to "Question A AND Question B" be “yes."

Because variants $\mathrm{C}$ and $\mathrm{D}$ each have only one subvariant, no further questions are needed to identify the subvariant once either $\mathrm{C}$ or $\mathrm{D}$ has been identified as the variant. Variant $\mathrm{E}$ has two subvariants, so one question should suffice to distinguish the two subvariants illustrated in figure 41. One distinguishing feature is captured by the question: "Does the 'I' have a bump in the middle?" Figure 41 would be made available to the user of the decision tree, with the location of the "bump" (if present) highlighted on each of the two subvariants as an aid in distinguishing the "yes" image from the "no" image. (Such Yes/No samples were presented in figures 20-24 to help identify Foolscap with Five-pointed Collar variant A.) The wording of this question provides an example of how a more precise labeling than the generic use of "bump" might increase confidence in the user's answer. ${ }^{40}$ Answering "yes" identifies E.b and "no" indicates E.a.
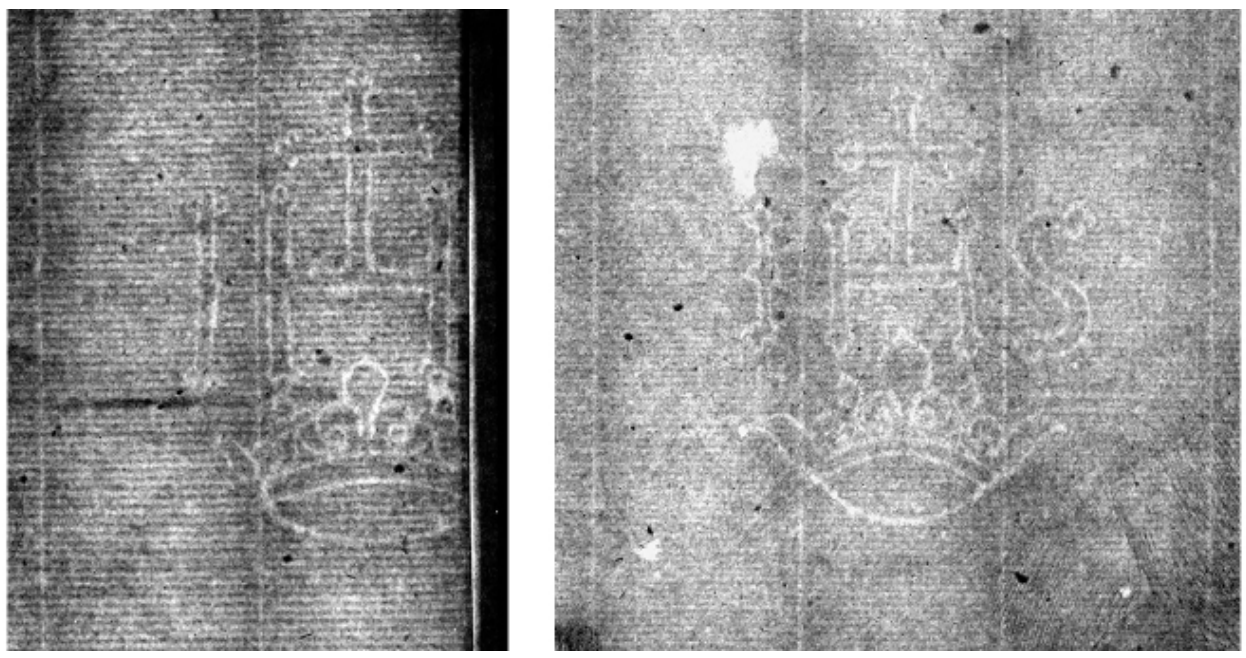

Fig. 41 Subvariants of IHS variant E: Left: E-a. Right: E-b (images courtesy of Sound and Vision Publishers BV) 
All six subvariants of variant B have letters below the "H" in "IHS," as illustrated with a sample from each subvariant in figure 42. The pairs of letters are a distinguishing feature that allows the same question to be asked repeatedly about a different pair of letters.

\begin{tabular}{|l|l|l|}
\hline \multicolumn{3}{|l|}{ Questions 04-09: Does the pair of letters XX appear below the H? } \\
\hline Q04 & YES for reversed letters IR (or LR?), B.a & NO for all others \\
\hline Q05 & YES for IG, B.a & NO for all others \\
\hline Q06 & YES for IR, B.b & NO for all others \\
\hline Q07 & YES for PB, B.c & NO for all others \\
\hline Q08 & YES for RC, B.d & NO for all others \\
\hline Q09 & YES for ET, B.e & NO for all others \\
\hline
\end{tabular}
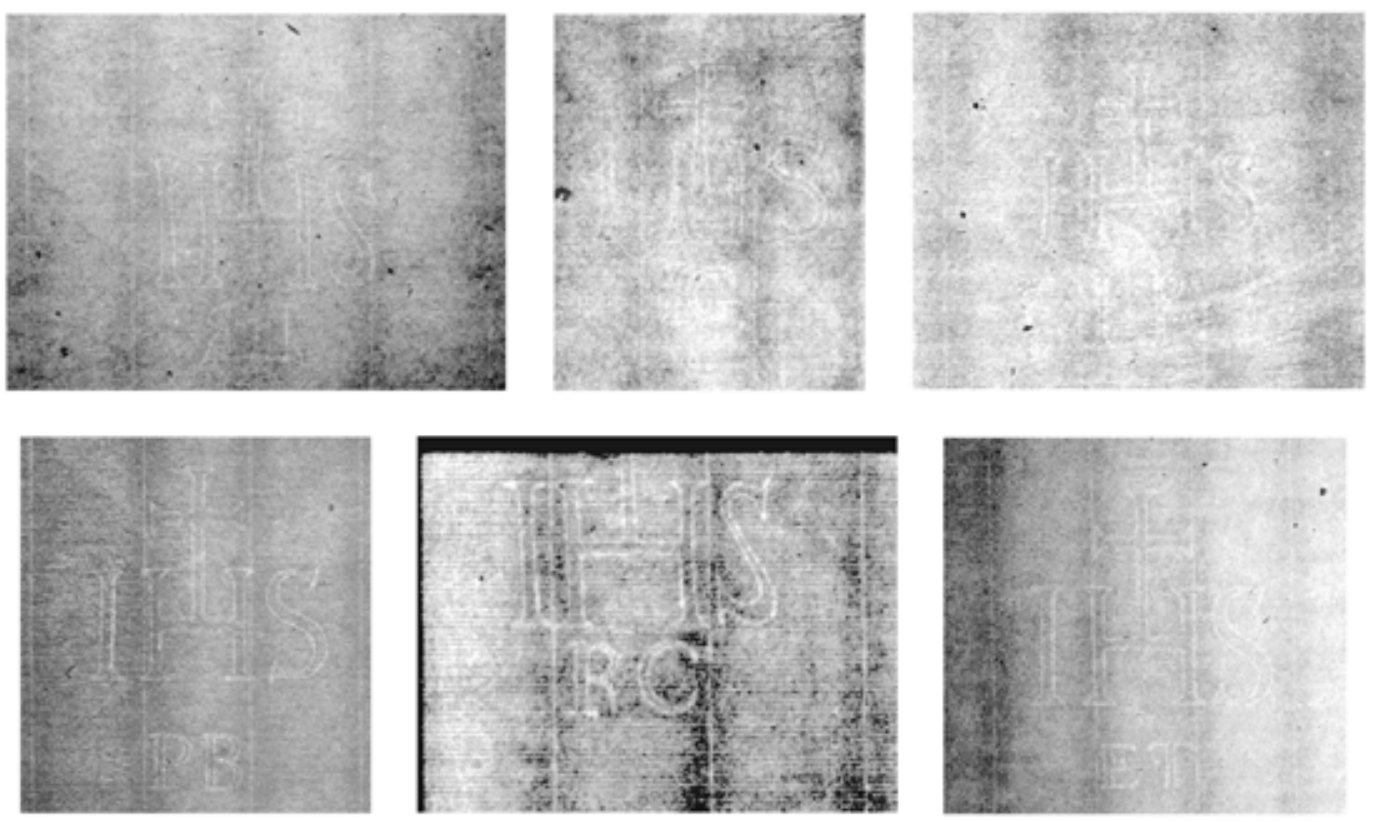

Fig. 42 Samples of each subvariant of IHS variant B: Top row (left to right): B'a, B.a.a, B.b.a. Bottom row (left to right): B.c, B.d, B.e.a (images courtesy of Sound and Vision Publishers BV)

60 This creates the decision table in Table 3.

61 As each column in Table 3 has only one nonzero entry, asking any five questions in any order will produce a decision tree classifying the subvariants of variant B, as in the left diagram in figure 43. Each of these five questions has only one choice among the five subvariants for which the answer is "yes." We will label such questions, for which only one subvariant generates the answer "yes" and all others have the opposite answer "no," as a "singular-yes" question. Other "singular-yes" 


\begin{tabular}{|c|c|c|cc|c|c|}
\hline & Q04 & Q05 & Q06 & Q07 & Q08 & Q09 \\
\hline B'.a & 1 & 0 & 0 & 0 & 0 & 0 \\
\hline B.a & 0 & 1 & 0 & 0 & 0 & 0 \\
\hline B.b & 0 & 0 & 1 & 0 & 0 & 0 \\
\hline B.c & 0 & 0 & 0 & 1 & 0 & 0 \\
\hline B.d & 0 & 0 & 0 & 0 & 1 & 0 \\
\hline B.e & 0 & 0 & 0 & 0 & 0 & 1 \\
\hline
\end{tabular}

Table 3: Decision Table for Subvariants of IHS Variant B

questions are possible, such as questions about certain individual letters or about a chain line down the center of the countermark, which separates out B.a. ${ }^{41}$

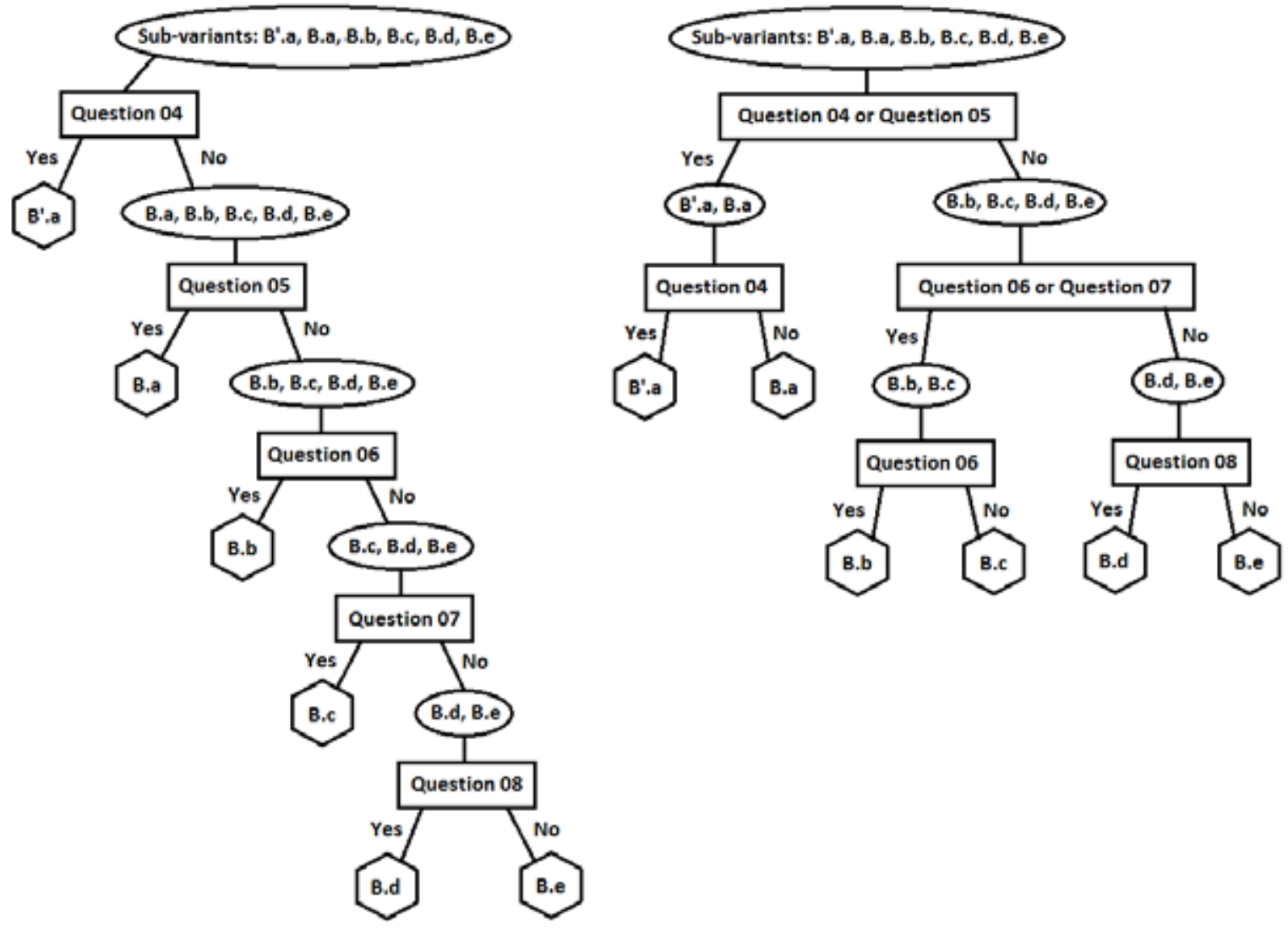

Fig. 43 Two possible decision-tree branches for identifying subvariants of HIS variant B (illustrations by author)

62 Samples of the subvariants of IHS variant A are illustrated in figures 44-45. We will start with as many "singular-yes" questions as we can readily derive from close looking. It is worth recalling that all questions need to be answerable with high confidence for all subvariants. The feature labels in figure 46, which exemplifies the chosen orientation, are used in the following questions. 


\begin{tabular}{|c|c|c|}
\hline \multicolumn{3}{|l|}{ Questions 10-17: Singular-Yes Questions } \\
\hline Q10: Is there a chrin line cutting vertically throught the "S"? & YES, A. ä & NO, all othere \\
\hline Q11: Does crosepost bend to right? & YES, A.c & NO, all others \\
\hline Q12: Is the "S" hackwards: & YFS, A.d & NO, all others \\
\hline $\begin{array}{l}\text { Q13: Does the left end of the crossbar touch the left chain } \\
\text { line? }\end{array}$ & YES, A.f & NO, all others \\
\hline Q14: Dues the right ed $\mathrm{d}_{\mathrm{g}}$ of the "H" bend to left?" & YES, A. 5 & $\mathrm{NO}$, all othere \\
\hline $\begin{array}{l}\text { Q15: Are both the left and right edges of }{ }^{2} \mathrm{H}^{\prime} \text { coincident with } \\
\text { chain lines? }\end{array}$ & YES, A.h & NO, all others \\
\hline Q16: Is there a chain linc entring vertirally through the I? & YFS, A.i & NO, all others \\
\hline $\begin{array}{l}\text { Q17: Is the wicth of the chainspace, which the "IH" is within, } \\
\text { greater than the height of the cross from its top to the bottom } \\
\text { of the cross bar in H? [Hint: Implement with marks mace on } \\
\text { the straight edge of a piece of paper placed adjacent to the wa- } \\
\text { termark image.] }\end{array}$ & YES, A.j & NO, all others \\
\hline
\end{tabular}
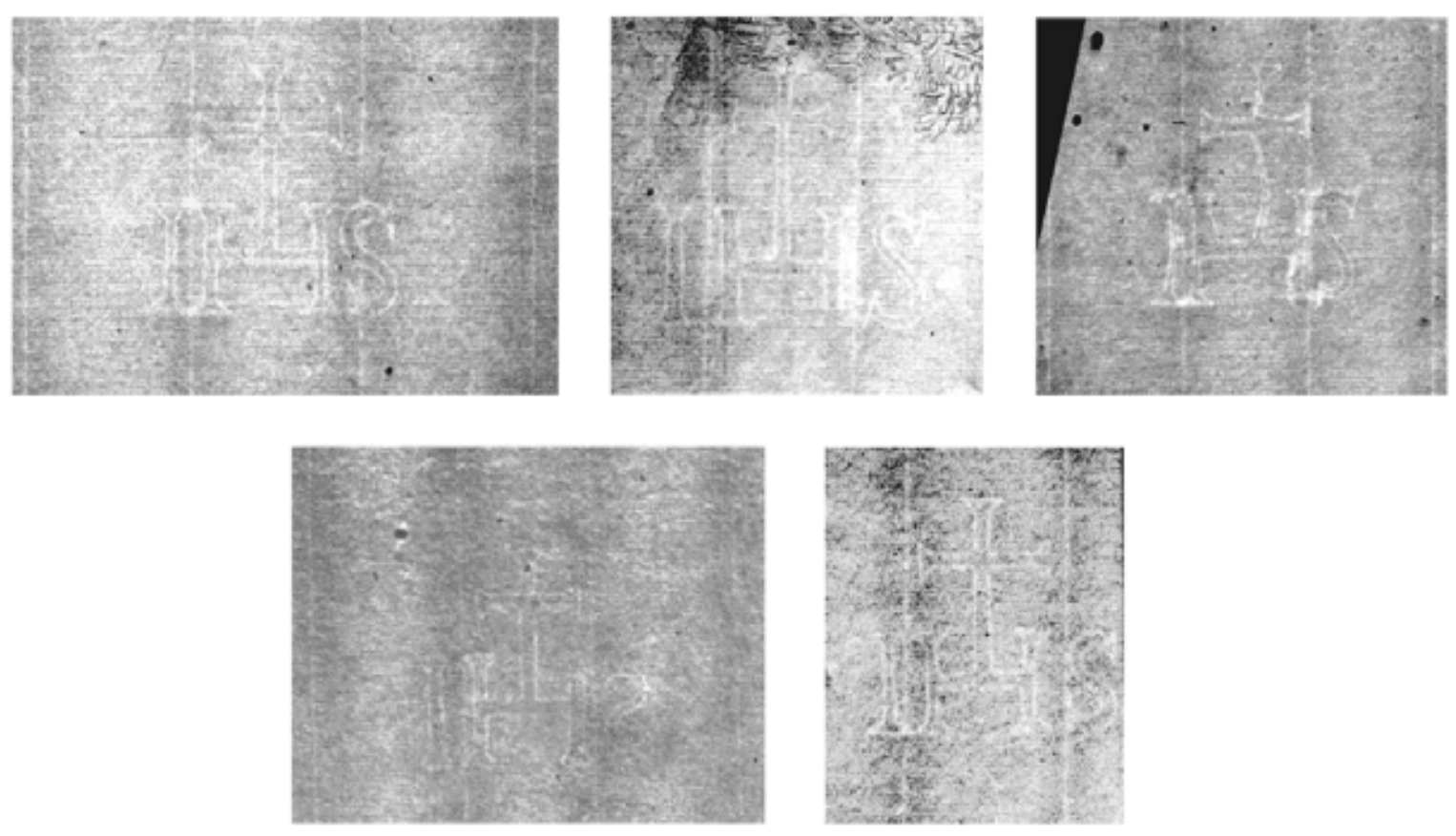

Fig. 44 Some subvariants of IHS variant A: Top row (left to right): A.a, A.b, A.c. Bottom row (left to right): A.d.a, A.e (images courtesy of Sound and Vision Publishers BV) 

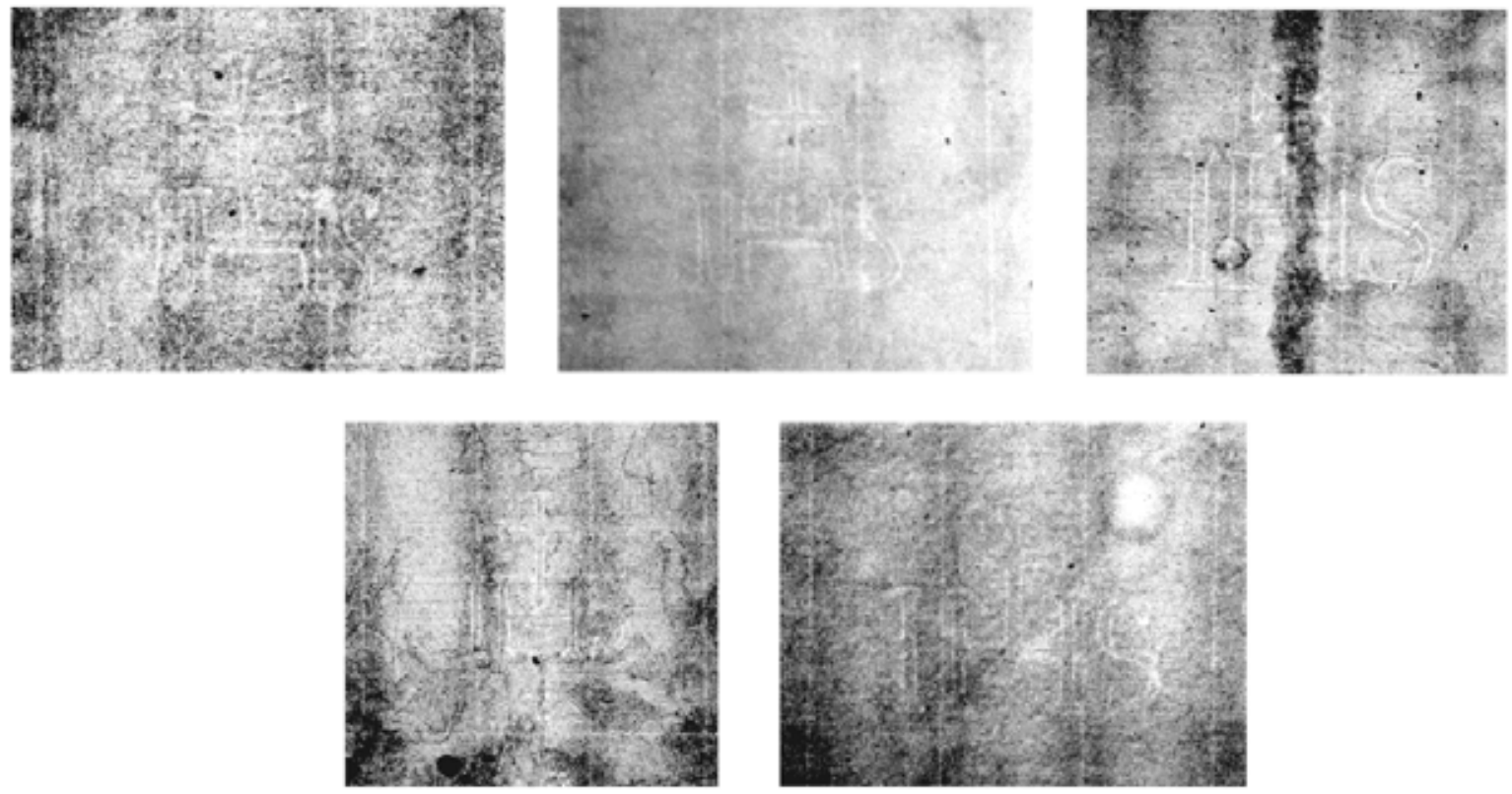

Fig. 45 Some more subvariants of IHS variant A: Top row (left to right): A.f.a, A.g, A.h. Bottom row (left to right): A.i, A.j (images courtesy of Sound and Vision Publishers BV)

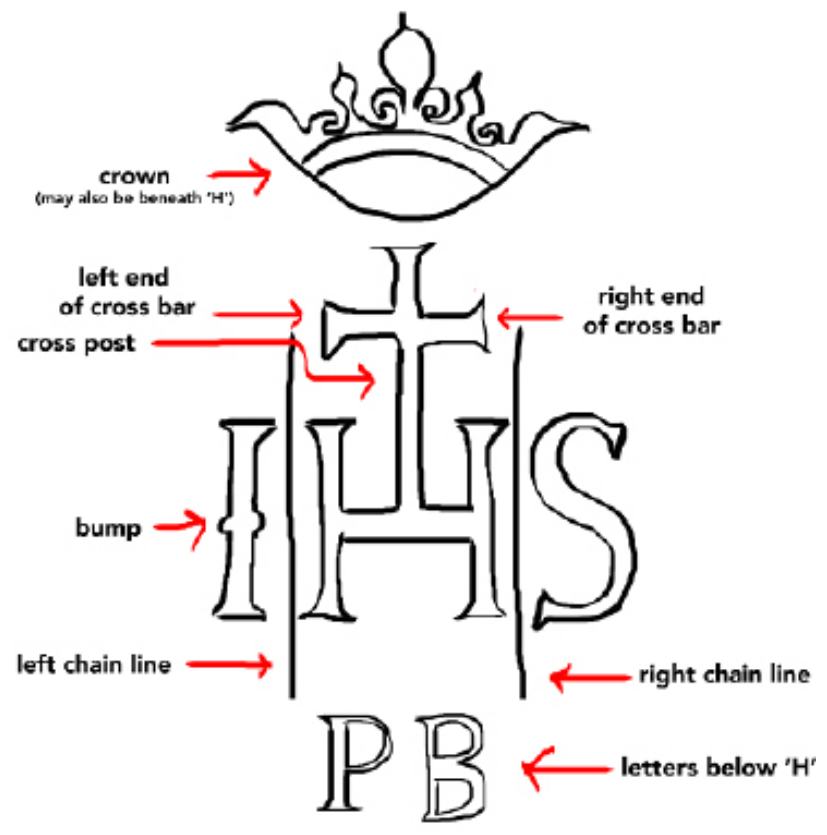

Fig. 46 Feature labels for IHS (illustration by Margaret N. Canfield (Cornell))

63 With eight singular-yes questions and nine subvariants to identify, we now form the decision table in Table 4 in order to see what remains to be done if we are to differentiate the various subvariants from one another. Because A.b and A.e have the same (eight zeros) code in Table 4, we just need to add a question that has different answers for A.b and A.e in order to produce a decision table with each subvariant having a different binary code. 


\begin{tabular}{|c|c|c|c|c|c|c|c|c|}
\hline & $\mathrm{Q} 10$ & $\mathrm{Q} 11$ & $\mathrm{Q} 12$ & $\mathrm{Q} 13$ & $\mathrm{Q} 14$ & $\mathrm{Q} 15$ & $\mathrm{Q} 16$ & $\mathrm{Q} 17$ \\
\hline A.a & 1 & 0 & 0 & 0 & 0 & 0 & 0 & 0 \\
\hline A.b & 0 & 0 & 0 & 0 & 0 & 0 & 0 & 0 \\
\hline A.c & 0 & 1 & 0 & 0 & 0 & 0 & 0 & 0 \\
\hline A.d & 0 & 0 & 1 & 0 & 0 & 0 & 0 & 0 \\
\hline A.e & 0 & 0 & 0 & 0 & 0 & 0 & 0 & 0 \\
\hline A.f & 0 & 0 & 0 & 1 & 0 & 0 & 0 & 0 \\
\hline A.g & 0 & 0 & 0 & 0 & 1 & 0 & 0 & 0 \\
\hline A.h & 0 & 0 & 0 & 0 & 0 & 1 & 0 & 0 \\
\hline A.i & 0 & 0 & 0 & 0 & 0 & 0 & 1 & 0 \\
\hline A.j & 0 & 0 & 0 & 0 & 0 & 0 & 0 & 1 \\
\hline
\end{tabular}

Table 4: Docision Table after Questions 10-17 for Subvariants of IHS Variant $A$, with A.b and A.e Having the Same Code

For example, consider the following question.

\begin{tabular}{|l|l|l|}
\hline \multicolumn{2}{|l|}{ Question 18} \\
\hline $\begin{array}{l}\text { Q18: Do the "I" and the "S" both touch chain lines } \\
\text { without crossing them? }\end{array}$ & YES, A.c, A.e, A.f, A.g; & NO, all others \\
\hline
\end{tabular}

65 Adding this eighteenth question to the partial decision table in Table 4 results in the decision table in Table 5, where each subvariant has a unique binary code. The decision tree for IHS, incorporating the questions in Table 5, asked in their numerical order, appears in figure 47.

\begin{tabular}{|c|c|c|c|c|c|c|c|c|c|}
\hline & $\mathrm{Q} 10$ & $\mathrm{Q} 11$ & $\mathrm{Q} 12$ & $\mathrm{Q} 13$ & $\mathrm{Q} 14$ & $\mathrm{Q} 15$ & $\mathrm{Q} 16$ & $\mathrm{Q} 17$ & $\mathrm{Q} 18$ \\
\hline A.a & 1 & 0 & 0 & 0 & 0 & 0 & 0 & 0 & 0 \\
\hline A.b & 0 & 0 & 0 & 0 & 0 & 0 & 0 & 0 & 0 \\
\hline A.c & 0 & 1 & 0 & 0 & 0 & 0 & 0 & 0 & 1 \\
\hline A.d & 0 & 0 & 1 & 0 & 0 & 0 & 0 & 0 & 0 \\
\hline A.e & 0 & 0 & 0 & 0 & 0 & 0 & 0 & 0 & 1 \\
\hline A.f & 0 & 0 & 0 & 1 & 0 & 0 & 0 & 0 & 1 \\
\hline A.g & 0 & 0 & 0 & 0 & 1 & 0 & 0 & 0 & 1 \\
\hline A.h & 0 & 0 & 0 & 0 & 0 & 1 & 0 & 0 & 0 \\
\hline A.i & 0 & 0 & 0 & 0 & 0 & 0 & 1 & 0 & 0 \\
\hline A.j & 0 & 0 & 0 & 0 & 0 & 0 & 0 & 1 & 0 \\
\hline
\end{tabular}

Table 5: Decision Table with Unique Codes for All Subvariants of THS Variant A 


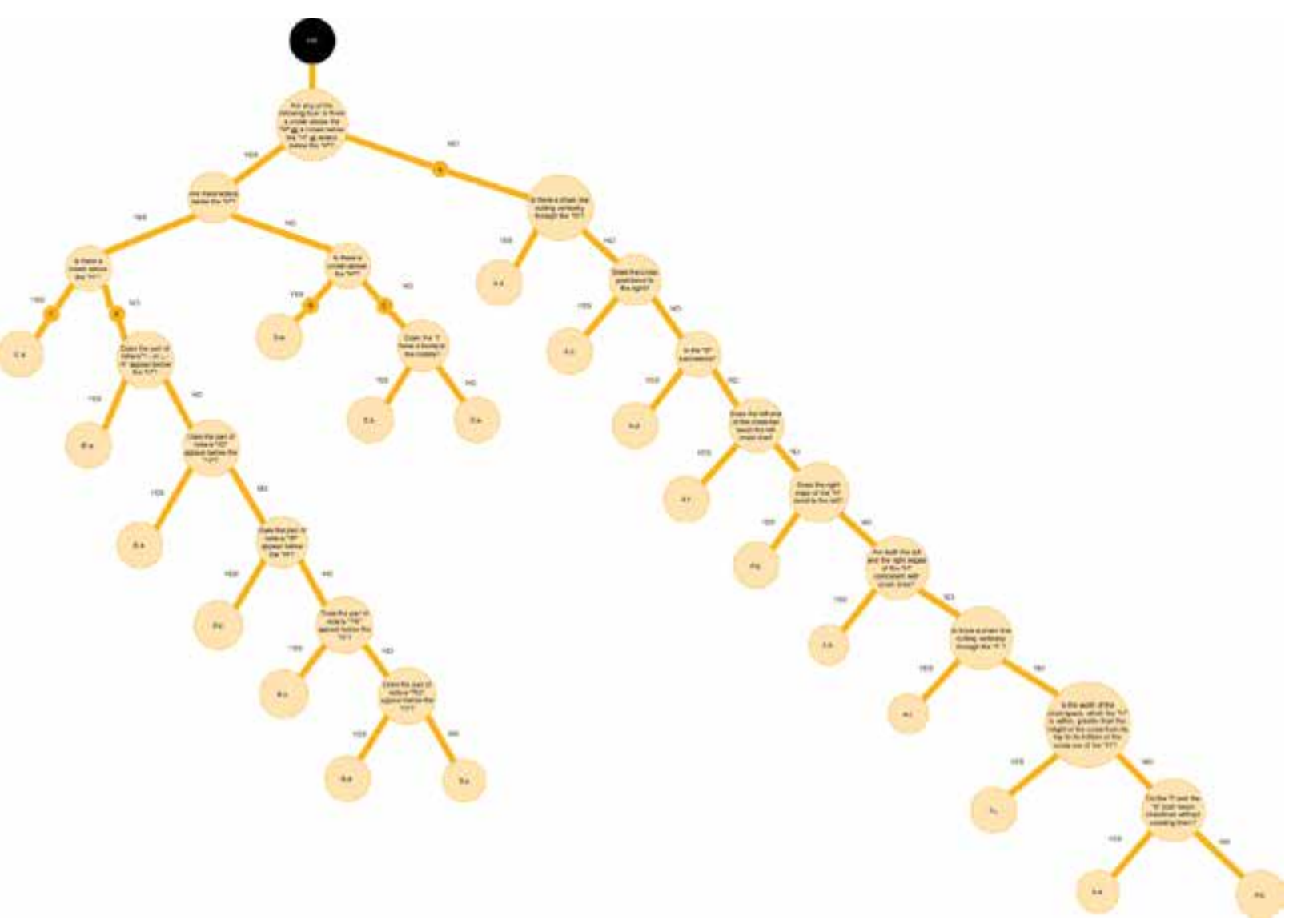

Fig. 47 Decision tree by the WIRE Project from type to subvariant for IHS in Rembrandt's etchings (illustration by Margaret N. Canfield (Cornell))

66 As a final note, two important decision-tree construction guidelines for the procedure embodied by the preceding example, of selecting distinguishing features for a layered decision tree, are:

Questions for type to variant layer must be confidently answerable, with the same answer (yes or no) for all subvariants of that variant.

Questions for variant to subvariant layer must be confidently answerable, with the same answer (yes or no) for all twins and nearly similar watermarks of that subvariant.

\section{Returning to Analysis of St. Francis Praying Beneath a Tree}

67 Answering five questions in the IHS decision tree in figure 47 identifies the countermark in the left half of figure 49.

68 The path to the subvariant designation of B.a is illustrated in figure 48. The countermark comparison in figure 49 and chainspace pattern match in figure 50 are consistent with a designation of B.a.a. 


\begin{tabular}{|c|c|}
\hline \multicolumn{2}{|l|}{ Questions and Answers Leading to IHS B.a } \\
\hline Is there a crown above the " $\mathrm{H}$," a crown below the " $\mathrm{H}$," or letters below the " $\mathrm{H}$ "? & YES \\
\hline Are there letters below the " $\mathrm{H}^{n}$ ? & YES \\
\hline Is there a crown above the " $\mathrm{H}$ "? & NO \\
\hline Does the pair of letters "IR" (or "LR") appear below the "H"? & NO \\
\hline Does the pair of letters "IG" appear below the "H"? & YES \\
\hline
\end{tabular}

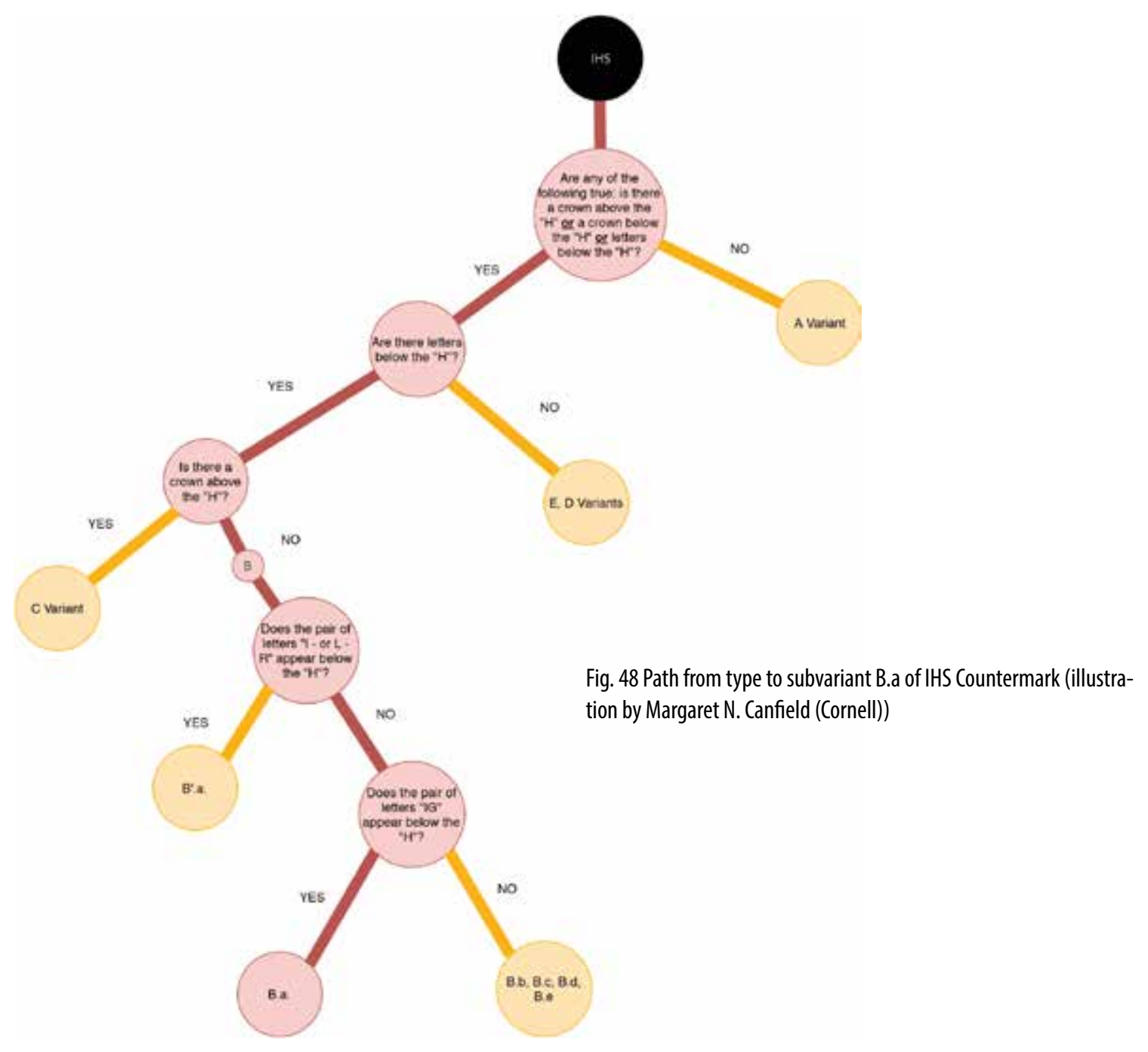

69 Not counting The Frick Collection's impression, Hinterding cites two prints and four impressions with the countermark IHS B.a.a and its twin B.a.b. ${ }^{42}$ The Frick Collection's St. Francis Praying Beneath a Tree is the second impression of the same print with this countermark. 


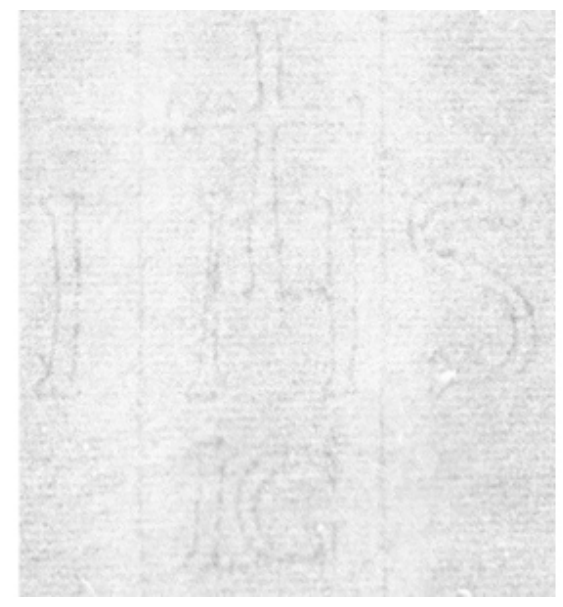

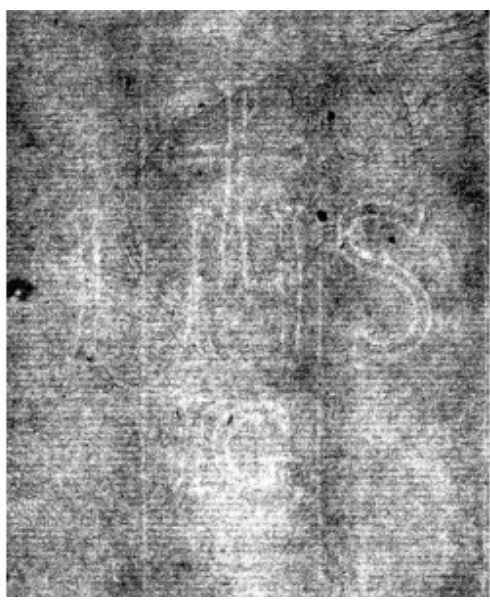

Fig. 49 Left: Countermark under investigation Right: IHS B.a.a (image courtesy of Sound and Vision Publishers BV)

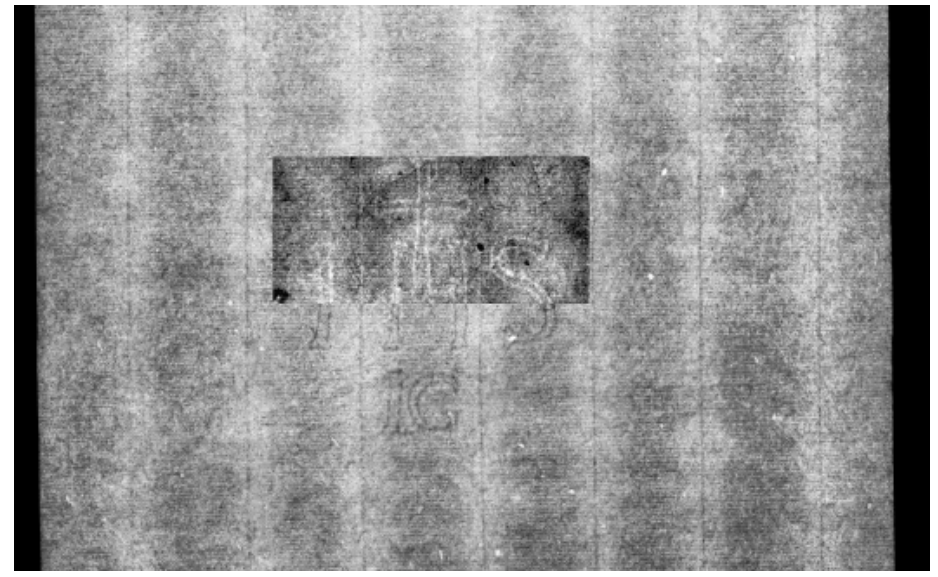

Fig. 50 Chainspace alignment of IHS B.a over watermark of interest and match (top image courtesy of Sound and Vision Publishers BV; overlay composed by Margaret N. Canfield (Cornell))

\section{Landscape with Three Gabled Cottages}
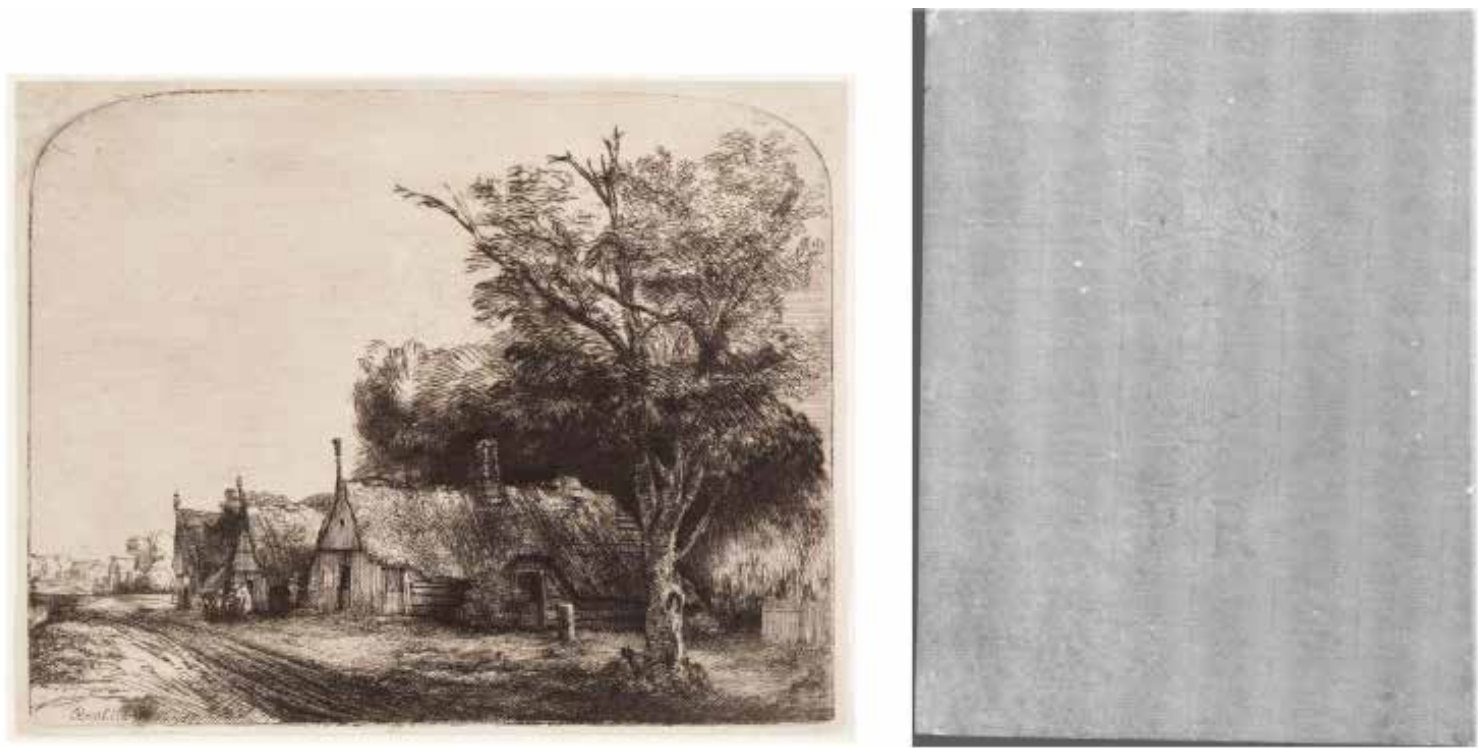

Fig. 10 Left: Rembrandt Harmenszoon van Rijn, Landscape with Three Gabled Cottages, The Frick Collection, 1916.3.30. Right: Beta-radiograph of portion around watermark (provided by Margaret Hoben Ellis (NYU) and Reba Fishman Snyder (Morgan)) 
Figure 10 reveals that The Frick Collection's Landscape with Three Gabled Cottages has a Strasbourg Lily watermark (fig. 53). Strasbourg Lily is a frequently occurring watermark in Rembrandt's etchings, with sixteen variants. ${ }^{43}$ A sketch of the Strasbourg Lily watermark, with feature labels, appears in figure 51. The full Strasbourg Lily decision tree appears in figure 52.
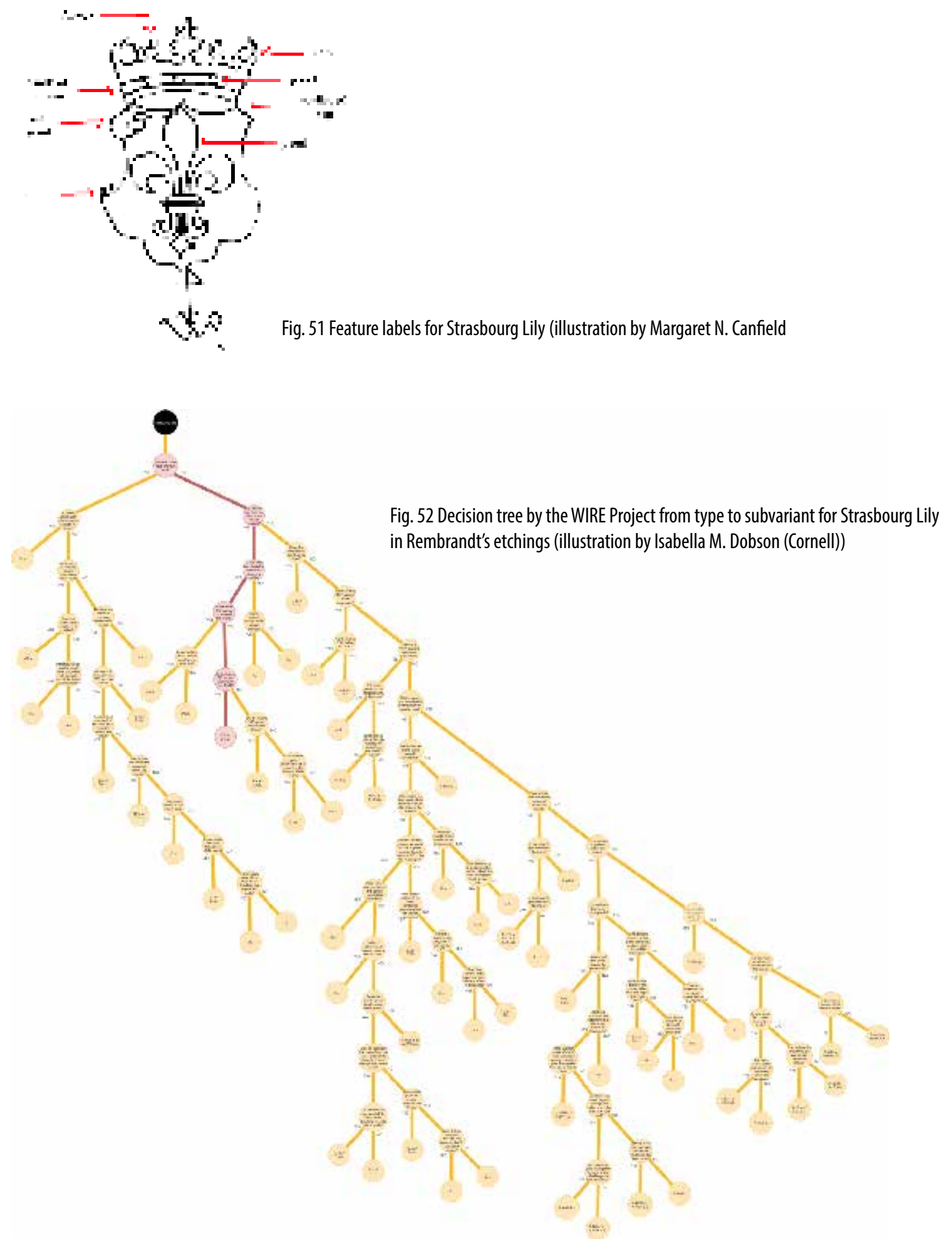
Answering five questions in the Strasbourg Lily decision tree in figure $\mathbf{5 2}$ identifies the watermark under investigation in figure 53.
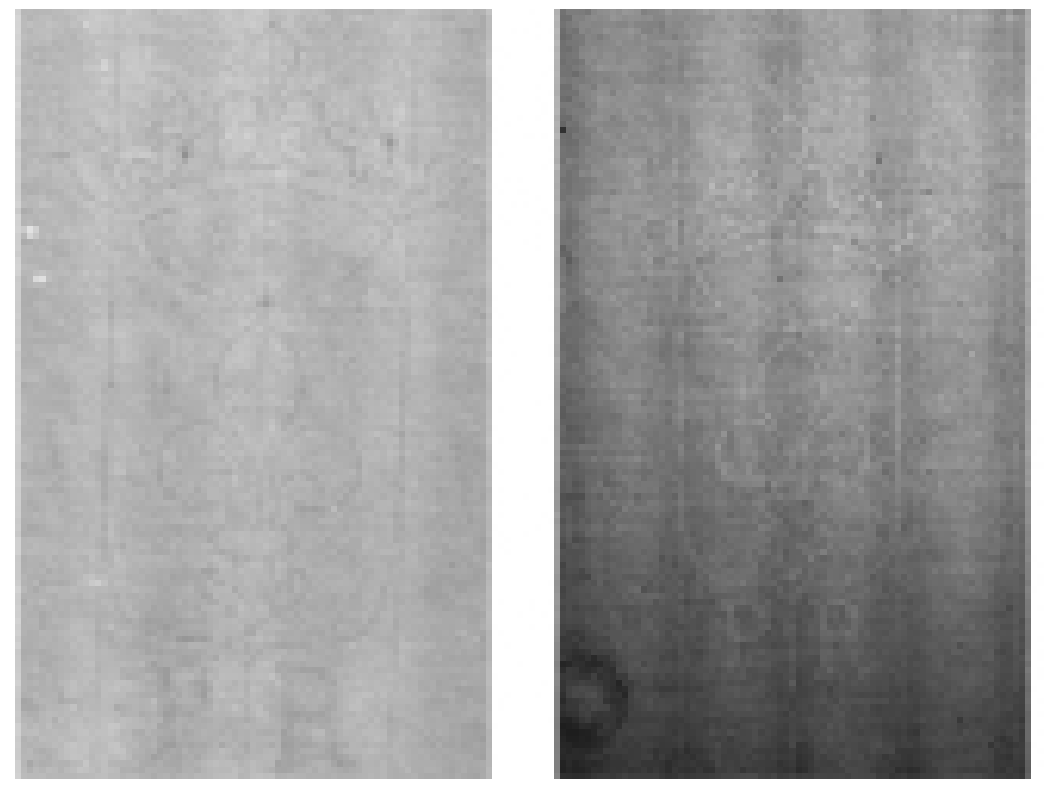

Fig. 53 Left: Watermark under investigation. Right: Strasbourg Lily E'a.a (image courtesy of Sound and Vision Publishers BV)

\begin{tabular}{|l|l|}
\hline Questions and Answers Leading to Strasbourg Lily E'.a \\
\hline Does the crown only have two bands? & NO \\
\hline Are the lines that form the sides of the shield straight? & YES \\
\hline Does a chain line divide the watermark down the middle? & YES \\
\hline Do the letters "SG" appear underneath the shield? & NO \\
\hline Do the letters "PR" appear underneath the shield? & YES \\
\hline
\end{tabular}

The decision-tree branch in figure 54 indicates a variant designation of E.a. Answering the question "Does the 'P' side of the shield overlap with the chain line?" in the affirmative identifies the label, including the subvariant indicator, as E.a.a. The watermark comparison in figure 53 and the chainspace pattern comparison in figure 55 support this designation. The apostrophe on the variant designation E' indicates that the watermark has a chain line down its center.

Hinterding cites nineteen prints with Strasbourg Lily watermark subvariant E.a.a, including one impression of Landscape with Three Gabled Cottages, and twenty prints with its twin E.a.b, including three impressions of Landscape with Three Gabled Cottages. ${ }^{44}$ Thus, The Frick Collection's Landscape with Three Gabled Cottages is the second impression of the same print with this watermark. As Strasburg Lily E.a.a is known to have a WK'a countermark, Hinterding lists 115 impressions of twenty-seven prints in the batch dated circa $1652 .{ }^{45}$ 


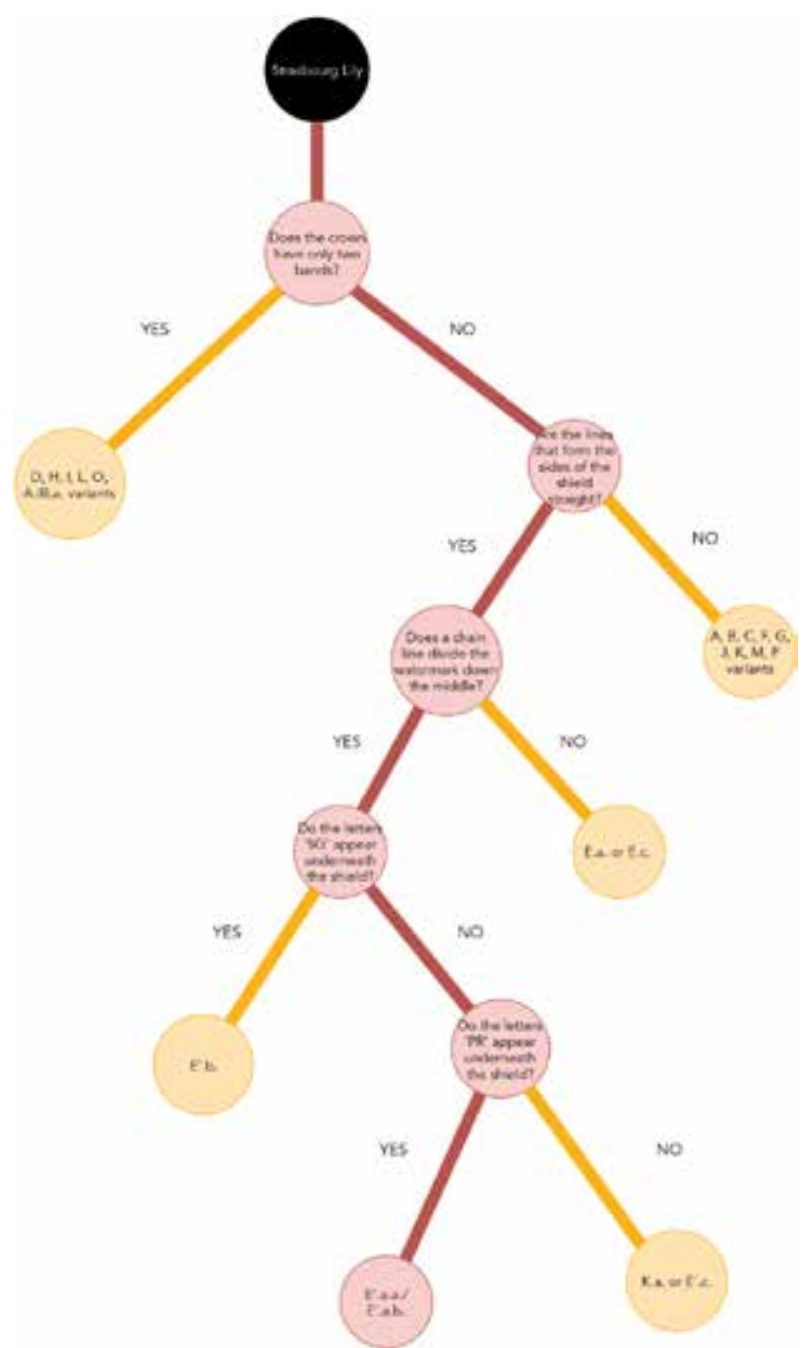

Fig. 54 Strasbourg Lily decision-tree branch to variant E'.a (illustration by Margaret N. Canfield (Cornell))

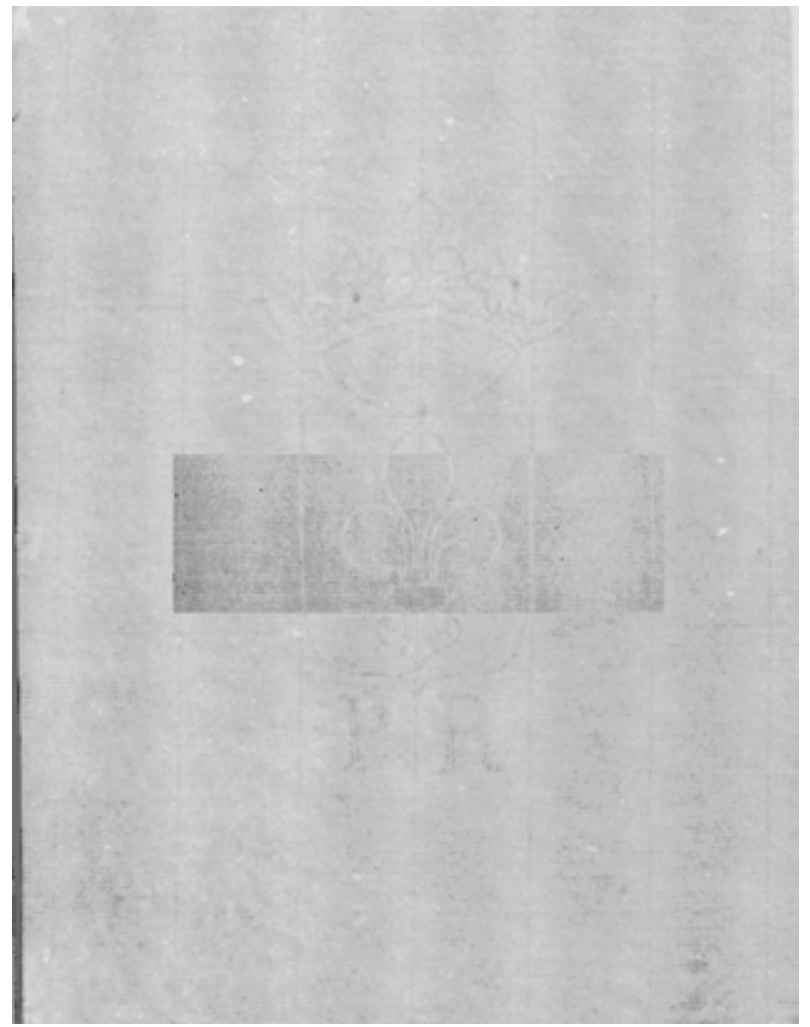

Fig. 55 Chainspace alignment of Strasbourg Lily E'.a.a over watermark of interest and match (top image courtesy of Sound and Vision Publishers BV; overlay composed by Margaret N. Canfield (Cornell))

\section{Detailing Discoveries among Seven Prints in The Frick Collection}

74. Having surveyed our decision-tree creation and exploitation process for seven prints in The Frick Collection, we can now return to our observations earlier in this article and rephrase them in greater detail.

Landscape with Haybarn and Flock of Sheep has a Foolscap with Five-pointed Collar K.a.a watermark. This leads to a date of circa 1650 using Hinterding's chronology. No other impressions of this print with this watermark or its twinmark were reported by Hinterding.

Landscape with Three Gabled Cottages has a Strasbourg Lily E.a.a watermark, which prompts a date of circa 1652 in Hinterding's chronology. ${ }^{46}$ Hinterding reports that impressions from nineteen different plates appear on paper with this watermark. 
The Goldweigher's Field and Clement de Jonghe are batchmates. Clement de Jonghe has the subvariant class RC.a mark, which is the countermark associated with watermark Paschal Lamb A variants. The Goldweigher's Field has the watermark Paschal Lamb A.b.

Jan (Johannes) Lutma the Elder is state iii and has the watermark N.a.b, as do states i and ii. State i was actually printed by Rembrandt, but the inscription on state iii suggests that possession of the plate had shifted to the sitter's family. The use of the same paper for all three states raises various possible scenarios leading to this fact.

Furthermore, we were able to identify all of the marks in the seven prints examined-watermarks in five prints as well as countermarks in the other two. The following list notes the watermark identified by WIRE and also, when possible, the date assigned by Hinterding to the watermark or countermark.

Landscape with Three Trees has the watermark Foolscap with Five-pointed Collar A.a.a, which is dated 1643 .

Jan (Johannes) Lutma the Elder has the watermark Foolscap with Five-pointed Collar N.a.b, which is dated 1656.

Landscape with Haybarn and Flock of Sheep has the watermark Foolscap with Five-pointed Collar K.a.a, which is dated 1650.

The Goldweigher's Field has the watermark Paschal Lamb A.b, which is dated 1651.

Clement de Jonghe has the countermark RC.a.a, which is dated 1651.

St. Francis Praying Beneath a Tree has the countermark IHS B.a.a, which is not dated in Hinterding's chronology.

Landscape with Three Gabled Cottages has the watermark Strasbourg Lily E.a.a, which is dated circa 1652 .

\section{WIRE Discoveries of New Watermarks}

76 During the decision-tree development the WIRE Project has unearthed a variety of "new" watermarks. The first category of discoveries includes new impressions of prints from the same plate/ state with a watermark previously associated with the print. This increases the counts of usage of paper with that particular watermark for that print. The Frick Collection's Landscape with Three Trees, Jan (Johannes) Lutma the Elder, St. Francis Praying Beneath a Tree, The Goldweighers Field, Clement de Jonghe, and Landscape with Three Gabled Cottages are all examples of this category.

77 The second category includes prints with watermarks not previously associated with that print but found in other prints, thereby adding to the known works with that particular watermark, with 
its own particular date. The Frick Collection's Landscape with Haybarn and Flock of Sheep is an example of this second category.

A third category includes any print bearing a previously unknown type, variant, or subvariant in Rembrandt's papers not documented by Hinterding. This category would indicate the existence of a previously unknown batch of paper. Though no discoveries of this third category occur in the prints studied from The Frick Collection, the WIRE Project has made such discoveries elsewhere. For example, in the collection of the Herbert F. Johnson Museum at Cornell University, the WIRE Project has discovered a new subvariant of the Basel Crosier watermark with proposed label E.b. This has been found in Rembrandt's Self-Portrait (?) with Plumed Cap and Lowered Sabre. ${ }^{47}$

\section{Going Forward}

79 The decision tree being developed by the WIRE project confirms that both the features chosen and the questions asked about them are sufficient to distinguish all of the subvariants among the watermarks in etchings by Rembrandt that Hinterding examined. The decision tree also offers another advantage with its use in establishing that a particular watermark is not included in Hinterding's published taxonomy. This is possible because Hinterding did not examine every extant Rembrandt print. Once the termination point of a decision-tree branch has been reached, assuming all questions have been answered correctly, the answers to the string of yes/no questions traversed is shared by no watermark in the full library other than the subvariant (or twin) indicated at the termination point. If the user finds that the sample image at the termination point does not match both the watermark being identified and its chainspace pattern, then the user can be assured that the watermark under consideration is new to scholars of Rembrandt's prints. ${ }^{48}$

This decision-tree process of identifying watermarks raises a variety of issues for further investigation. These include:

Automation of Watermark Identification: A decision tree for a particular variant contains a number of yes/no questions, the answers to which are verifiable by a human observer. Can image processing be used to answer questions that are simple for a human to answer but appear quite complicated for a computer to answer with similar confidence? Such automation should retain the use of an identifying yes/no visible feature-question string and Hinterding's classification taxonomy.

Data Collection: The WIRE Project team has considered using the decision tree to identify the watermark in an owner's Rembrandt in exchange for permission to post the image of the watermark in the planned online version of the decision-tree identification tool and dataset. One research/development goal to boost this effort would be the fabrication of a modestly priced, portable imaging device that captures watermarks, chain lines, and laid lines without radiography. ${ }^{49}$ The assembled dataset should include as many examples as possible of each specific watermark. ${ }^{50}$

A Dynamic Decision Tree: Incorporating new watermarks discovered in collections beyond those catalogued by Hinterding raises the issue of standardizing a procedure for augmentation of the decision tree. ${ }^{51}$ This need for such decision-tree growth faithful to 
the architecture of Hinterding's taxonomy while retaining his labels is an unusual twist on basic decision-tree theory.

Extension of Batchmate Identification to Laid Papers without Watermarks: Since approximately two-thirds of Rembrandt's impressions do not have watermarks or fragments, it would be hugely advantageous to develop some technique of connecting laid papers that are batchmates but have no watermarks to papers with a specific watermark. One path could be to assemble an image revealing chain lines, watermark, and countermark (if present) of a full broadsheet, perhaps from constituent folio images, and attempt to match paper without watermarks to portions of the full broadsheet lacking a watermark. The main impediment here is that museums are not inclined to image paper supports without watermarks.

New Tools Aiding Visual Moldmate/Batchmate Verification: One restriction in human-selected features is a justifiable lack of confidence in visually assessing the relative distances within one figure between two pairs of endpoints. Such doubt is a measure of the human susceptibility to optical illusions. This could be overcome by the ability to mouse click on the endpoints and have the computer evaluate the ratio of the lengths (e.g., in pixels) of the two line segments. Using a ratio bypasses the need for precise physical measurement capability, which would require some care in imaging and/or digitization.

Extension to Other Maker's Marks: Decision trees should be useful in a variety of cultural heritage tasks, such as the identification of maker's marks. One potential application that shows promise is the further identification of panel maker marks and guild brands. ${ }^{52}$

Expanding the Rembrandt Watermark Universe: Assuming Rembrandt would sometimes use the same paper for prints and drawings, collecting a dataset of watermarks in Rembrandt's drawings seems appropriate and could possibly provide valuable insights into the artist's working method. The expansion should also consider prints and drawings by pupils and collaborators, who may have shared materials with Rembrandt and each other. Watermarks have been found in two drawings by Rembrandt's pupil, Ferdinand Bol, that appear in prints by Rembrandt. ${ }^{53}$ It should be noted that expansion to include other Dutch artists active in Rembrandt's time in Amsterdam is also appealing. One concern is that such a proliferation may include a vastly increased variety of highly similar, but distinct, watermarks, making unaided visual classification impractical. Simple-to-use, computer-based tools designed for the specific tasks of watermark feature evaluation and comparison will help address this concern.

\section{Appendix: Provenance, ${ }^{54}$ States, ${ }^{55}$ and Links to Online Catalogue Entries}

The links provided to the online catalogue of The Frick Collection include the Bartsch number, the date assigned by The Frick Collection, the technique and medium, and the print's measurements.

Landscape with Three Trees, The Frick Collection, 1915.3.28

Alfred Strolin. Knoedler. Frick, 1915 
only state

https://collections.frick.org/objects/646/landscape-with-three-trees

The Goldweigher's Field, The Frick Collection, 1915.3.31

Colnaghi. Knoedler. Frick, 1915

only state

https://collections.frick.org/objects/647/the-goldweighers-field

Landscape with Haybarn and Flock of Sheep, The Frick Collection, 1916.3.29

Colnaghi. Knoedler. Frick, 1916

state ii of ii $(2 / 2)$

https://collections.frick.org/objects/640/landscape-with-haybarn-and-flock-of-sheep

Landscape with Three Gabled Cottages, The Frick Collection, 1916.3.30

Knoedler. Frick, 1916

state iii of iii $(3 / 3)$

https://collections.frick.org/objects/641/landscape-with-three-gabled-cottages

St. Francis Praying Beneath a Tree, The Frick Collection, 1916.3.35

H. Danby Seymour and Alfred Seymour (Lugt 176). Knoedler. Frick, 1916

state ii of ii $(2 / 2)$

https://collections.frick.org/objects/642/st-francis-praying-beneath-a-tree

Clement de Jonghe, The Frick Collection, 1916.3.36

Colnaghi. Knoedler. Frick, 1916

state $\mathrm{i}$ of $\mathrm{x}(1 / 10)$

https://collections.frick.org/objects/643/clement-de-jonghe

Jan (Johannes) Lutma the Elder, The Frick Collection, 1916.3.37

Pierre Mariette (Lugt 1788-90, dated 1670). Knoedler. Frick 1916.

state iii of $v(3 / 5)$

https://collections.frick.org/objects/644/jan-johannes-lutma-the-elder-ca-15841669

\section{Acknowledgements}

I wish to express my gratitude to Robert van Langh (Head of the Department of Conservation and Restoration, Rijksmuseum, and Chair of the Netherlands Institute for Conservation, Art and Science [NICAS]), as well as the Rijksmuseum, for my appointment as a Scientific Researcher of the Rijksmuseum since 2013. This appointment facilitated my interaction, which began in 2013, with Erik Hinterding (Curator of Prints, Rijksmuseum).

The WIRE Project emerged from examination of an attempt to use the chain line pattern as an identifier of the laid-paper supports of Rembrandt's prints, a task I began in 2012 with Margaret Holben Ellis (Eugene Thaw Professor of Paper Conservation, New York University). The results of this early work were initially reported at the conference New Directions in the Study of Rembrandt and His Circle held at the Bader International Study Centre, Herstmonceux Castle, East Sussex, 
UK, July 18-21, 2013, and subsequently published in revised form. ${ }^{56}$ At this conference, I met Nadine M. Orenstein (Drue Heinz Curator in Charge of Prints and Drawings at the Metropolitan Museum of Art), who offered to assist by providing images of watermarks in Rembrandt's prints in the Met's collection. These watermark images were added to the beta-radiographs of Rembrandt prints in the collection of The Morgan Library \& Museum provided by Reba Fishman Snyder (Paper Conservator, The Morgan Library \& Museum) to create our starter set for the development of computer-based algorithms for chain line pattern marking and matching. In 2014, the dataset was greatly enlarged by the access that was granted by the Dutch University of Art History (Florence, Italy) to their set of hundreds of radiographs of Rembrandt's prints containing watermarks, a set collected by Erik Hinterding. ${ }^{57}$ In 2015, the need to identify the watermarks in the accumulated dataset in order to check the accuracy of moldmate matching (by earlier chain line pattern analysis) resulted in the creation of the WIRE project, which I codirected from the start with Andrew C. Weislogel (Seymour R. Askin, Jr. '47 Curator of Earlier European and American Art, Herbert F. Johnson Museum of Art, Cornell University). The WIRE Project has been fortunate to have Erik Hinterding, Margaret Holben Ellis, and Nadine M. Orenstein as advisors since its founding. In 2019, Sound \& Vision Publishers BV gave the WIRE Project at Cornell permission to use their images from Hinterding's book in research and publication. These images will also be appearing in the online version of the WIRE decision tree.

The WIRE Project was conceived as a student-powered project from its inception. I am indebted to the Cornell University students who have participated (so far) in the WIRE Project: Margaret Canfield, Isabella Dobson, Katrina Ferreira, Virginia Girard, Sara Gorske, Riley Henderson, Amanda House, Orrin Kigner, Dong Ki Kim, So Jeong Lim, Hao Lu, Anjum Malik, Elizabeth Martinson, Katarina Martucci, Alison McCann, Kira Nicolai, Margaret Orbon, Oscar Rieveling, Phoebe Ross, Jason Setter, Samantha Siegler, Nina Simpkins, Louisa Smieska, Daniel Terry, and Xuelei Xi. Teaching and guiding these students would not have been possible without my colleagues Andy Weislogel and Brittany Rubin, who are members of the curatorial staff at the Johnson Museum at Cornell.

Louisa Wood Ruby (Head of Research, Frick Art Reference Library) and Ellen Prokop (Associate Head of Research, Frick Art Reference Library) at The Frick Collection provided access to images of The Frick Collection's Rembrandt prints and invited me to speak on the WIRE Project in December 2018 in The Frick Collection's Digital Art History Lab Lecture series. ${ }^{58}$ (Subsequently, in the first week of 2019, I was offered-and accepted-an appointment as Senior Research Advisor to the Frick Art Reference Library, New York, NY.) Chris Stolwijk (Director, RKD Netherlands Institute for Art History) selected me as the 2018 RKD Visiting Fellow in Computational Art History, which resulted in my teaching a short course at the RKD, in October 2018, on identifying watermarks in Rembrandt's etchings. Those lectures, both at The Frick Collection and at the RKD, are the basis for this paper.

I thank the editorial staff of the Journal of Historians of Netherlandish Art, in particular Alison Kettering, Bret Rothstein, Jessica Skwire Routhier, and Heidi Eyestone, for their efforts in conquering the challenges of this article with its technical core and reliance on a large collection of figures and lists. 
The WIRE Project at Cornell has been supported by a National Endowment for the Humanities Digital Humanities Advancement Grant (HAA-256123-17, "Building a Decision Tree for Watermark Identification in Rembrandt's Etchings-The WIRE Project," October 2017-March 2020) and a National Science Foundation Early-concept Grants for Exploratory Research (EAGER) Grant (CCF-1822007, "Automated Watermark and Moldmate Identification," March 2018-February 2020).

C. Richard Johnson, Jr. is the Geoffrey S. M. Hedrick Senior Professor of Engineering at Cornell University in Ithaca, NY. He received the first PhD minor in Art History granted by Stanford University in 1977, along with a PhD in Electrical Engineering. Since 2007, his research has used digital signal processing to address issues in computational art history, primarily through the matching of manufactured patterns in art supports. Professor Johnson's contributions to canvas weave-mapping using Fourier analysis for rollmate identification, photographic paper classification via texture analysis, laid paper chain line pattern analysis for moldmate verification, and watermark identification using decision-tree construction for batchmate designation have appeared in the Burlington Magazine, the Metropolitan Museum Journal, Studies in Conservation, the Journal of the American Institute for Conservation, Art Matters, the Journal of Historians of Netherlandish Art, the International Journal for Digital Art History, the Journal of Interactive Technology and Pedagogy, Visual Resources, Signal Processing, and the IEEE Signal Processing Magazine. He is the lead editor of and a contributing author to Counting Vermeer: Using Weave Maps to Study Vermeer's Canvases, RKD Studies, 2017 (http://countingvermeer.rkdmonographs.nl).

\section{crj2@cornell.edu}

\section{List of Illustrations}

Fig. 1 Twin molds with dashed lines indicating the cutting up of full broadsheets into separate sheets of paper, all of which are batchmates (illustration by author)

Fig. 2 Transmitted-light photograph of a blank sheet of laid paper from a 1536 French book. Left: Right half of a full-mold sheet containing Foolscap with Five-pointed Collar watermark. Right: Enlargement of region around watermark with chain lines and laid lines (sheet from study collection of Conservation Center in the Institute of Fine Arts provided by Margaret Hoben Ellis (New York University); photographs provided by S. Schlick and P. Messier (Yale))

Fig. 3 Rembrandt Harmenszoon van Rijn, The Flight into Egypt, after Hercules Seghers, Herbert F. Johnson Museum, Cornell University, Ithaca, NY, etching, drypoint and engraving on paper, 21.6 x $28.6 \mathrm{~cm}$ (sheet), B56vi(?), 84.010, c. 1652

Fig. 3-1 Rembrandt Harmenszoon van Rijn, The Flight into Egypt, after Hercules Seghers, Transmitted-light image showing watermark

Fig. 3-2 Rembrandt Harmenszoon van Rijn, The Flight into Egypt, after Hercules Seghers, Excerpt 
from beta-radiograph

Fig. 4 Left: Rembrandt Harmenszoon van Rijn, Landscape with Three Trees, The Frick Collection, 1915.3.28. Right: Beta-radiograph of portion around watermark (provided by Margaret Hoben Ellis $\{\mathrm{NYU}\}$ and Reba Fishman Snyder $\{$ Morgan $\}$ )

Fig. 5 Left: Rembrandt Harmenszoon van Rijn, Jan (Johannes) Lutma the Elder, The Frick Collection, 1916.3.37; Right: Beta-radiograph of portion around watermark (Provided by Margaret Hoben Ellis (NYU) and Reba Fishman Snyder (Morgan))

Fig. 6 Left: Rembrandt Harmenszoon van Rijn, Landscape with Haybarn and Flock of Sheep, The Frick Collection, 1916.3.29. Right: Beta-radiograph of portion around watermark (provided by Margaret Hoben Ellis (NYU) and Reba Fishman Snyder (Morgan))

Fig. 7 Left: Rembrandt Harmenszoon van Rijn, The Goldweigher's Field, The Frick Collection, 1915.3.31. Right: Beta-radiograph of portion around watermark (provided by Margaret Hoben Ellis (NYU) and Reba Fishman Snyder (Morgan))

Fig. 8 Left: Rembrandt Harmenszoon van Rijn, Clement de Jonghe, The Frick Collection, 1916.3.36. Right: Beta-radiograph of portion around watermark (provided by Margaret Hoben Ellis (NYU) and Reba Fishman Snyder (Morgan))

Fig. 9 Left: Rembrandt Harmenszoon van Rijn, St. Francis Praying Beneath a Tree, The Frick Collection, 1916.3.35. Right: Beta-radiograph of portion around watermark (provided by Margaret Hoben Ellis (NYU) and Reba Fishman Snyder (Morgan))

Fig. 10 Left: Rembrandt Harmenszoon van Rijn, Landscape with Three Gabled Cottages, The Frick Collection, 1916.3.30. Right: Beta-radiograph of portion around watermark (provided by Margaret Hoben Ellis (NYU) and Reba Fishman Snyder (Morgan))

Fig. 11 Four variants of Foolscap with Five-pointed Collar. Left to right: A.a.a., H.b.a., K.a.a., N.a.b (images courtesy of Sound and Vision Publishers BV)

Fig. 12 Four subvariants of Foolscap with Five-pointed Collar, variant K. Left to right: K.a.a., K.c.a., K.e.a., K.f.a (images courtesy of Sound and Vision Publishers BV)

Fig. 13 Two twins of Foolscap with Five-pointed Collar, subvariant A.a. Left to right: A.a.a., A.a.b (images courtesy of Sound and Vision Publishers BV)

Fig. 14 Feature labels for Foolscap with Five-pointed Collar (illustration by Margaret N. Canfield (Cornell))

Fig. 15 Decision tree for four variants of Foolscap with Five-pointed Collar in figure 11 (illustration by author) 
Fig. 16 Decision tree by the WIRE Project from type to subvariant for Foolscap with Five-pointed Collar in Rembrandt's etchings (illustration by Margaret N. Canfield (Cornell))

Fig. 17 Flowchart for watermark identification (illustration by author)

Fig. 18 Left to right: Watermark under investigation, A.a.a., A.a.b (middle and right images courtesy of Sound and Vision Publishers BV; red markings by author)

Fig. 19 Type to subvariant path through decision tree to Foolscap with Five-pointed Collar A.a in Rembrandt's etchings (illustration by Margaret N. Canfield (Cornell))

Fig. 20 Does the collar have 4 points? Left: YES. Right: NO (images courtesy of Sound and Vision Publishers BV; red markings by Margaret N. Canfield (Cornell))

Fig. 21 Are the roundels in a pyramid configuration (one on top and two on bottom)? Left: YES. Right: NO (images courtesy of Sound and Vision Publishers BV; red markings by Margaret N. Canfield (Cornell))

Fig. 22 Are the peaks of the caps divided by stripes? Left: YES. Right: NO (images courtesy of Sound and Vision Publishers BV; red markings by Margaret N. Canfield (Cornell))

Fig. 23 Does the collar point below the face bend underneath the chin? Left: YES. Right: NO (images courtesy of Sound and Vision Publishers BV; red markings by Margaret N. Canfield (Cornell))

Fig. 24 Does the "4" point in the same direction as the face? Left: YES. Right: NO (images courtesy of Sound and Vision Publishers BV; red markings by Margaret N. Canfield (Cornell))

Fig. 25 Chainspace alignment test (watermark of interest over Foolscap with Five-pointed Collar A.a.a) and match (images courtesy of Sound and Vision Publishers BV; overlay composed by Margaret N. Canfield (Cornell))

Fig. 26 Left: Watermark under investigation. Right: Foolscap with Five-pointed Collar N.a.b (image courtesy of Sound and Vision Publishers BV)

Fig. 27 Path from type to subvariant of Foolscap with Five-pointed Collar N.a (illustration by Margaret N. Canfield (Cornell))

Fig. 28 Chainspace alignment test (Foolscap with Five-pointed Collar N.a.b over watermark of interest) and match (images courtesy of Sound and Vision Publishers BV; overlay composed by Margaret N. Canfield (Cornell))

Fig. 29 Path from type to subvariant of fragment of Foolscap with Five-pointed Collar K.a (illustration by Margaret N. Canfield (Cornell)) 
Fig. 30 Left: Watermark fragment under investigation; Right: Foolscap with Five-pointed Collar K.a.a (image courtesy of Sound and Vision Publishers BV)

Fig. 31 Chainspace alignment of Foolscap with Five-pointed collar K.a.a (top) and watermark of interest and match (top image courtesy of Sound and Vision Publishers BV; composition by author)

Fig. 32 Decision tree by the WIRE Project from type to subvariant for Paschal Lamb in Rembrandt's etchings (illustration by Margaret N. Canfield (Cornell))

Fig. 33 Feature labels for Paschal Lamb (illustration by Margaret N. Canfield (Cornell))

Fig. 34 Type to subvariant path for Paschal Lamb fragment subvariant A.b (illustration by Margaret N. Canfield (Cornell))

Fig. 35 Left: Watermark under investigation. Right: Paschal Lamb A.b (image courtesy of Sound and Vision Publishers BV)

Fig. 36 Chainspace alignment of Paschal Lamb A.b over watermark of interest and match (top image courtesy of Sound and Vision Publishers BV; overlay composed by Margaret N. Canfield (Cornell))

Fig. 37 Top: Watermark under investigation Bottom: RC (Countermark) RC.a.a (image courtesy of Sound and Vision Publishers BV)

Fig. 38 Chainspace alignment of RC.a.a excerpt over watermark of interest and match (image courtesy of Sound and Vision Publishers BV; overlay composed by Margaret N. Canfield (Cornell))

Fig. 39 One sample from each IHS variant. Top row (left to right): A.a, B.a.a. Bottom row (left to right): C.a.a, D.a.a., E.b (images courtesy of Sound and Vision Publishers BV)

Fig. 40 Two possible decision-tree realizations for classifying variants of IHS (illustrations by author)

Fig. 41 Subvariants of IHS variant E: Left: E-a. Right: E-b (images courtesy of Sound and Vision Publishers BV)

Fig. 42 Samples of each subvariant of IHS variant B: Top row (left to right): B.a, B.a.a, B.b.a. Bottom row (left to right): B.c, B.d, B.e.a (images courtesy of Sound and Vision Publishers BV)

Fig. 43 Two possible decision-tree branches for identifying subvariants of HIS variant B (illustrations by author)

Fig. 44 Some subvariants of IHS variant A: Top row (left to right): A.a, A.b, A.c. Bottom row (left 
to right): A.d.a, A.e (images courtesy of Sound and Vision Publishers BV)

Fig. 45 Some more subvariants of IHS variant A: Top row (left to right): A.f.a, A.g, A.h. Bottom row (left to right): A.i, A.j (images courtesy of Sound and Vision Publishers BV)

Fig. 46 Feature labels for IHS (illustration by Margaret N. Canfield (Cornell))

Fig. 47 Decision tree by the WIRE Project from type to subvariant for IHS in Rembrandt's etchings (illustration by Margaret N. Canfield (Cornell))

Fig. 48 Path from type to subvariant B.a of IHS Countermark (illustration by Margaret N. Canfield (Cornell))

Fig. 49 Left: Countermark under investigation Right: IHS B.a.a (image courtesy of Sound and Vision Publishers BV)

Fig. 50 Chainspace alignment of IHS B.a over watermark of interest and match (top image courtesy of Sound and Vision Publishers BV; overlay composed by Margaret N. Canfield (Cornell))

Fig. 51 Feature labels for Strasbourg Lily (illustration by Margaret N. Canfield (Cornell))

Fig. 52 Decision tree by the WIRE Project from type to subvariant for Strasbourg Lily in Rembrandt's etchings (illustration by Isabella M. Dobson (Cornell))

Fig. 53 Left: Watermark under investigation. Right: Strasbourg Lily E'a.a (image courtesy of Sound and Vision Publishers BV)

Fig. 54 Strasbourg Lily decision-tree branch to variant E.a (illustration by Margaret N. Canfield (Cornell))

Fig. 55 Chainspace alignment of Strasbourg Lily E.a.a over watermark of interest and match (top image courtesy of Sound and Vision Publishers BV; overlay composed by Margaret N. Canfield (Cornell))

\section{Bibliography}

Ash, Nancy, and Shelley Fletcher. Watermarks in Rembrandt's Prints. Washington, DC: National Gallery of Art, 1998.

Baker, Cathleen Ann. From the Hand to the Machine: Nineteenth-century American Paper and Mediums: Technologies, Materials, and Conservation. Ann Arbor, MI: Legacy Press, 2010. https:// doi.org/10.5860/rbm.13.1.370

Delaney, John K., and Murray Loew. "Use of Infrared Hyperspectral Imaging (960-1680 nm) and Low Energy X-Radiography to Visualize Watermarks." Proceedings of the Conference 
on Information Sciences and Systems, Princeton, NJ, March 2018. https://doi.org/10.1109/ ciss.2018.8362321

Harris, Neil. Paper and Watermarks as Bibliographical Evidence. 2nd ed. Lyon: Institut d'histoire du livre, 2017. http://ihl.enssib.fr/en/paper-and-watermarks-as-bibliographical-evidence.

Hinterding, Erik. Rembrandt as an Etcher: The Practice of Production and Distribution. 3 vols. Ouderkerk aan den Ijssel, Netherlands: Sound \& Vision, 2006.

-. Rembrandt Etchings from the Fritz Lugt Collection. 2 vols. Loughborough, UK: THOTH, 2008.

Hinterding, Erik, and Jaco Rutger. Rembrandt: The New Hollstein Dutch and Flemish Etchings, Engravings, and Woodcuts 1450-1700. Ouderkerk aan den Ijssel, Netherlands: Sound \& Vision, 2013.

Johnson, C. Richard, Jr., William A. Sethares, Margaret Holben Ellis, and Saira Haqqi. "Hunting for Paper Moldmates Among Rembrandt's Prints." IEEE Signal Processing Magazine 32 (July 2015): 28-37. https://doi.org/10.1109/msp.2015.2404931

Johnson, C. Richard, Jr., William A. Sethares, Margaret Hoben Ellis, Saira Haqqi, Reba Snyder, Erik Hinterding, Idelette van Leeuwen, Arie Wallert, Dionysia Christoforou, Jan van der Lubbe, Nadine M. Orenstein, Angela Campbell, and George Dietz. "Chain Line Pattern Matching in Rembrandt's Prints." In Rembrandt and His Circle: Insights and Discoveries, edited by Stephanie Dickey, 319-34. Amsterdam: Amsterdam University Press, 2017.

Johnson, C. Richard, Jr. "WImBo Watermark Imaging Box Project: A Digital Art History Data Acquisition Tool." Proceedings of the Conference on Information Sciences and Systems, Princeton, NJ, March 2018. https://doi.org/10.1109/ciss.2018.8362290

Kenney, Nancy. "Paper Trail: How Watermarks Illuminate Rembrandt's Creative Process." The Art Newspaper 309 (February 2019). https://www.theartnewspaper.com/news/paper-trail-how-watermarks-reveal-history.

Kushel, Dan. "Radiographic Methods in the Recording of Structure and Watermarks in Historic Paper." In Fresh Woods and Pastures New: Seventeenth-Century Dutch Landscape Drawings from the Peck Collection, 117-23. Chapel Hill, NC: Ackland Art Museum at the University of North Carolina, Chapel Hill, 1999.

Stevenson, Alan H. "Watermarks are Twins." Studies in Bibliography 4 (1951-52): 57-91.

-. "Chain-Indentations in Paper as Evidence." Studies in Bibliography 6 (1953-54): 181-195.

Vignau-Wilberg, Thea. Rembrandt auf Papier: Werk und Wirkung. Munich: Hirmer, 2001.

Wadum, Jørgen. “The Antwerp Brand on Paintings on Panel.” In Looking Through Paintings: The 
Study of Painting Techniques and Materials in Support of Art Historical Research, edited by Erma Hermens, 179-198. London: Archetype Publications, 1998.

Weislogel, Andrew C., and C. Richard Johnson, Jr. "Decision Trees and Fruitful Collaborations: The Watermark Identification in Rembrandt's Etchings (WIRE) Project at Cornell.” In Lines of Inquiry: Learning from Rembrandt's Etchings, 32-5. Ithaca, NY: Herbert F. Johnson Museum of Art, Cornell University, 2017. http://museum.cornell.edu/sites/default/files/DecisionTrees-WeislogelJohnson2017-LinesofInquiry.pdf

Xi, Xuelei, David Conathan, Amanda House, William A. Sethares, and C. Richard Johnson, Jr. "Automated Chain Line Marking and Pattern Matching in Radiographs of Rembrandt's Prints." Paper presented at the 50th Asilomar Conference on Systems, Signals, and Computers, Pacific Grove, CA, November 2016. https://doi.org/10.1109/acssc.2016.7869010

${ }^{1}$ From chapter 5 of Neil Harris, Paper and Watermarks as Bibliographical Evidence, 2nd ed. (Lyon: Institut d'histoire du livre, 2017), HTTP://IHL.ENSSIB.FR/EN/PAPER-AND-WATERMARKS-AS-BIBLIOGRAPHICAL-EVIDENCE

${ }^{2}$ Louisa Wood Ruby, Director of Research, Frick Art Reference Library, to the author, July 24, 2019.

${ }^{3}$ Plus a deckel, which is a removable wooden rim used by both molds in the twin pair that fits on top of each mold, contains the pulp, and sets the size of the sheet.

${ }^{4}$ A video documenting an attempt to recreate the pre-1800 papermaking process is a solid introduction: Tim Barrett, "Chancery Papermaking at the University of Iowa's Center for the Book," filmed 2013 at the University of Iowa, video, 11:24, HTTP:/NOW.UIOWA.EDU/2013/05/ CENTER-BOOK-RELEASES-SHORT-FILM-ABOUT-PAPERMAKING. A compact verbal description of the laid papermaking process appears in Cathleen Ann Baker, From the Hand to the Machine: Nineteenth-Century American Paper and Mediums: Technologies, Materials, and Conservation (Ann Arbor, MI: Legacy Press, 2010), 34: "Once the fibers were beaten to a particular degree and any non-fibrous additives, such as an internal sizing agent, color, and/or filler, were added, the formation of the paper remained the same: pulp was deposited onto the surface of a sieve-like covering and remained there until sufficient water drained away so that the sheet or web of paper could be transferred to a damp felt and pressed to compact the paper and remove some water. The paper was then dried before other wet processes, such as the application of an external sizing agent or coating, took place. Finishing procedures usually involved combinations of repeated pressings, or plating or calendaring to make the surface(s) smoother."

${ }^{5}$ See Dan Kushel, "Radiographic Methods in the Recording of Structure and Watermarks in Historic Paper," in Fresh Woods and Pastures New: Seventeenth-Century Dutch Landscape Drawings from the Peck Collection (Chapel Hill, NC: Ackland Art Museum at the University of North Carolina, Chapel Hill, 1999), 117-23.

${ }^{6}$ This watermark is discussed briefly in Andrew C. Weislogel and C. Richard Johnson, Jr., "Decision Trees and Fruitful Collaborations: The Watermark Identification in Rembrandt's Etchings 
(WIRE) Project at Cornell," in Lines of Inquiry: Learning from Rembrandt's Etchings, 42-43 (Ithaca, NY: Herbert F. Johnson Museum of Art, Cornell University, 2017), HTTP://MUSEUM.CORNELL.EDU/SITES/DEFAULT/FILES/DECISIONTREES-WEISLOGELJOHNSON2017-LINESOFINQUIRY.PDF.

Nancy Ash and Shelley Fletcher, Watermarks in Rembrandt's Prints (Washington, DC: National Gallery of Art, 1998).

${ }^{8}$ Erik Hinterding, Rembrandt as an Etcher: The Practice of Production and Distribution, 3 vols. (Ouderkerk aan den Ijssel, Netherlands: Sound \& Vision, 2006); Ash and Fletcher, Watermarks in Rembrandt's Prints.

${ }^{9}$ C. Richard Johnson, Jr., William A. Sethares, Margaret Hoben Ellis, and Saira Haqqi, "Hunting for Paper Moldmates Among Rembrandt's Prints," IEEE Signal Processing Magazine 32 (July 2015): 28-37; Xuelei Xi, David Conathan, Amanda House, William A. Sethares, and C. Richard Johnson, Jr., "Automated Chain Line Marking and Pattern Matching in Radiographs of Rembrandt's Prints," paper presented at the 50th Asilomar Conference on Systems, Signals, and Computers, Pacific Grove, CA, November 2016, DOI: 10.1109/ACSSC.2016.7869010; and C. Richard Johnson, Jr., William A. Sethares, Margaret Hoben Ellis, Saira Haqqi, Reba Snyder, Erik Hinterding, Idelette van Leeuwen, Arie Wallert, Dionysia Christoforou, Jan van der Lubbe, Nadine M. Orenstein, Angela Campbell, and George Dietz, "Chain Line Pattern Matching in Rembrandt's Prints," in Rembrandt and His Circle: Insights and Discoveries, ed. Stephanie Dickey, 319-34 (Amsterdam: Amsterdam University Press, 2017).

${ }^{10}$ The WIRE Project at Cornell is described in Weislogel and Johnson, "Decision Trees and Fruitful Collaborations." A brief overview of the WIRE Project appeared in Nancy Kenney, "Paper Trail: How Watermarks Illuminate Rembrandt's Creative Process," The Art Newspaper, February 26, 2019, HTTPS://WWW.THEARTNEWSPAPER.COM/NEWS/PAPER-TRAIL-HOW-WATERMARKS-REVEAL-HISTORY

${ }^{11}$ In order for some verbal questions to work, a specific orientation of the viewed image, such as head:top and nose:left, will be necessary. Both "yes" and "no" example images will adhere to that orientation. This will require proper image orientation, which is typically type-dependent, by the user at the start of a watermark identification session.

${ }^{12}$ For readers who wish to go straight to the "answer," feel free to jump ahead to the section entitled "Detailing Discoveries among Seven Prints in The Frick Collection."

${ }^{13}$ Appendix 3, "Chronological list of Rembrandt's papers," in Hinterding, Rembrandt as an Etcher, 2:333-416, describes the methodology of building this chronology. The utility of this chronology in analysis of Rembrandt's prints is evident in the essays in volume 1 of Hinterding, Rembrandt as an Etcher. A more recent description of this methodology can be found in Erik Hinterding, Rembrandt Etchings from the Fritz Lugt Collection (Loughborough, UK: THOTH, 2008) 1:15-36.

${ }^{14}$ The numbers of watermarks and watermark types and of the variants and subvariants of the Foolscap with Five-pointed Collar type are drawn from Hinterding, Rembrandt as an Etcher.

${ }^{15}$ This and other abbreviations used in Hinterding, Rembrandt as an Etcher, are listed on page 15 of vol. 2 .

${ }^{16}$ The pioneering exposition on twinmarks and suggestions for their identification appears in Alan H. Stevenson, "Watermarks are Twin," Studies in Bibliography 4 (1951-52): 57-91. This influential work was followed by Alan H. Stevenson, "Chain-Indentations in Paper as Evidence," 
Studies in Bibliography 6 (1953-54): 181-95, which with it provides a groundbreaking description of the benefits of identifying manufactured patterns in handmade laid paper.

${ }^{17}$ Volume 3 of Hinterding, Rembrandt as an Etcher, contains Hinterding's catalogue of watermarks. The WIRE Project Team is currently adding the fragments classified by Hinterding to the decision-tree branches. The fragments in The Frick Collection's Rembrandt prints identified in this article use the decision-tree branches for full watermarks, and associated decision tables, as a starting point for development of a specialized branch path.

${ }^{18} \mathrm{~A}$ mismatch at this point may indicate a mistake in answering a feature assessment question, or it may indicate the discovery of a new watermark type, variant, subvariant, or twin not in Hinterding's catalogue. While such discoveries should be rare, they are possible, since Hinterding's catalogue is based on a limited number of collections (approximately three dozen). The WIRE Project has examined Rembrandt prints at a variety of collections at American university museums and has discovered new watermarks not catalogued by Hinterding, as described in Weislogel and Johnson, "Decision Trees and Fruitful Collaborations."

${ }^{19}$ While paper shrinkage post-production, due, for example, to treatments of the paper including wetting and drying, are widely recognized as causes for altering the dimensions of the paper, few published studies exist that examine the extent to which such size changes can make originally identical papers appear to no longer be from the same mold. One such study that suggests that these changes are likely to be more modest than might be expected appears in Johnson et al., "Chain Line Pattern Matching in Rembrandt's Prints."

${ }^{20}$ Attempts to identify moldmates solely from matching chain line patterns emphasize the need for prints to contain, e.g., five or more chainspaces. With chainspaces typically approximately one inch, the need for five or more chainspaces is not satisfied for many of Rembrandt's prints that are smaller than this once they have been trimmed over time to the edge of the platemark. Furthermore, radiographic images of prints are typically limited to those with watermarks. See C. Richard Johnson, Jr., William A. Sethares, Margaret Hoben Ellis, and Saira Haqqi, "Hunting for Paper Moldmates Among Rembrandt's Prints," IEEE Signal Processing Magazine 32 (July 2015), 28-37; and Xi et al., "Automated Chain Line Marking."

${ }^{21}$ These seven Rembrandt prints with watermarks or watermark fragments in The Frick Collection were not examined in the preparation of Hinterding's catalogue.

${ }^{22}$ Hinterding, Rembrandt as an Etcher, 2:116-17. The Bartsch number of Landscape with Three Trees is B212.

${ }^{23}$ Hinterding, Rembrandt as an Etcher, 2:371-72.

${ }^{24}$ Hinterding, Rembrandt as an Etcher, 2:134. The Bartsch number of Jan (Johannes) Lutma the Elder is B276.

${ }^{25}$ Listed as batch 94 in Hinterding, Rembrandt as an Etcher, 2:407.

${ }^{26}$ All state designations in this article were provided by Erik Hinterding. "There may not be a difference between [states 2 and 3]. It is just that the best impressions of state 2 are so dark that it is impossible to recognize the inscription." Hinterding to the author, September 9, 2019.

${ }^{27}$ Hinterding, Rembrandt as an Etcher, 1:146 notes as "particularly remarkable" that three watermarks appear in both states i and ii. One of them is Foolscap with Five-pointed Collar N.a, which is similarly remarkable for its appearance in all three states. This adds to the evidence "that Rembrandt must have had several small batches of paper on hand when he was printing the plates and 
used them in a single session."

${ }^{28}$ The redundancy of the latter three of the five questions about the bottom fragment was noted by Margaret N. Canfield (Cornell) during the creation of figure 29.

${ }^{29}$ The Bartsch number of Landscape with Haybarn and Flock of Sheep is B224. Hinterding, Rembrandt as an Etcher, 2:303-24, lists eleven impressions of B224 with other watermarks, including four with an "Unidentified" Foolscap watermark. Hinterding notes that The Frick Collection's print is state ii and "probably the first edition, with this watermark." Hinterding to the author, February 2, 2019.

${ }^{30}$ Hinterding, Rembrandt as an Etcher, 2:386-89.

${ }^{31}$ Hinterding, Rembrandt as an Etcher, 2:162. The Bartsch number of The Goldweigher's Field is B234.

${ }^{32}$ Hinterding, Rembrandt as an Etcher, 2:162-64.

${ }^{33}$ Hinterding, Rembrandt as an Etcher, 2:392-94.

${ }^{34}$ Hinterding, Rembrandt as an Etcher, 2:92.

${ }^{35}$ Hinterding, Rembrandt as an Etcher, 2:92.

${ }^{36}$ Hinterding, Rembrandt as an Etcher, 2:154-58.

${ }^{37}$ Subvariants B.f and D.b are missing from the decision tree being constructed because the only available image of B.f is obstructed and the only available image of D.b is a fragment.

${ }^{38}$ Hinterding, Rembrandt as an Etcher, 2:154-58.

${ }^{39}$ The features from Hinterding, Rembrandt as an Etcher, are not suited to distinguishing the variants needed for a decision tree when a feature shared by all subvariants of a particular variant is also not shared by all subvariants of another variant. Answering such a question would unintentionally split the subvariants of one variant, thereby not providing a decision tree that first divides all variants of a specific type into separate groups with each subvariant of a particular variant in a single group with its related subvariants. As an example, refer to the "platform" feature for variants D, G, and H of Arms of Amsterdam in Hinterding, Rembrandt as an Etcher, 3:29-41. Some subvariants of variant $\mathrm{D}$ have a platform and some do not, while all of the full-watermark images of variants $\mathrm{G}$ and $\mathrm{H}$ do have a platform beneath the lions. As another example, the presence of initials is not a feature suited to variant extraction of Strasbourg Lily, as variant A has subvariants with and without initials, as is apparent from Hinterding, Rembrandt as an Etcher, 3:414-16, where the subvariant images are labeled "Strasbourg lily-A-without-initials."

${ }^{40}$ Periodic reassessment by the WIRE Project team of the features used, the particular wording of the questions, and their accompanying sample images is ongoing during the decision-tree development phase.

${ }^{41}$ In Hinterding, Rembrandt as an Etcher, the apostrophe is used to indicate a chain line down the center of a watermark or countermark.

${ }^{42}$ Hinterding, Rembrandt as an Etcher, 2:155-56.

${ }^{43}$ Hinterding, Rembrandt as an Etcher, 2:191-231.

${ }^{44}$ Hinterding, Rembrandt as an Etcher, 2:211-15. The Bartsch number of Landscape with Three Gabled Cottages is B217.

${ }^{45}$ Hinterding, Rembrandt as an Etcher, 2:398-402.

${ }^{46}$ The Frick Collection online catalogue displays a date of 1650; see http://collections.frick. org/ 
objects/641, accessed September 10, 2019. Links to the online catalogue pages of all of the seven prints studied here from The Frick Collection are provided in the appendix to this article, "Provenance, States, and Links to Online Catalogue Entries."

${ }^{47}$ Illustration and discussion of this example can be found in Weislogel and Johnson, "Decision Trees and Fruitful Collaborations." Discoveries of all three types (a)-(c) are listed in Appendix 2 of Weislogel and Johnson, "Decision Trees and Fruitful Collaborations." A companion article is currently in preparation: Andrew C. Weislogel, C. Richard Johnson, Jr., et al., "A Collaborative Approach to Rembrandt Watermark Identification and Data Collection: Research Method, Tools, and Discoveries."

${ }^{48}$ With respect to the watermarks catalogued in Hinterding, Rembrandt as an Etcher, and incorporated in the decision tree from the WIRE Project.

${ }^{49}$ For example, C. Richard Johnson, Jr., "WImBo Watermark Imaging Box Project: A Digital Art History Data Acquisition Tool," paper from the 2018 Conference on Information Sciences and Systems, Princeton, NJ, March 2018; and John K. Delaney and Murray Loew, "Use of Infrared Hyperspectral Imaging (960-1680 nm) and Low Energy X-Radiography to Visualize Watermarks," paper from the 2018 Conference on Information Sciences and Systems, Princeton, NJ, March 2018.

${ }^{50}$ The initial manifestation of the WIRE decision tree was based on the set of single images of each distinctly classified watermark in volume 3 of Hinterding, Rembrandt as an Etcher. This does not assure flawless behavior of the WIRE decision tree in every occurrence of multiple impressions with different treatment and imaging histories. Among such a group, the confidence in answering some questions about distinguishing features may weaken enough that those questions should be replaced. Fortunately, the WIRE Project has access, from the archives of the Dutch University Institute for Art History in Florence, to the multisample dataset collected by Erik Hinterding in composing volume 2 of Rembrandt as an Etcher, in which multiple impressions having the same watermark are listed. As the completion of the first edition of the WIRE decision tree approaches, such multi-impression, same-watermark investigations of its behavior are beginning. Decision-tree refinements will be forthcoming.

${ }^{51}$ Hinterding, Rembrandt as an Etcher.

${ }^{52}$ An introduction to the utility of the classification of panel guild brands is provided in Jørgen Wadum, "The Antwerp Brand on Paintings on Panel," in Looking Through Paintings: The Study of Painting Techniques and Materials in Support of Art Historical Research, ed. Erma Hermens, 179-198 (London: Archetype), 1998.

${ }^{53}$ In February 2017, the author discovered-and subsequently vetted with Erik Hinterding-that the drawing The Steadfastness of Caius Fabricius Luscinus by Ferdinand Bol, which is cat. no. 41 of Thea Vignau-Wilberg, Rembrandt auf Papier: Werk und Wirkung (Munich: Hirmer, 2001), has the countermark IHS E.b in Hinterding, Rembrandt as an Etcher, 3:313, and the drawing Solomon Offering a Sacrifice of Peace Offerings by Ferdinand Bol, which is cat. no. 44 in Vignau-Wilberg, Rembrandt auf Papier, has the watermark Strasbourg Bend D'a.a in Hinterding, Rembrandt as an Etcher, 3:373. Images of the watermarks of both of these Bol drawings appear in Vignau-Wilberg, Rembrandt auf Papier, 343. This cross-use discovery was highlighted in the display of the WIRE Project's interactive decision tree in the exhibition "Rembrandt's Laboratory: Rembrandt's Technique Unravelled” at the Rembrandthuis, Amsterdam, September 21, 2019-February 16, 2020.

${ }^{54}$ Provided by Louisa Wood Ruby. 
${ }^{55}$ State designations provided in Erik Hinterding and Jaco Rutger, Rembrandt: The New Hollstein Dutch and Flemish Etchings, Engravings, and Woodcuts 1450-1700 (Ouderkerk aan den Ijssel, Netherlands: Sound \& Vision, 2013).

${ }^{56}$ Johnson et al., "Chain Line Pattern Matching."

${ }^{57}$ Hinterding, Rembrandt as an Etcher.

${ }^{58}$ C. Richard Johnson, Jr., "The Watermark Identification in Rembrandt's Etchings (WIRE) Project at Cornell," lecture presented at The Frick Collection, New York, December 6, 2018, HTTPS:// WWW.FRICK.ORG/INTERACT/WIRE_PROJECT_CORNELL.

Recommended Citation:

C. Richard Johnson Jr., "Decision Trees for Watermark Identification in Rembrandt's Etchings," Journal of Historians of Netherlandish Art 12:2 (Summer 2020) D0I: 10.5092/jhna.12.2.5 